ORBIT - Online Repository of Birkbeck Institutional Theses

Enabling Open Access to Birkbeck's Research Degree output

\title{
The utility of perceived community efficacy in emer- gency preparedness
}

https://eprints.bbk.ac.uk/id/eprint/40185/

Version: Full Version

Citation: Watt, Frank (2016) The utility of perceived community efficacy in emergency preparedness. [Thesis] (Unpublished)

(C) 2020 The Author(s)

All material available through ORBIT is protected by intellectual property law, including copyright law.

Any use made of the contents should comply with the relevant law. 
Birkbeck, University of London.

This dissertation is submitted for the degree of

Doctor of Philosophy

The Utility of Perceived Community Efficacy in Emergency Preparedness 


\section{Declaration}

This thesis is the result of my own work and includes nothing that is the outcome of work done in collaboration except where specifically indicated in the text. It has not been submitted in whole or in part for consideration for any other degree or qualification at this university or any other institute of learning and complies with the Birkbeck guidelines on length and format. 
Acknowledgements

In 1996, I was asked to mentor a young student, P. Tissington, in the ways of the fire and rescue service. In 2008, the roles reversed and it would appear that the student became the master. I am therefore very grateful to my supervisor, Professor Patrick Tissington, for his enthusiastic support throughout this research and for sharing a wee streapach now and again. He was in turn supported by Dr George Michaelides who showed great patience during my skirmish with the statistics. I am indebted to them both.

A large number of people helped me secure the various sources for the qualitative and quantitative phases of this research, many of whom were the actual respondents who allowed me to interview them and took the time to fill in surveys.

I am also indebted to Kevin Teoh who helped me tame SPSS version 22.

I must also mention Professor Jarret Broder and Brian Misner for their support in allowing me to present some of my early research findings at the Governor's Hurricane Conference, 2015, Orlando, Florida. The experience and feedback was extremely beneficial.

Finally my debt to my wife, Lorraine is hard to describe. She has been my cajoler and supporter throughout this process and I am not certain I could have completed it without her love, kindness and patience. 
Abstract

The present study adopts a mixed methods approach, integrating data from qualitative and quantitative studies, to examine the utility of perceived community efficacy in measuring a community's collective beliefs towards undertaking preparedness measures. Previous research indicated that social cognitive theory and the construct of collective efficacy were important in understanding behaviours that contributed to the achievement of goals. Although research studies had employed the construct of perceived community efficacy to investigate problems, none had focused on community beliefs and actions regarding emergency preparedness. The qualitative study used 20 semi-structured interviews to elicit detailed information on beliefs about collective community activities. Both inductive and deductive approaches were used to develop an a priori model. Three individual constructs taken from community based research domains; community network structure, social capital and community capacity were integrated to form a composite model that was used to investigate how social and community aspects influence beliefs and behaviours of residents. The model was used as a guide for the thematic analysis of the transcripts and the construction of an item pool consisting of 40 items to be used in a quantitative study. The quantitative study involved over 500 respondents who resided within flood risk zones. The data from this study were used in the instrumentation of the model. Exploratory factor analysis was used to explore factorability and hierarchical regression would be used to explore relationships between variables. Confirmatory factor analysis was used to determine goodness of fit. The major finding of the qualitative study was the participants' collective belief that their respective communities would engage in preparedness activities. The quantitative study supported the main findings of the qualitative study. The contribution of this model to community based theory has been to generate new knowledge on how the constructs of community network structure, social capital and 
community capacity act collectively to influence a residents' beliefs and actions. A measurement scale was developed to elicit new knowledge regarding perceived community efficacy as a predictor of the likelihood of a community in undertaking preparedness measures in an emergency. Being able to predict likely future performance or behaviours is key to understanding whether or not a community might protect themselves in the future against an imminent natural hazard or disaster. The research has established the application of social cognitive theory in disaster and emergency research and extends the current body of knowledge on community preparedness research. The results, implications for the profession and future research are discussed. 


\section{Table of Contents}

Title Page

Declaration

Acknowledgements

Abstract

Table of Contents

List of Tables

List of Figures

Chapter 1.0

$\begin{array}{llr} & \text { Introduction } & 10 \\ 1.1 & \text { Introduction to Chapter } & 10 \\ 1.2 & \text { Statement of the Problem } & 13 \\ 1.3 & \text { Rational of the Research } & 15 \\ 1.4 & \text { Research Questions } & 16 \\ 1.5 & \text { Definition of Terms } & 18 \\ 1.6 & \text { Organisation of the Thesis } & 19 \\ 1.7 & \text { Summary } & 21\end{array}$

Chapter 2.0

Chapter 3.0

Literature Review

2.1 Introduction and Background 23

2.2 Structure of the Review 24

2.3 Natural Disasters and Climate $\quad 25$

$\begin{array}{lll}2.4 & \text { Vulnerability } & 27\end{array}$

2.5 Social Vulnerability 28

2.6 The Nature of Vulnerability, Risk and Hazard 29

$\begin{array}{lll}2.7 & \text { Vulnerability and Resiliance } & 30\end{array}$

2.8 Disaster and Emergency Management Systems 33

2.9 International Disaster Organisation $\quad 35$

2.10 National Disaster Organisation 36

2.11 Local Emergency Management $\quad 37$

$\begin{array}{lll}2.12 & \text { Community Involvement } & 37\end{array}$

2.13 Review of Theoretical Position of Emergency and Disaster Management $\quad 40$

2.14 Social Cognitive and Efficacy Believes 46

2.15 Summary $\quad 55$

Methodology $\quad 58$

3.1 Introduction $\quad 58$

3.2 Rational for Selecting the Research Design 59

$\begin{array}{lll}3.3 & \text { Epistemological and Paradigmic Considerations } & 60\end{array}$

3.4 Methodology and Methods $\quad 64$

3.4.1 Qualitative Study - Methods $\quad 67$

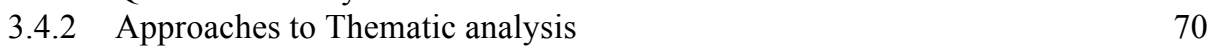

$\begin{array}{ll}3.4 .3 & \text { Developing Themes and Codes }\end{array}$

$\begin{array}{lll}3.4 .4 & \text { Writing the Items } & 73\end{array}$

$\begin{array}{lll}3.4 .5 & \text { Item reduction } & 74\end{array}$

$\begin{array}{ll}3.5 & \text { Quantitative Study - Methods } \\ & 75\end{array}$

$\begin{array}{lll}3.5 .1 & \text { Exploratory Factor Analysis } & 75\end{array}$

3.5.1.1 Sample Size $\quad 75$

3.5.1.2 Sample to Variable Ratio (N:p ratio) 76

3.5.1.3 Factorability of the Correlation Matrix $\quad 77$

3.5.1.4 KMO Measure of Sampling Adequacy/Bartlett's Test of Sphericity 77

3.5.1.5 Initial Factor Extraction $\quad 78$

$\begin{array}{ll}3.5 .1 .6 & \text { Selection of Rotational Methods }\end{array}$

$\begin{array}{lll}\text { 3.5.1.7 Interpretation } & 79\end{array}$

$\begin{array}{ll}\text { 3.5.2 Hierarchical Regression Analysis } & 81\end{array}$

3.5.2.1 Tests Selected for this Study $\quad 81$

3.5.3 Confirmatory Factor Analysis $\quad 82$

3.5.3.1 Fit Indices Selected for the Study $\quad 83$

$\begin{array}{lll}3.5 .4 & \text { Validity } & 84\end{array}$

3.5.4.1 Content Validity $\quad 85$

$\begin{array}{lll}3.5 .4 .2 & \text { Construct Validity } & 87\end{array}$ 
$\begin{array}{lll}3.6 & \text { Summary } & 88\end{array}$

$\begin{array}{lll}\text { Chapter 4.0 } & \text { Qualitative Study } & 90\end{array}$

4.1 Introduction $\quad 90$

4.2 Development of an a priori Model and Qualitative Questions 91

4.2.1 Sampling Risk Population 93

$\begin{array}{ll}\text { 4.2.2 Pilot Study } & 94\end{array}$

4.3 Main Study 99

$\begin{array}{ll}\text { 4.3.1 Findings and Analysis } & 100\end{array}$

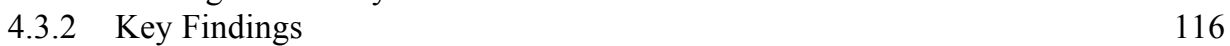

$\begin{array}{lll}\text { 4.3.3 Summary of Findings } & 117\end{array}$

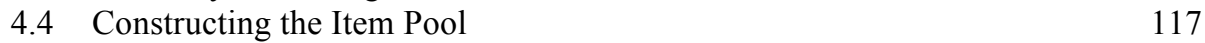

$\begin{array}{lll}4.4 .1 & \text { Item Reduction } & 117\end{array}$

4.5 Content Validity of Item Pool 119

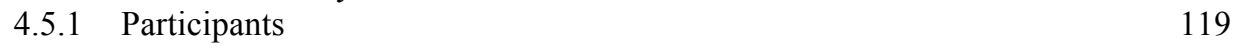

$\begin{array}{ll}4.5 .2 \text { Guidance } & 120 \\ 4.5 .3 & \text { Procedure }\end{array}$

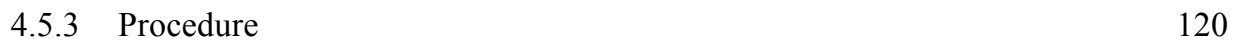

$\begin{array}{ll}\text { 4.5.4 Data Analysis } & 121\end{array}$

4.5.5 Findings from Content Validity Analysis 121

$\begin{array}{lll}4.6 & \text { Summary } & 122\end{array}$

$\begin{array}{lll}\text { Chapter 5.0 } & \text { Quantitative Study, Exploratory and Confirmatory Phases } & 124\end{array}$

$\begin{array}{ll}5.1 \text { Introduction } & 124\end{array}$

- Exploratory Phase 125

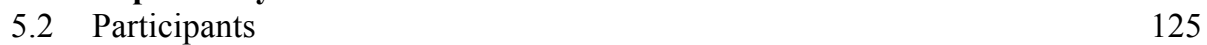

$\begin{array}{lll}5.3 \text { Materials } & 126\end{array}$

$\begin{array}{llr}5.4 & \text { Procedure } & 126\end{array}$

$\begin{array}{lll}5.5 & \text { Participant Data Analysis } & 127\end{array}$

$\begin{array}{lll}5.6 & \text { Data Screening } & 130\end{array}$

$\begin{array}{lll}5.7 & \text { Data Distribution } & 131\end{array}$

$\begin{array}{llr}\text { 5.7.1 Skewness } & 131\end{array}$

$\begin{array}{lll}5.7 .2 & \text { Kurtosis } & 133\end{array}$

$\begin{array}{llr}5.8 & \text { Data Transformation } & 135\end{array}$

5.9 Correlation Matrix 136

$\begin{array}{lll}5.10 & \text { Exploratory Factor Analysis } & 137\end{array}$

5.10.1 Selection of Exploratory Factor Analysis Tests 138

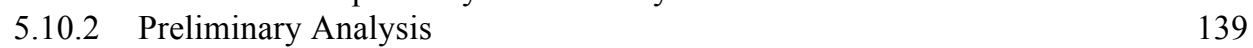

$\begin{array}{lll}\text { 5.10.2.1 A priori model factor analysis } & 139\end{array}$

$\begin{array}{lll}\text { 5.10.2.2 Two Factor Analysis } & 142\end{array}$

5.10.3 Label Development - Social Capacity 145

5.11 Reliability of the A Priori and Two Factor Model 147

5.12 Analysis of the Adapted CSSE scale - Prepared Community 148

$\begin{array}{ll}5.13 \text { Hierarchical Factor Analysis } & 150\end{array}$

5.13.1 HRA Results for the A Priori model 151

5.13.2 HRA Results for the Two Factor model 153

$\begin{array}{ll}\text { Confirmatory Phase } & 156\end{array}$

5.14 Confirmatory Factor Analysis $\quad 156$

$\begin{array}{lll}5.14 .1 & \text { Modification Indices } & 160\end{array}$

$\begin{array}{lll}5.15 & \text { Summary } & 161\end{array}$

$\begin{array}{lll}\text { Chapter 6.0 } & \text { Integrated Discussion } & 164\end{array}$

$\begin{array}{lll}6.1 & \text { Introduction } & 164\end{array}$

6.2 Main Findings and Theoretical Contribution 164

$\begin{array}{lll}6.3 \text { Discussion } & 166\end{array}$

$\begin{array}{ll}6.4 \text { Conclusions } & 179\end{array}$

6.5 Research Limitations 181

6.6 Professional Relevance $\quad 182$

$\begin{array}{lll}6.7 & \text { Recommendations } & 182\end{array}$

$\begin{array}{lll}6.8 & \text { Summary } & 183\end{array}$ 
Appendix A

Appendix B

Appendix C

Appendix D

Appendix E

Appendix F

Appendix G

Appendix $\mathrm{H}$

Appendix I

Appendix J

Appendix K

\section{List of Tables}

Table 1

Table 2

Table 3

Table 4

Table 5

Table 6

Table 7

Table 8

Table 9

Table 10

Table 11

Table 12

Table 13

Table 14

Table 15

Table 16

Table 17

Table 18

Table 19

\section{List of Figures}

Figure 1

Figure 2

Figure 3

Figure 4

Figure 5

Figure 6

Figure 7

Figure 8
Dimensions, Sub-dimensions, References and Questions

Qualitative Questions

Participant Information and Consent 216

$\begin{array}{ll}\text { Thematic Analysis Matrix } & 217\end{array}$

$\begin{array}{ll}\text { Content Validity - Subject Matter Experts } & 219\end{array}$

Content Validity Index Output 223

Item Pool for Quantitative Study - Amended 227

Questionnaire - Excerpt of Screen Shot 231

Correlation Table for Item Pool 236

Path Diagram Models from Confirmatory Factor Analysis 241

CSSE Scale and Adapted Items for Criterion Scale 247

$\begin{array}{ll}\text { Thematic Analysis from Boyatizis, (1984) } & 71\end{array}$

$\begin{array}{ll}\text { Construct, Dimensions and Themes } & 93\end{array}$

Construct, Dimensions and Themes (amended) 97

Summary Results for I-CVI and S-CVI 122

$\begin{array}{lr}\text { Gender } & 128\end{array}$

$\begin{array}{ll}\text { Ethnicity } & 139\end{array}$

Residents Perceptions' on Whether they Lived in a Flood Zone 130

Residents Perceptions' of Flood Intervention 131

$\begin{array}{ll}\text { Factor Loading for a priori Model } & 142\end{array}$

Factor loading for Two Factor Eleven Item Model 143

Results Exploratory Factor Analysis for Prepared Community. 149

$\begin{array}{ll}\text { Correlations between Predictor Variables and Prepared Community. } & 151\end{array}$

$\begin{array}{ll}\text { Regression of Predictor Variables } & 152\end{array}$

$\begin{array}{ll}\text { Correlations between predictor variables and prepared community. } & 154\end{array}$

$\begin{array}{ll}\text { Regression of Predictor Variables } & 154\end{array}$

$\begin{array}{ll}\text { Fit Indices for Three Factor and Two Factor models } & 156\end{array}$

Fit Indices for Two Factor, Ten Item Mode 158

Fit Indices for Three Factor, Ten Item Model 159

Item, Item Label and Element Structure for a priori Model. 160

Four Phases of Emergency Management $\quad 34$

Example of Acceptable Level of Skewness $\quad 132$

$\begin{array}{ll}\text { Example of Positive Skewness } & 133\end{array}$

Example of Negative Skewness $\quad 133$

Example of Acceptable Level of Kurtosis $\quad 134$

$\begin{array}{ll}\text { Example of Negative Kurtosis } & 135\end{array}$

Example of Positive Kurtosis 135

$\begin{array}{lr}\text { Scree Plot - Three Factor Model } & 140\end{array}$ 
This page is intentionally left clear 


\section{Chapter 1.0 Introduction}

\section{$1.1 \quad$ Introduction}

“Court disaster long enough, and it will accept your proposal”. Mason Cooley (Cooley, Cited in Pelling, 2003) made this statement referring to social change but equally Cooley's observation can be applied to natural disasters and how social and environmental change has resulted in higher risks to local populations (Paton, 2000, p. 109). Social vulnerability is partially the product of social inequalities that result from populations moving to highly hazardous areas due to economic, industrial and urban development. This leads to lower growth rates, poor economic viability, urbanisation and higher population densities in areas prone to natural disasters (Cutter, 1996; Cutter, 2001; Dow, 1992; Wisner, Blaikie, Cannon, \& Davies, 2004). Between 1994 and 2013, an average of 218 million people were affected by natural disasters every year, according to the EM-DAT database (CRED, 2015). Over this period, EM-DAT recorded 6,873 disasters, which claimed a total of 1.35 million lives, an average of almost 68,000 deaths per year (CRED, 2015). Since 2000, EM-DAT recorded an average of 341 climate-related disasters per annum, up 44\% from the 1994-2000 average and well over twice the level in 1980-1989 (CRED, 2015). The United Kingdom is in a similar position, experiencing an increase in the frequency, severity and duration of natural disasters (O'Brien, 2008). At this point it would appear that socio economic factors are casual to the rising level of social vulnerability as populations become ever more exposed to the effects of rising severity and frequency of natural disasters (Blaikie, Cannon, Davis, \& Wisner, 1994; Cutter et al., 2008; Putnam, 2000; Tierney, Lindell, \& Perry, 2001).

In order to deal with both the socioeconomic issues and the hazards associated with severe natural events, there are a wide variety of formal organisations at local, national and international levels that have the responsibility of planning for and 
responding to emergencies (Coppola, 2007). The concept of emergency management is well established in most countries throughout the world and communities have come to expect that their governments will intervene in times of these natural disasters and come to their aid (Coppola, 2007). Public bodies such as emergency planning departments, police, fire and rescue as well as non-government organisations (NGO's) that include the International Federation of the Red Cross and the Salvation Army represent some of the main organisations in responding to natural disasters (Wisner et al., 2008). The diverse range of government preparedness actions may be grouped into the mitigation, prevention, response and recovery (MPRR) elements (Drabek, 2004). (A more detailed explanation of MPRR appears in chapter 2, p. 30). Within the scope of MPRR, hazard risk assessments determine the hazards, the priority they are dealt and the potential outcomes within the affected community. Based on hazard assessments, resources will be deployed to control the hazard and reduce the risk to local communities (Haddow \& Bullock, 2004; Kates, 1971; Lindell, 1994).

However, the extent and duration of these severe natural events, challenge the capacity of emergency authorities to deploy resources to initially control the event and assist communities in the post disaster recovery stage (Alexander, 2005). Many countries have taken the opportunity in gaining community participation in preparing, protecting and responding to natural disasters by developing formal community structures such as community emergency response teams (CERTs) and volunteer rescue teams (Brennan, Barnett, \& Flint, 2007, p. 73; Drabek, 2004). Although there are professional organisations that have the responsibility for planning and responding to the situations caused by natural extreme events there are identified capacity issues, especialy where the event is widescale (Pitt, 2008). An added resource are community volunteeers that can be seen as an extension of both formal and informal organisations. 
The following section outlines the research that investigates preparedness activities in a less formal context.

Recognition of the consequences of natural disasters on a population has prompted research into the factors and processes that influence the capacity of people and communities to co-exist with natural extreme events that can frequently constitute highly damaging and potentially life-threatening hazards (Adeola, 2009; Burnside, Miller, \& Rivera, 2007; Elder et al., 2007; Elliot \& Pais, 2006; Paton, 2000). Building this capacity becomes an important aspect of risk management as the level of protection afforded is dependent on whether community protective measures are either adopted, or not (Paton, 2005). That is, the degree to which a community collectively prepares for a natural hazard events. In reducing or eliminating the likelihood or the consequences of a hazard, mitigation seeks to control the hazard such that it impacts society to a lesser degree (Coppola, 2007, p. 175). Mitigation is a key strategy for governments and professional bodies where structural protection is afforded by engineered solutions (Lichterman, 2000, p. 262). Preparedness involves equipping people who may be affected by a disaster or who may be able to help those impacted with tools, skills and knowledge to increase their chance of survival and to minimise their financial and other losses (Coppola, 2007, p. 209). At the lowest level, individual or family preparation can encompass physical activities; storing of water, food and sandbags and non physical activities such as developing household emergency plans, and ensuring information on hazards are regularly updated and circulated. At this level, these simple activities will protect the individual and family in the event of a natural hazard, and afford them a level of resilience that may safeguard their well-being (Lichterman, 2000, p. 263). Taken at a neighbourhood or community level, the cumulation of individual and family preparedness activities can be seen as a collective set of behaviours and activities. They form the foundation from which community level preparedness evolves (Lichterman, 
2000, p. 265). A key issue here is that community members, without the presence of emergency management professionals, can undertake preparedness measures. King (2000), however, found in an analysis of floods in relation to emergency preparedness, a consistent inadequacy for household preparedness for predictable and regularly occurring hazards. These findings do not bode well for emergency professionals seeking to engage communities to develop their own preparedness. Nor does this provide the critical safety message to communities to have a degree of self-sufficiency when professional resources are strained during disaster events (Paton, 2006).

It has been established that socio-economic factors are casual to the rising level of social vulnerability as populations become ever more exposed to the effects of natural disasters. Although there are professional resources that are deployed to respond to community needs, local preparedness for disasters and emergencies can have a significant positive effect on reducing the level of risk and consequence of an extreme natural event, however not all communities are prepared. The next section outlines the main issues regarding local preparedness and community participation and the problems that can arise from the expectations of a community regarding preparedness activities.

\subsection{Statement of the Problem}

There is now a significant move within the field of emergency management to engage with communities in order to better prepare for disasters (Johnston, Becker, \& Paton, 2008). Many initiatives are being explored where community members provide support and backup to professional services (Johnston et al., 2008; Mileti, 1991). Much of the current literature on community involvement focusses on community members being selected and trained to form types of community emergency response teams. However this type of formal arrangement may not suit many communities who do not want this level of committment but who may be willing to undertake some type of informal hazard mitigation behaviour (Bach \& Kaufman, 2009). There are also sections of the 
community who see the role of mitigating the effects of natural disasters as that of local authorities (DeMarchi, Scolobig, Delli Zotti, \& Del Zotto, 2007; Wang \& Kapucu, 2007). According to West \& Orr (2007) there may be difficulties in engaging people in socially vulnerable areas where local population feel fatalistic about disasters and fear there is nothing that can be done to protect themselves. In the event of a major natural disaster, national and local emergency resources are prioritised to life threatening situations, and therefore communites may well have to fend for themselves for considerable periods of time. The UK government has published guidance confirming that there may be no initial response from recognised agencies, and has an expectation that communities will be involved in local preparation and response to emergencies and disasters (Cabinet Office, 2011). Calls for caution have been raised however, about romanticising the role of communities in managing local resources. Agrawal \& Gibson (1999) observed that there can be a conflict of interest for resources required for shortterm survival and long-term risk reduction. Furthermore in the case of disasters, there are instances where communities are being held up as the replacement for the state and as such responsibility for preparedness, response and recovery being handed over to the victims (Christoplos, 2003). If governments and emergency management agencies have an expectation of local communities being involved in disaster preparedness then this is an area that requires research in order to establish whether local communities believe they have the necessary skills and resources to carry out such activities. It is also essential that emergency authorities and communities identify the likihood of community members to engage in preparitory activites to reduce the level of community risk.

Having established that there are many effective initiatives with regard to local preparedness measures, not all are attractive to certain members of the community. Furthermore, the literature review has identified that certain groups within communities 
will not engage or participate in preparedness activities. This is contrary to the expectations from government, in that communities should carryout preparedness activities at a local level. Having identified a number of problems that are central to this research the next section details the rationale for the research.

\subsection{Rationale for the Research}

The gap in the natural hazard literature is defining the processes through which people attribute meaning to natural hazard events. This includes the meaning that people attach to the event itself, its consequences and the risk information that is provided by emergency management organisations. What is lacking from the literature perspective is the research on beliefs and expectations of people living in communities at risk of natural hazards. The present research will demonstrate that engaging in a dialogue with people living in at risk communities can reveal important data regarding specific aspects of their social environment that influence hazard preparedness decisions. Underlying this statement is the notion that information alone does not determine action, but the interpretations of people in the context of their experience, beliefs and expectations (Gibson, 1999; Goddard, 2001; Ohmer, 2007; Omher, 2010; Sampson 2004). The rationale for this thesis emanates from the social context within which people form, articulate and take action based on their beliefs regarding natural hazards and the preparedness measures needed to reduce community risk. The argument forwarded by this research is that decisions to prepare for natural hazards are not made in isolation but reflect a cognitive process, that encompasses individuals' collective beliefs that are shaped by their social environment and four key sources of information: performance accomplishments, vicarious experience, verbal persuasion and physiological cues (Bandura, 1977, p. 101). Social cognitive theory (Bandura, 2000, p. 75) underpins these assertions and the associated construct of perceived community efficacy is used to investigate community beliefs in preparedness for natural hazard events. While a more 
detailed discussion on the relationship between individuals' beliefs and natural hazard events will be presented in chapter two, it is important to acknowledge the significant role of efficacy beliefs in forming peoples' intentions to prepare for natural hazards. An approach used within the domains of health, education and crime reduction is the concept of community efficacy. Based on Bandura's social cognitive theory, efficacy is a construct that can be identified in individuals groups and larger populations (Bandura 2000). Whilst there is substantial research within the domains above there is very little carried out in the emergency management domain. A literature review carried out by this researcher concerned with disasters and emergency management revealed that there was more emphasis placed by government and agencies for communities to be more involved in local preparedness measures. However research by De Marchi et al. (2007), Wang \& Kapucu (2007), and Werrity, Houston, Ball, Tavendale, and Black, (2007) have shown that not all members of communities will engage in preparedness measures. The literature review included an investigation on the theoretical perspectives of human functioning, which focused on personal agency, social capital and social cognitive theory. Whilst there have been many studies carried out in a range of domains the literature was particularly sparse on emergency management and the effects of efficacy in community preparedness for natural hazard events. The purpose of the subsequent section is to provide information on identified gaps in the extant literature and knowledge base. The research questions are detailed in order of preference as dictated by the research methodology.

\subsection{Research Questions}

This investigation will argue that decisions to prepare for natural hazards are not made in isolation but reflect a cognitive process, that encompasses individuals' collective beliefs that are shaped by their social environment: community networks, social infrastructure and community capacities. The information that supports these decisions 
stems from four key sources: performance accomplishments, vicarious experience, verbal persuasion and physiological cues. It is important to ascertain the likelihood of collective preparedness actions as the UK government has published guidance confirming that there may be no initial response from recognised agencies. Furthermore the government has an expectation that communities will be involved in local preparation and response to emergencies and disasters. It is therefor essential that emergency management authorities identify the likihood of community members to engage in preparitory activites to reduce the level of community risk. The first proposed gap is an absence of natural hazard literature regarding the use of Social Cognitive Theory to investigate residents' beliefs and behaviours towards preparing for emergency and disasters events. The second gap is the absence of a model that reflects the complex community structures and how they influence residents' beliefs and associated collective actions when faced with the onset of weather related emergencies. The third gap would appear to be a means of measuring community beliefs on whether or not community members are likely to respond in the preparedness stage of an emergency or natural hazard event. Research questions have been constructed to address gaps in the knowledge concerning percieved community efficacy and distaster preparedness. These will reflect a mixed method approach where the qualitative research is focussed on gaining rich data from communities regarding collective beliefs and actions. Once synthesised, the data will help inform the development of the quantitative research survey items. The quantitative element will explore a community's efficacy beliefs in undertaking activities that would make a difference in preparedness levels. Relationships between socio-demographic variables such as age, gender, ethnicity, and percieved community efficacy are also investigated. The overarching, mixed methods question will provide guidance on the integrated output of the qualitative and quantitative elements of the research. This will take the form of an 
survey instrument where the level of community efficacy can be measured and will indicate the level of collective beliefs. A higher level indicates that a community would be effective in its approach to reducing the level of risk and increasing the level of resilience.

Research Question 1 - Can the construct of perceived community efficacy be operationalised to measure the beliefs of community residents in undertaking collective actions to prepare for natural hazards?

Research Question 2. - What does the concept of community mean to the resident sample group?

Research Question 3. - What are the perceptions of individual residents on natural hazard preparedness activities associated with the sub-dimensional levels of community networks, social capital and community capacity?

Research Question 4. - What are the significant predictors of perceived community efficacy in the domain of natural hazard preparedness?

Research Question 5. - Are socio-demographic factors significant predictors of perceived community efficacy?

\subsection{Definition of Terms}

Self-Efficacy: Self-efficacy beliefs determine how much effort will be exerted in an endeavour and how long a person will persevere in the face of obstacles (Bandura, 1989)

Community Efficacy: the ability to meet environmental demands through a variety of mechanisms including coordination of resources, solving community conflicts and setting community goals. Interventions that enhance community efficacy may provide important ingredients for successful individual and community-wide adaptation in defending the community against the effects of disasters (Benight, 2004). Community - groups of people linked by a common bond (Cabinet Office, 2011). 
Community Resilience - Communities and individuals harnessing local resources and expertise to help themselves in an emergency, in a way that complements the response of the emergency services (Cabinet Office, 2011).

Disaster Management - the systems developed to deal with risk and risk avoidance whether this is in a natural or manmade environment (Haddow and Bullock, 2004).

\subsection{Organisation of the Thesis}

The flow of the thesis, to a degree, reflects the methodology employed to undertake the research. Having developed the research questions it is necessary to design the research so that it addresses the main issues in the premise (Bryman and Bell, 2007, p. 304; Cresswell and Tashakkori, 2007, p. 207; Onwuegbuzie and Leech, 2006, p. 475). Firstly there is the construct to consider and how best to investigate the constituent parts, such as community and its beliefs. Secondly there is the aspect of measurement and how to assess high and low levels of the construct. Lastly there is the issue of the domain, which is based on the preparedness timescale before an emergency event. In order to explore the construct of perceived community efficacy a number of methods can be employed; these being observations, questionnaires or interviews (Corring and Cook, 2007; Opdenakker, 2006). However in order to assess the relationship between the construct and the domain of emergency preparedness and more specifically the ability of community efficacy beliefs to measure community behaviours in this domain, there needs to be an element of measurement (DeVellis, 2003). The following section will outline the layout of the thesis in relation to reporting on the various stages of the research.

Chapter $\mathbf{2}$ is the literature review, which will investigate the relationship between natural hazard events and populations. This will include a review of topics such as social vulnerability, risk and hazard and emergency management structures that have been developed in order to safeguard communities. Theories relevant to disaster 
research are discussed with a more detailed approach being given to social cognitive theory. The chapter concludes where an a priori model is identified consisting of three main dimensions: community network structure, social capital and community capacity.

Chapter Three describes the epistemological, methodology and methods that have guided this research. A pragmatic approach has been taken to ensure the research questions were fully explored. A mixed methods design was considered to be the most appropriate methodology benefitting from both qualitative and quantitative techniques. A sequential model was used where the results of the qualitative study informed the quantitative study.

Chapter Four is the main qualitative study where transcripts of semi structured interviews were analysed using a thematic approach. The results were used to develop an item pool that would be used in the quantitative study. The chapter concludes with a content validity analysis to ensure the items have an acceptable level of content validity. This is also taken as an important contribution towards construct validity of the final scale.

Chapter Five is the quantitative study that seeks to develop the item pool into a measurement scale that is valid and reliable. The main methods used were exploratory factor analysis, confirmatory factor analysis and a hierarchical multiple regression analysis. Descriptions and results of each analysis are reported in detail.

Chapter Six is the concluding chapter where the findings of chapters four and five are integrated and discussed. Both sets of findings are compared and synthesised to provide a comprehensive treatment of the research questions. Key findings are explored in relation to the theories used in this research. Conclusions stemming from the findings and discussion are also provided. The main conclusion will assert that social cognitive theory and more specifically perceived community efficacy, has a utility in the measurement of community beliefs in the domain of emergency preparedness. 
Theoretical contribution is also established where this research has added new knowledge to and extended the scope of social cognitive theory. Three individual constructs taken from community based research domains - community network structure, social capital and community capacity - were integrated to form a new composite model that was used to investigate how social and community aspects influence beliefs and behaviours of residents. The contribution of this model to community based theory and in particular perceived community efficacy has been generate new knowledge on how all three constructs influence a community's collective beliefs and actions. A new scale has been developed that was able to elicit new knowledge regarding perceived community efficacy as a predictor of the likelihood of a community in undertaking preparedness measures in an emergency. Being able to predict likely future performance or behaviours is key to understanding whether or not a community might protect themselves against an imminent disaster. The research has established the application of social cognitive theory in disaster and emergency research and extends the current body of knowledge on community preparedness research. Limitations of the research are identified and recommendations are made regarding the scale, its further development and potential use in the field.

\section{$1.7 \quad$ Summary}

Disasters are a global phenomenon with devastating effects. Over the past 10 years there has been an increase in the frequency and severity of reported natural disasters. In the event of a major natural disaster, communites may well have to fend for themselves for considerable periods of time, it is therefore essential that emergency authorities and communities identify the likihood of community members in participating in preparitory activites to reduce the level of community risk. Reliable and valid measurement tools represent a crucial step in the assessment and evaluation of 
community resilience; however, a well-developed measurement scale designed to assess community engagement in preparedness measures was not revealed in a review of the published literature. The aim of the present study was to develop a scale that may provide an incite into utility of community efficacy in relation to emergency preparedness in local residential communities. Theoretical contribution has been established where this research has added to the existing knowledge of Social Cognitive Theory. Further, this scale may contribute to future measurement and preparedness efforts within the field of natural hazard and emergency research. 


\section{Chapter 2.0 Literature Review}

\subsection{Introduction and Background}

Published research on the management of disasters dates back go back as far as the 1930s (Neal, 1997, p. 240). From these early times, both scholars and practitioners within the field of humanitarian response and disaster management have developed various models relating to the phases of disaster in order to understand their field of study as well as to improve the response to disaster events more effectively (Neal, 1997, p. 239). In spite of this theorising, the practical approach to disaster management was still mainly focused on response and relief efforts following disaster events (Lewis, O’Keefe, \& Westgate, 1976, p. 3; Twigg, 2004, p. 3; UNISDR 2004, p. ix). From 1970 to 1980 , there was a dramatic increase in disaster events that caused increased deaths and greater economic losses than in previous decades (Wisner et al., 2004). This caused a change from the traditionally post disaster response to a focus on pre disaster activities (Wisner et al., 2004). With the recurrent and increasing human and financial costs of disaster came the understanding that there must be a more effective way of utilising funds than merely providing relief (Cuny, 1983). Pre-disaster planning seemed to be a practical and necessary component to complement traditional thinking (Lewis et al., 1976). The earliest example of a disaster management cycle proposed by Baird, O’Keefe, Westgate, and Wisner, (1975) was comprised of six different phases, namely, reconstruction, mitigation and prediction, preparedness for relief, warning, relief and rehabilitation. Since then many adaptations and changes have occurred in the composition of the disaster management cycle, as well as its application (Alexander, 2002; Holloway, 2003; Khan, Vasilescu, \& Khan, 2008). Reducing the cycle of a disaster to two phases, Larson, Metzger, and Cahn, (2006, p. 246) suggests a need for additional research to develop decision-oriented, operations research models to improve 
the preparedness phase and the response phase of emergency events. One theme emerging from the examination of the literature this far, is very few of the models and solutions proposed include any form of consultation or engagement with the people who are most at risk; the local population living in a risk zone. In addressing this omission Brown and Damery (2002, p. 422) stress the importance of public knowledge and local engagement if formal emergency management strategies are to become more effective. The benefits of engaging of the local population is acknowledged by Paton (2005, p. 11) where he suggests that facilitating preparedness is more about interacting with the community in ways that address their needs in reducing risk from natural hazards. In providing guidance to assist communities to be more resilient the UK government gives a stark warning and states that local emergency responders will always have to prioritise those in greatest need during an emergency, especially where life is in danger. Individuals and communities therefore may need to rely on their own resources to ensure they are able to cope with the consequences of the emergency (Cabinet Office, 2011, p. 2).

\subsection{Structure of the Review}

This review aims to examine the present state of the emergency management in relation communities and how they are affected by natural disasters. This will involve exploring the phenomenon of natural hazards such as hurricanes and earthquakes and flooding and the risk posed for local communities. The human interface with hazardous natural environments produces risks that require to be managed therefore the review will try to ascertain what approaches are employed and how successful they are. Social vulnerability due to natural disasters is explored where populations live within or close to risk zones duty to social demographic factors. The link between social deprivation and the risk due to natural hazards risk is highlighted. Further readings investigate how 
risk and hazards are mitigated by both technical and emergency management response solutions. The infrastructure of emergency management comes under scrutiny both in terms of international and United Kingdom perspective. Community involvement in both pre and post-disaster phases will provide an overview of how a population responds to the different phases of a disaster and how this may be a passive or interactive response to emergency management personnel. It will also attempt to understand different approaches to research into populations and measuring their response in relation to disasters and emergencies.

Social cognitive theory is discussed and the construct of efficacy is examined. The review will also extend the investigations to consider what is 'a sense of community' and community theory. Finally the elements of perceived community efficacy, which will be discussed in this literature review, will be integrated to provide the epistemological basis for the rest of the thesis and also help to articulate a series of research issues and questions that the qualitative and quantitative elements of the thesis will attempt to address.

To acquire the literary foundation for this review nine different databases (JSTOR, EBSCO, Web of Science, ProQuest, Questia, Google Scholar, Aston University Catalogue, Birkbeck Catalogue, and the British Library) were searched, using disaster management and community as the search terms. In addition, individual searches were made of journals relevant to emergency management, research methods, psychology and the social and natural environment.

\subsection{Natural Disasters and Climate}

Natural disasters are, for many researchers in the field of disaster management, the epitome of what makes a disaster. The physical forces and destructive power that can generate through natural occurrences such as earthquakes, flooding and hurricanes have 
been captured by the media and projected as the essence of what a disaster may look like (Bryant, 1991; Smith, 2001). This review focuses on four major categories: geophysical, hydrological, meteorological and climatological disasters. Taken together, hydrological, meteorological and climatological events are also referred to as climaterelated disasters. Between 1994 and 2013, EM-DAT recorded 6,873 natural disasters worldwide, which claimed 1.35 million lives or almost 68,000 lives on average each year. In addition, 218 million people were affected by natural disasters on average per annum during this 20-year period. The frequency of geophysical disasters (earthquakes, tsunamis, volcanic eruptions and mass movements) remained broadly constant throughout this period, but a sustained rise in climate-related events (mainly floods and storms) pushed total occurrences significantly higher. Since 2000, EM-DAT recorded an average of 341 climate-related disasters per annum, up 44\% from the 1994-2000 average and well over twice the level in 1980-1989 (CRED, 2015).

The United Kingdom is in a similar position experiencing an increase in the frequency, severity and duration of natural disasters, (O'Brien, 2008). O'Brien also observes that, although the hazard type may not have changed; flooding, hurricane, winds, large snow falls, and levels of exposure have increased due mainly to the urban/rural interface being closer. For example, populations in urban environment, moving to the rural environment for lifestyle factors (Werritty et al., 2007). Equally the built environment has allowed for concentrated, large populations in small areas. The reshaping of waterways with culverts and underground manmade congestion has increased the risk. Large quantities of water are forced out of existing control structures and cause extensive flooding to urban populations (Adeola, 2009; Werritty \& Chatterton, 2004).

Climate related events are also predicted to increase in the United Kingdom. In research conducted by Kendon, $(2015$, p.1) she observed that rainfall would be heavier 
in short outbreaks. In particular, intense rainfall with the potential to cause serious flash flooding could become a more common occurrence. This finding is of major importance due to the potential for flooding: a threshold of $30 \mathrm{~mm}$ per hour is used by the Met

Office and Environment Agency Flood Forecasting Centre as guidance to indicate likely flash flooding. The results suggest this may be exceeded more often (up to five times) and over a wide area in the future (p.1).

Most research on disasters emphasizes the 'trigger' role of geo-tectonics, climate or biological factors arising in nature (Alexander, 1993; Bryant, 1991; Smith, 2001; Tobin and Montz 1997). Others focus on the human response, psychosocial and physical trauma, economic, legal, and political consequences (Dynes, DeMarchi, \& Pelanda, 1987; Lindell and Perry, 1992; Oliver-Smith, 1996; Platt, 1999). These two different approaches have produced a lack of consensus in defining disasters, why they occur or understanding their complexity. A crucial point about understanding why disasters happen is that it is not just natural events or the social environment but a combination of both (Wisner et al., 2004, p.4). Having reviewed climate related disasters and emergencies; attention is turned to the environment and the human interface

\subsection{Vulnerability}

The commonplace meaning of vulnerability can be defined as being prone to or susceptible to damage or injury (Wisner et al., 2004, p. 11). However within the hazards literature, vulnerability has many different meanings, depending on the research orientation and perspective (Cutter, 1996, Cutter, 2001; Dow, 1992). In order to fully appreciate the diversity in vulnerability research it is necessary to examine the various models within the literature. There are a number of models in vulnerability research that seek to explain the interface between a population, a place, social conditions and an event. The identification of conditions that make people or places vulnerable to extreme 
natural events is representative of an exposure model where the emphasis is risk identification (Burton, Kates, \& White, 1993; Anderson, 2000). An alternative model makes the assumption that vulnerability is a social condition, a measure of societal resistance or resilience to hazards (Blaikie et al., 1994; Hewitt, 1997).

The model espoused by Cutter, Mitchell, and Scott, (2000) is the integration of potential exposures and societal resilience with a specific focus on particular places (Kasperson, Kasperson, \& Turner, 1995). Zakour, (2008, p. 15) suggests that disasters are a mix of environment and population. This theme is in accord with Tierney (2006) who describes disasters as comprising three major factors, those being the disaster agent; flood, hurricane, tsunami, the environment; urban, rural, built and the population vulnerability; material resources, networks and social protection. A simple working definition of vulnerability in the context of disasters is provided by Wisner et al., (2004, p. 11) who state that vulnerability is "the characteristics of a person or group and their situation that influence their capacity to anticipate, cope with, resist and recover from the impact of a natural hazard". The definition is a combination of factors that determine the degree to which someone's life, livelihood, property and other assets are put at risk by a distinct and recognizable event in nature, at a specific location. Furthermore it appears to captures the essence of the models detailed above: environmental exposure, population and social conditions, and a sense of place. In all the models detailed above there is an implicit articulation of the connection between social structures and vulnerability. The next section provides an investigation into the literature regarding social vulnerability.

\subsection{Social Vulnerability}

Those characteristics that influences social vulnerability most often found in the literature are generally accepted are age, gender, race, and economic status (Cutter, Boruff, \& Shirley, 2003, p. 245). Other social vulnerability characteristics include 
ethnicity, health, type of dwelling unit and employment (Wisner, 2004, p. 12). The quality of human settlements (housing type and construction, infrastructure, and lifelines) and the built environment are also important in understanding social vulnerability, especially as these characteristics influence potential economic losses, injuries, and fatalities from natural hazards (Cutter et al., 2000, p. 726). According to Wisner et al, (2004, p.327) social vulnerability is partially the product of social inequalities, that is, those social factors that influence or shape the susceptibility of various groups to harm and that also govern their ability to respond. However, it also includes place inequalities, meaning characteristics of communities, and the built environment, such as high urbanization, low growth rates, and poor strength of economy that contribute to the social vulnerability of places (Cutter et al., 2000, p.717).

There is also consensus within the social science community about some of the major factors that influence social vulnerability. These are more concerned with a lack of social fabric and include: lack of access to resources (including information, knowledge, and technology); limited access to political power and representation; social capital, including social networks and connections; beliefs and customs; building stock and age; frail and physically limited individuals; and type and density of infrastructure and lifelines (Blaikie et al., 1994; Putnam, 2000; Tierney et al., 2001). In this treatment of vulnerability the individual and combined affects of risk and hazard must be included as to omit would prevent the full appreciation of the disaster model. The following section provides a range of observations from the disaster literature.

\subsection{The Nature of Vulnerability - Risk and Hazard}

According to Cutter et al (2000, p. 243) risk is an objective measure of the likelihood of a hazard event. Risk, for Wisner et al (2004, p. 49) needs to be considered with at least the same degree of importance that is devoted to understanding and addressing natural hazards. They suggest that the risk of disaster is a compound function of the natural 
hazard and the number of people, degrees of vulnerability to that specific hazard and the period of time of exposure to the hazard event (Wisner et al., 2004). Hewett (1983, p. 167) argues that a disaster hazard refers to the potential for damage that exists only in the presence of a vulnerable community. The concept of an agent (natural occurrence) that causes harm to persons or communities is supported by Alexander (2000) and Tobin and Montz (1997) who describe the consequences of hazards are influenced by varying degrees of intensity and severity of that hazard. This can be mitigated by spending less time in the hazard zone (reducing exposure) and increasing the distance from location of hazard (lessening proximity).

In combining the concepts of risk, hazard and vulnerability Alexander (2000) provides clear demarcation of vulnerability and risk. Vulnerability refers to the potential for casualty, destruction, damage, destruction but also other forms of loss in a particular element. Risk combines this with a probable level loss to be expected from a predictable magnitude of harm that can be considered as the manifestation of the agent (hazard) that produces the loss (p. 151). In the case of risk and hazard, a simpler approach to describing the constituent parts of a disaster and their interaction is afforded by Wisner et al., (2004, p. 50) where they observe that disasters occur when the risk level is met or exceeded and a significant number of vulnerable people experience a hazard and suffers severe damage and disruption of their livelihood system in such a way that recovery is unlikely without external aid. A communitys' ability to recover will rely of many factors that can be included in both hazard resistance and resilience.

\subsection{Vulnerability and Resilience}

The literature on vulnerability stresses the primacy of public risk perception and understanding in mediating the success of attempts to increase hazard resistance and resilience. Crucially it places emphasis on the need to tackle the root causes of community vulnerability (Bankoff, 2001). This view explicitly recognises that the 
public are differentiated in both the degree of risk when exposed to a hazard, implying resistance to the effects of an extreme event (Morrow, 1999; Quarantelli, 1998) and in their ability to cope with the impact of the hazardous event, implying resilience and the ability to recover after an extreme event (Fordham, 1998; Ketteridge \& Fordham, 1995). Research carried out by Milletti (1999) sought a new philosophical approach to reducing losses from natural disasters, which was based on the notion of the development of disaster resistant communities. The application of this early concept of resilience to natural hazards entailed the ability of a community to recover by means of its own resources.

Masten and Obradovic (2007) argue that "all disasters are local," at least in the short term, and that all human resilience is local, emerging from the actions of individuals, and small groups of people, in relation to each other and powered by the adaptive systems of human life and development. Larger systems facilitate this resilience, but are not likely to be directly available during an unfolding disaster on the scale of a flu pandemic or unfolding natural disaster (Masten and Obradovic, 2007). This notion is of particular relevance in areas that are densely populated, where both catastrophes and recovery from them are most complex (Tidball \& Krasny, 2015). Larger systems emphasise the interactive traits of natural and human systems, the built environment and the role of human agency in producing hazards and disasters thereby increasing levels of vulnerability (Cutter et al., 2008, p. 599).

Norris, Stevens, Pfefferobaum, Wyche, \& Pfefferbaum (2008) also focus on community resilience and view it as a process linking adaptive capacities such as the levels of social capital and economic development to responses and changes after adverse events. The concept of resilience in this case is as a set of capacities that can be fostered through interventions and policies, which in turn help build and enhance a community's ability to respond and recover from disasters. Up until this point 
community resilience was very much about response after the event, however Norris and colleagues appear to include mitigation or preparedness elements (Norris et al., 2008).

A very different interpretation of disaster resilience comes from the engineering research, with an emphasis on buildings and critical infrastructure resilience. Bruneau et al. (2003) proposed a resilience framework with a focus on structural mitigation, especially the engineered solution concepts of robustness, redundancy, resourcefulness, and rapidity. More recent research on resilience from a homeland security perspective (primarily protecting critical infrastructure from terrorism), (Kahan, Allen, \& George, 2009) also focuses on critical infrastructure resilience assuming that resilience is an outcome measure with an end goal of limiting damage to infrastructure (termed resistance); mitigating the consequences (called absorption); and recovery to the preevent state (termed restoration). Cutter, Burton, and Emrich, (2010, p. 2) observes that while useful for counterterrorism and protection of critical infrastructure, the management systems used in protecting critical infrastructure ignore the dynamic social nature of communities and the process of developing resilience within and between communities. The researcher believes that this may be an oversight by Cutter et al. (2010) as increasing resilience in national infrastructure against terrorism may have the added benefit of protection from natural extreme events. The increase in resilience will also provide for a higher level of resilience for local communities that may rely on critical infrastructure for power, water or even employment.

The provision of local resilience by developing national resilience is a key strategy for Government in the United Kingdom. In its National Security Strategy and Strategic Defence and Security Review, the Government prioritised the need to improve the security and resilience of the infrastructure most critical to keeping the country running against attack, damage or destruction. International terrorism, cyber attacks, 
major accidents and natural hazards are identified as among the most serious risks to the UK's national security interests (Cabinet Office, 2011). This level of resilience cannot be undertaken without a national organisational infrastructures that are able to draw on human and financial resources achieve the necessary level of protection. In the next section the review will outline disaster and emergency management systems and provide examples from an international and national perspective.

\subsection{Disaster and Emergency Management Systems}

In order to provide clarity and understanding, Haddow and Bullock (2004) provide a useful description where the term 'disaster or emergency management' is applied to the systems developed to deal with risk and risk avoidance whether this is in a natural or manmade environment. This concept of emergency management is well established in most countries and extends to the mitigation, preparation, response and recovery (MPRR) elements of the disaster management cycle (Drabek, 2004). Mitigation involves reducing or eliminating the likelihood or the consequences of a hazard, or both. Mitigation seeks to "treat" the hazard such that it impacts society to a lesser degree (Coppola, 2007, p. 175). Preparedness involves equipping people who may be impacted by a disaster or who may be able to help those impacted with the tools to increase their chance of survival and to minimise their financial and other losses (Coppola, 2007, p. 209). Response involves taking action to reduce or eliminate the impact of disasters that have occurred or are currently occurring, in order to prevent further suffering, financial loss, or a combination of both. Relief, a term commonly used in international disaster management, is one component of response (Coppola, 2007, p. 251). Recovery involves returning to a normal state following the impact of disaster consequences. The recovery phase generally begins after the immediate response has ended, and can persist for months or years thereafter (Coppola, 2007, p. 299).

Various diagrams illustrate the cyclical nature by which these and other related 
factors are performed over time, though disagreement exists concerning how such a "disaster management cycle" is visualised. These diagrams are generalizations and it must always be understood that many exceptions can be identified in each. In practice, all of these factors are intermixed and are performed to some degree before, during, and after disasters (Alexander, 2002, p. 138). Disasters tend to exist in a continuum, with the recovery from one often leading straight into another. The graphics in Figure 1. Shows the overlap of adjacent phases. This acknowledges that critical activities frequently cover more than one phase, and the boundaries between phases are seldom precise. Haddow and Bullock (2006, p. 138) also emphasize that important interrelationships exist among all the phases. For example, "mitigating" flood damage by restricting development in a flood plain will reduce the problems in "responding" to flooding (Haddow and Bullock, 2006, p. 139).

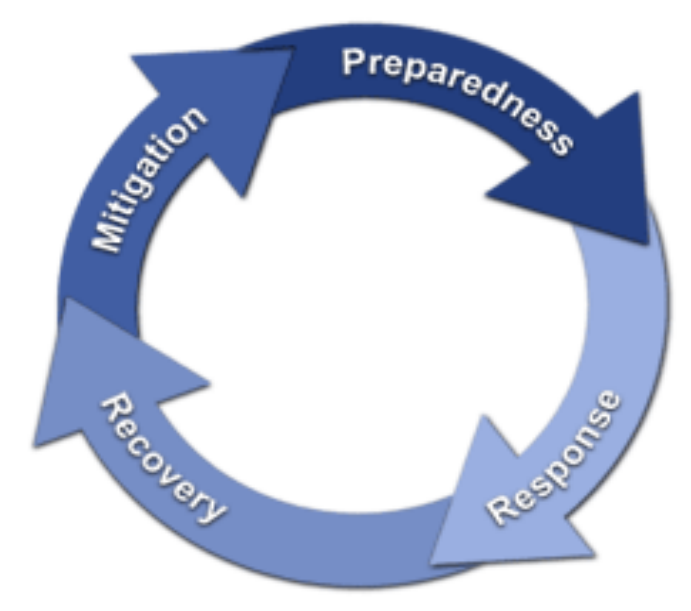

Figure 1. Four Phases of Emergency Management (Coppola, 2007, p. 7)

Although the "four phases" are part of the common language and theoretical underpinning of emergency management globally (Coppola, 2007, p. 8) a number of adaptations can be found. There are now models that refer to five or six phases rather than four. Other models have changed the descriptive terms for one or more of the 
phases. Some recent changes are subtle and involve only additional words; perhaps to be more descriptive, for instance, mitigation may be changed to prevention (Coppola, 2007, p. 8).

In the UK, Integrated Emergency Management (IEM) is a concept on which civil protection is based. The IEM is a holistic approach to preventing and managing emergencies that entails six key steps: anticipation; assessment; prevention; preparation; response, and recovery (Cabinet Office, 2013, p. 8). The systems outlined above have been adopted and adapted to suit the various organisations that provide emergency management at international, national and local levels. The next sections provide an insight into the multi dimensional organisational structures that are put in place to oversee and manage disasters.

\subsection{International Disaster Organisation}

At an international level the United Nations (UN) is the organisation most involved in the mitigation repeated this response and recovery of disasters around the world. In January 2005 in Hyogo, Japan the UN held a world conference on disaster reduction. This resulted in a framework with strategic goals and objectives. The ISTR2 2005 was a framework that outlines general considerations and identifies disaster management priorities for 2005 to 2015. The United Nations General Assembly Resolution (A/RES/67/209) decided to hold the Third UN World Conference on Disaster Risk in Sendai, Japan. The Senai Framework for Disaster Risk Reduction 2015-2030 was agreed with 4 main principles generally reflecting and strengthening the previous framework; Priority 1: Understanding disaster risk; Priority 2: Strengthening disaster risk governance to manage disaster risk; Priority 3: Investing in disaster risk reduction for resilience; Priority 4: Enhancing disaster preparedness for effective response and to "Build Back Better" in recovery, rehabilitation and reconstruction (UNIDSR, 2015). 


\subsection{National Disaster Organisation}

After a series of crisis in the UK including fuel shortage, the millennium bug and nation wide flooding, the Civil Contingencies Secretariat (CCS), within Cabinet Office was established in 2001 and lead responsibilities were transferred to this organization (O'Brien \& Read, 2005). The aftermath of 9/11 terrorist attacks and increasing threat of manmade disasters brought question about the readiness and sufficiency of the UK government emergency management structure with the intent of providing effective civil protection. The concern of terrorism and establishment of effective disaster response framework led to structural change and reformation (O'Brien \& Read, 2005). The Civil Contingencies Act (CCA) of 2004 introduced a single framework for civil protection in UK and brought new changes to the table such as replacing and updating former Civil Defense and Emergency Power legislations. The CCA is now composed of two parts. Part 1 defines regulations, guidance, clear set of goals, and responsibilities for all involved organizations at the local level. The local responders are divided into different sections and categories based on their specific duties and roles. Part 2 updates Emergency Power Act of 1920 and focuses on most serious emergencies and future risk profile (Cabinet Office, 2009a; Office of Public Sector Information, 2004). The core changes that were brought by the establishment of CCA can be described as: defining the term emergency; identifying the clear boundaries, roles, and responsibilities of all involved organizations and parties in depth; exploring new duties of local and governmental agencies; replacing outdated system of emergency powers; and, in general, giving UK government ranging powers in an emergency (O’Brien \& Read, 2005).

An emergency, as defined in CCA, "is a situation or series of events that threatens or causes serious damage to human welfare, the environment or security in the United Kingdom” (Cabinet Office, 2005, p.1). Civil protection and emergency response 
and management system of UK has gone through extensive changes and reforms due mainly to responding to emergencies increasing in number and severity. Nevertheless, the overall structure of disaster management has generally remained the same with the central government fulfilling the role of coordinator and providing guidance, while local agencies and governments deal with and respond to disasters (O’Brien \& Read, 2005).

\subsection{Local Emergency Management}

The structure of emergency management in UK is decentralized. Most emergencies and incidents, based on scale or complexity, are handled at local level with no involvement of Central Government (Civil Contingencies Secretariat, 2009a). Local agencies are always the first responders and the ones who carry the burden of emergency management. Although the fire and rescue service and the local authority emergency planning department with be extensively involved, in most cases the police are considered one of the leading responding actors in local disasters. When police are given the task of responding to disasters at the local level, the Police Gold Commander is appointed by the local Chief Officer with the primary mission of managing the response. The Police Gold Commander usually chairs the Strategic Coordination Group (SCG), which comprises senior representatives and executive authority from local organizations.

\subsection{Community Involvement}

The extent and duration of natural disasters and emergencies can challenge the capacity of local, national and international resources that can made available in order for communities to recover from the effects of natural disasters. Where events exceed expectations, such as the European heat wave in 2003, Hurricane Katrina in 2005 and the Brisbane floods in 2011, then there is danger that this institutional focus may be an insufficient response, particularly for extreme events (Cabinet Office, 2011). To manage in such conditions requires resilience in both the response function and society. This 
requires a change of emphasis in emergency management from an institutional focus to one that promotes resilience within society and includes public preparedness (Boin, 2005; O'Brien, 2008). In response to capacity issues, many countries have taken the opportunity in gaining community participation in preparing, protecting and responding to natural disasters. Larson et al. (2006) contends that the effectiveness of community participation in emergency management is determined by the level of training, organization and clear objectives to undertake. This principle has led to the establishment of formalised structures such as community emergency response teams (CERTs), volunteer rescue teams and other structured approaches to providing fire and paramedic services (Brennan and Flint, 2007, p. 73; Drabek, 2004, Dynes). Internationally, the use of volunteers to assist with pre and post disasters is common practice (Brennan, 2007). This has been largely based on governments acceptance of the concept of volunteers in the disaster management arena and until recently has been focused on response to an imminent or post disaster phase. In a number of countries the volunteer effort has been recognised as a national and local resource in the event of emergencies and can take the form of emergency volunteers, under a national umbrella structure, reporting locally to a regional or community section. (Brennan and Flint, 2007, p. 72; Lindell, 1994).

These structures are reflected in the UK to some extent where volunteering is increasingly linked in government policy and political discourse. Since 1997, volunteering in the UK has received an unprecedented level of attention and funding to generate civil renewal and community cohesion (Paine, Locke, \& Jochum, 2006, p. 1). However recent episodes of natural and human made disasters have identified the role of volunteers in the United Kingdom as a passive one, assisting professional and emergency services in a support role within the post disaster phase and not as an integrated resource involved at the planning and prevention stages. There has now been 
a call for change where the United Kingdom Government has an expectation that communities and local people will be involved in the preparation and response to emergencies and disasters (Cabinet Office, 2011).

There is now a significant move within the field of emergency management to engage with communities in order to better prepare for disasters where many initiatives are being explored engaging community members to provide support and backup to professional services (Johnston, Becker, \& Paton, 2008). Although there are many informal community support organisations, one example of a more formal, organised community response has been established by Bedfordshire Local Resilience Forum. CERTs are distributed throughout the county to provide an initial response and to assist emergency services when required.

Engaging with communities in order to better prepare for disasters has also been extended to flooding where Brown and Damery (2002, p. 413) proposed that there should be less reliance placed on hard engineering solutions, and use more of a "people dimension" in flood risk management. Werritty (2004) also stressed the need for a paradigm shift in which flood risk management relies less on state intervention and more on individuals accepting more responsibility. For example, working with communities to disseminate warnings and provide assistance in sandbag deployment offers the possibility of community-based resilience. Furthermore far from being ignorant or irrational in their understandings of risk, and their behaviour during an emergency, the public appeared to bond and help each other through their identification with others in the emergency (Brown and Damery, 2002; Drury, Novelli, \& Stott, 2015).

However, success in harnessing these community-based resources has been inadequate in providing a viable alternative to local authority interventions. Given the general reluctance to accept personal responsibility for flood defence, such a lack of 
community engagement is not unexpected (Wang and Kapucu, 2007). Indeed as local authorities reach out to propose self-help, the community often takes a step back on the assumption that the local authority is accepting responsible for flood alleviation. Also, the longer the interval since the last flood, the greater is the likelihood of such disengagement. Mobilising community resources to assist in disseminating warnings and rendering emergency assistance thus remains a major challenge (Werritty et al., 2007). With the severity of disasters increasing, there are issues of capacity, where current level of resources may be insufficient to deal with the effects of severe weather related emergencies. Whilst some countries have a formal, community based structure to assist professional emergency services; it is not the norm for others where there is evidence of complacency or a perception that the responsibility for disaster preparedness lies elsewhere. If governments have an expectation of local communities being involved in disaster preparedness then this is an area that requires research in order to establish whether local communities believe they have the necessary skills and resources to carry out such activities.

\subsection{Review of Theoretical Position of Emergency and Disaster Management}

This section of the literature review, examined the literature for a foundation theory in relation to disaster and crisis management, which may be used to examine community involvement in preparedness activities. However, whilst there are a number of explanatory models, there is no grand or overarching theory of disaster management (Drabek, 2004; McIntire, 2004a; Sementelli, 2007). Disaster management research is diverse and researchers are engaged in constant debate and competing theoretical arguments on differing perspectives. If a grand theory can be developed which is sufficiently broad in scope to allow subtle differences to coexist it may therefore permit an overall consensus to be established. Equally, if there are common perspectives, it may lead to the development of a theory that can be tested and in this way gain 
consensus. At this time there are no common overarching perspectives and no grand theory to explain the observed consistencies that may constitute a disaster (McIntire, 2004b).

The current state of theory development in disaster management therefore reflects the position reached its research community in that it is either objective or subjective. The concept of objective, the stance taken by those that see the physical nature of disasters are isolated from the influence of those involved in disasters either through the management of or victims (Drabek, 2004). One of the early emerging themes has been the social aspects in disaster events. Research of this kind is generally underpinned by social theories and frameworks such as social construction formulation, used by Stallings (1995) and structural-functional theory used by Dynes (1970) (Drabek, 2004). Generally, emergency and crisis research looks at the emergency response and the population requiring that response. The resultant theoretical underpinnings have been of both a normative and substantive nature where normative theory is translated into strategies and plans indicating the actions emergency responders ought to take and substantive is utilised in explaining and describing the behaviour of a population (Drabek, 2004).

Further investigation into disasters where people are involved leads to research carried out on behavioural aspects (Dynes, 1970; Aguirre, Wenger, \& Rico, 1998). In reviewing theory, much of the psychology is grounded in social theories as outlined below (Kreps and Drabek, 1996; McIntire, 2004). In this respect social theories can and have been used to explain behaviours either pre or post disaster. However, no single social science theory can account for all actions undertaken by communities following a disaster. Drabek $(2004,2007)$ has observed there are several theoretical frameworks in the social sciences useful for explaining and predicting particular aspects of human behaviour that occur before, during, and after disasters. For example, he noted that the 
social construction formulation used by Stallings (1995) and others helps explain how hazards and disasters are framed as social problems (Kreps and Drabek, 1996) and that the structural-functional theory used by Dynes (1970) and extended by Kreps and his colleagues (Kreps and Bosworth, 2006) furthers understanding of how groups and organizations respond to community disasters. Similarly, the social vulnerability perspective advanced by several scholars (Bolin, 2006; Cutter, et al., 2003; Enarson, 2007; Wisner et al., 2004) places disasters in their social, political and economic context, thereby helping to explain the differential exposure of groups to disaster risks based on socio-demographic factors. These theoretical themes have emerged in the scholarly literature following decades of social science hazards and disaster research (Anderson, 2008, p. 200). While they do not constitute an integrated theory, considered collectively they can strengthen the analysis of disaster-related behaviour, actions, and consequences (Drabek 2004, 2007). The focus of the research is in the ability of a community to prepare for the onset of disaster or emergency, reducing its level of vulnerability and in doing so increase the level of community resilience. Throughout the early stages of the literature review a number of theories were considered with which to explore themes within disaster management. The themes selected had clear links to human behaviour in disasters and other emergencies. Much of the reviewed research was concerned with evacuation or non-evacuation behaviours. The literature on emergency evacuation was found to be comprehensive although not complete. Burnside et al (2007, p. 727) concurs, finding that 'evacuation of the public was well researched from a variety of perspectives'.

Latterly the literature review involved studies advocating the involvement of community members in dealing with the outcome of disaster, mainly actions during and after an event. Theory related to behaviours in disasters emanate largely from a sociological perspective. Three theories were selected for further investigation, these 
being; Agency Theory, regarding goal conflict and cooperative behaviours; Social Capital Theory and its links to social infrastructure, access to it and the quality of networks between and among members; and Social Cognitive Theory where individual and group beliefs have been linked to performance outcomes. A brief review of each of the theories follows with an explanation of why the may or may not be useful within this research.

Agency theory has been used in research focusing on responses to risk on the part of an organisation's principles and agents (Eisenhardt, 1989, Jensen and Meckling 1976). The origins of agency theory have much in common with the research carried out by Barnard (1938) on the nature of cooperative behaviour. This early work identified goal conflict as an important construct of agency theory and is inherent in individuals with differing perspectives engaged in cooperative behaviours. There is also a political dimension with the pursuit of self-interest at the individual level and goal conflict at the organisational level (March, 1962, Pfeffer, 1981). Although mainly associated with organisations and their internal interactions, Paton (2008) uses this theory to explore the concept of the community response in the event of a disaster. In this context, there would also be scope in using agency theory to explore the capacity of a community to prepare for disasters however research on this topic is relatively comprehensive.

There has also been considerable research carried out on the concept of human capital. Wilson and Musik (1997) describe human capital as any stock of knowledge or characteristics the worker has, either innate or acquired, that contributes to his or her productivity. Whilst the theory of human capital can pertain to disasters it has more use in the investigation of the effectiveness of emergency management employees. It is however, social capital that has received attention by researchers in the disaster management domain. It is useful at this stage to clarify that research on post disaster has led much of the response elements being introduced into current emergency and disaster 
management (Haddow and Bullock, 2004). The bulk of the research focuses on what professional bodies are developing to manage pre and post disaster phases in effected communities and involved the coverage of the contribution of social capital in communities being able to cope, respond and recover (Zakour, 2008). Social capital as opposed to human capital is not located in individual people but is found in social infrastructure and access to it and the quality of networks between and among members of a community (Kilpatrick \& Abbot-Chapman, 2005). These connections between people can be used to guide collective action in emergency situations. When disasters occur there can be losses to both physical and human capital, social capital is less affected, can be quickly repaired, and provides an essential resource in accomplishing critical tasks (Dynes, 2006). The application of social capital theory and social networks to disaster management has shed new light in the interconnections of human behaviour, their reliance on their immediate environment and the capacity for higher levels of resilience (Goddard, Hoy, \& Hoy, 2004; Kilpatrick \& Abbot-Chapman, 2005; Ohmer 2007; Parisi, Grice, Taquino, \& Gill, 2002; Zakour, 2008). Similarly to Agency theory, much has been written about social capital theory and its application to understanding community behaviour in emergencies.

Two themes have emerged from investigating these two theories. The first theme is the concept of agency and the belief in self-action whereas the second theme is the concept of social networks and the interconnection of people in a community. Whilst both themes have been extensively used to research post disaster behaviours, they may now have value pre disaster, in researching a community's predisposition in undertaking preparedness activities. In addressing the emerged themes, self beliefs and social networks, a more useful theory may be Bandura's (1988) social cognitive theory and its use in explaining self beliefs, group beliefs in solving problems and community beliefs in providing a community approach to collectively overcoming problems. Much 
of the research into efficacy beliefs stems from health prevention studies. Evidence for the utility of social cognitive theory therefore will initially come from research into how people make decisions regarding their health risk behaviours and the adoption of health protective behaviours. This has stemmed from the appreciation that an individual's health behaviour (i.e. how individuals deal with threats to their well being) is influenced by those relationships that form their social context (Bennett \& Murphy, 1997). Social cognitive models account for the cognitive elements of an individuals' motivation for adopting specific behaviours as well as the determinants of behaviour that are specific to the individual and to the social environment (Abraham and Sheeran, 2005; Connor \& Norman, 1996). Models such as the theory of Planned Behaviour (Ajzen, 1991) and the Health Action Process Approach (Schwarzer \& Renner, 2000) have identified the crucial role of factors such as outcome expectancy, self-efficacy and behavioural intentions in predicting sustained adoption of protective measures (Schwarzer \& Renner, 2000). The Health Behaviour Model for example contains a diagnostic element on self-efficacy. Elder et al. (2007) used this model to good effect in analysing disaster behaviour and the ability of a community to cope, post disaster. The Theory of Planned Behaviour (Ajzen, 1991) argues that the formation of intentions to act is predicated on positive attitudes, subjective norms and control beliefs regarding the performance of the behaviour. The Health Action Process Approach (Schwarzer \& Renner, 2000) describes motivation as being initiated by a perception of threat, or perceived risk, with action on this being influenced by outcome expectancies and self-efficacy judgements. The stage at which a decision is made is characterised by the individual adopting and maintaining health protective strategies. Both these models have been used to predict intentions to perform health behaviours such as exercise (Norman, Boer, \& Seydel, 2000), blood donation (Giles, McClenahan, Cairns, \& Mallet, 2004) and improving dietary behaviours (Schwarzer \& Luszczynska, 2008). Social cognitive theory and in particular, 
efficacy beliefs warrants further investigation within the literature review as it may provide a theoretical lens in which to frame the research and investigate preparedness behaviours prior to a disaster.

\subsection{Social Cognitive Theory and Efficacy Beliefs}

This section will initially examine perceived collective and community efficacy. After discussing the theoretical and research literature on social cognitive theory, efficacy is then explored in different domains with a view to its application in the domain of emergency management. The theoretical perspective is then discussed and the findings of research related to collective and community efficacy perceptions. The study of efficacy beliefs is grounded in social cognitive theory. Social cognitive theory accounts for how people, as individuals and as members of collectives, exercise some level of control over their futures. A central notion of social cognitive theory is that self and group agency is powerfully influenced by the strength of efficacy beliefs. When individuals and groups believe themselves capable of realising goal accomplishment, they are more likely to approach those goals with the effort and persistence required to achieve success. A low sense of efficacy reflects the belief that goal attainment is unlikely and that effort and persistence is pointless. Therefore, the lower the sense of efficacy is, the less likely a sustained effort would be undertaken in the face of adversity. This research is seeking to explore the use of efficacy beliefs to reduce levels of vulnerability in urban and rural communities prone to natural disasters.

It is useful at this stage to define the concepts of efficacy. Self-Efficacy: Self-efficacy beliefs determine how much effort will be exerted in an endeavour and how long a person will persevere in the face of obstacles (Bandura, 1989). Group Efficacy: a group's belief that it can perform effectively. Research has shown that group efficacy was high when the task or problem uncertainty was low. A shared understanding produced higher levels of group efficacy (Gibson, 1999). Community Efficacy: the 
ability to meet environmental demands through a variety of mechanisms including coordination of resources, solving community conflicts and setting community goals. Interventions that enhance community efficacy may provide important ingredients for successful individual and community-wide adaptation in defending the community against the effects of disasters (Benight, 2004).

Perceived community efficacy is a construct derived from social cognitive theory that refers to the beliefs that community member's hold about their capability to attain desired goals (Bandura 1997). Community efficacy beliefs are important to the study of community-based activity because the control that communities exercise over their future status is intensely influenced by the strength of their efficacy beliefs. The stronger a community's efficacy beliefs, the more likely its members are to undertake sustained effort and persistence in achieving desired goals. High levels of perceived community efficacy are associated with sense of purpose that assists overcoming obstacles rather than not tackling them where this would lead to a sense of failure and low efficacy beliefs. Interest in perceived efficacy beliefs as a community characteristic has grown, based on the results of studies that indicate communities characterised by higher levels of perceived efficacy have higher levels of success in community based programmes (Gibson, 1999; Goddard, 2001; Ohmer, 2007; Omher, 2010; Sampson 2004). Furthermore efficacy beliefs are related to the performance of social systems in education, business, health care, crime reduction, and sports (Campion, Metzger, \& Riggs, 1993; Kozub and McDonnell, 2000; Pescosolido, 2001; Sampson, Raudenbush, \& Earls, 1997; Ronan et al., 2008). Significantly, the majority of community efficacy belief studies focus on the outcomes of planned activity; however, the factors that influence perceived efficacy within communities are far less frequently studied.

According to Bandura (1997) perceived personal and collective efficacy differ in the unit of agency but in both forms efficacy beliefs has similar sources, serve similar 
functions, and operate through similar processes (p. 478). Given the importance of efficacy beliefs to individual and more importantly group or organisational agency, this research will focus on the types of information and experiences that residents and community groups consider when assessing whether or not to undertake a challenge or task. Bandura (1977, p. 191) asserts that "expectations of personal efficacy are derived from four key sources of information: performance accomplishments, vicarious experience, verbal persuasion and physiological cues".

Past performance accomplishment provides persuasive feedback to individuals and organisations. Successes and failures are clearly important to thoughts about capabilities, both individually and collectively. For example, when a person is repeatedly successful at a task, self-efficacy increases, however, if failure happens, the sense of self-efficacy declines (Zulkosky, 2009). In addition to past performance accomplishment, individuals are also persuaded of certain possibilities through vicarious experience. Collective efficacy beliefs are strengthened by directly observing individuals and organizations, especially those that are successful in attaining similar goals.

Social persuasion refers to convincing a person or group that they are capable of being successful. Influence that is exerted through social persuasion, in the context of sports, where athletes and coaches comment on the need for individual team members to believe in one another and the ability of the team in order to be successful. (Feltz \& Lirgg, 2001). Crain (2000) views verbal encouragement to be very influential and states, "success usually depends more upon the effort we put into a task than upon any inherent ability" (p. 203). Such statements highlight the influential relationship between social persuasion and collective efficacy beliefs in the context of group and community goal attainment. 
The concluding source of efficacy-shaping information proposed by social cognitive theory concerns the ways in which the physiological cues or affective states of individuals and organizations are related to efficacy beliefs (Bandura, 1997). The longterm magnitudes of a discouraging or stimulating event for community success are partially shaped by the affective state that individuals experience in reaction to the event. The strength of emotional responses such as fear or anger can either support or undermine a community's ability to tolerate pressure in the face of crises (Bandura, 1998). The belief that a community would not be able to effectively prepare in the case of a disaster could lead to a greater sense of personal vulnerability. Conversely, communities with higher levels of collective efficacy would perceive the community to be more effective at exerting influence in order to coordinate preparedness activities in the most effective way (Benight, 2004).

Perceived community efficacy is not just an outcome of just past performance accomplishment and vicarious experience, social persuasion, and affective states; the exercise of human and organisational agency depends on how individuals and groups interpret their experiences and how that then shapes their efficacy beliefs. Experiencing an emergency or disaster event will have an effect on a community member's efficacy beliefs. Although not an outcome of the actual events but more what community members make of those events, in the context of the social networks within which group members act (Duncan, 2003). Raudenbush et al., (1992) explained this aspect of Bandura's (1986) social cognitive theory by describing perceived efficacy as "a cognition that mediates between knowledge and action" (p. 150). From this perspective, for example, social persuasion alone will not necessarily lead to change. Community members will also consider the integrity and honesty of the persuader, their own prior past performance accomplishments and vicarious experiences, and how they feel before deciding how confident they actually are in the capabilities of others in the community 
to organise and execute activities required to mitigate the effects of natural disasters at local level. Bandura refers to this stage of the formation of efficacy beliefs as "cognitive processing." It is important to note that within many other domains, research evidence consistently suggests the importance of collective efficacy beliefs to the achievement of group goals. For example, Little and Madigan (1997) have shown that perceived collective efficacy is a strong positive predictor of the effectiveness of manufacturing work teams. They observed that collective efficacy beliefs had a mediating, or facilitating effect on team performance (p. 518). Similar results have been obtained in the context of health care. Specifically, Gibson (2001) showed that the effectiveness of nursing teams in three medium-sized hospitals, as reported by patients, was directly and positively related to nursing team perceptions of group efficacy assessed prior to the delivery of care. In addition to its relationship to formally organized endeavours such as education, manufacturing, and health care, collective efficacy beliefs also appear to be important to the informally organized efforts of residents who value neighbourhood safety.

Sampson et al. (1997) demonstrated, for example, that the more robust the sense of collective efficacy in city neighbourhoods, the less likely was the occurrence of neighbourhood violence. This is because neighbourhoods in which residents reported a strong sense of collective efficacy were ones in which citizens felt an expectation for action that predisposed them to intervene to decrease violent activity. Such social sanctions serve as deterrents to those who might otherwise violate group expectations for neighbourhood safety. The theoretical and conceptual basis for this study is theory and research in disasters, social networks, social capital, community capacity, and perceived efficacy, both self and community. It is essential then to investigate the construct of perceived community efficacy in relation to the dimensions that are central to its makeup. Sampson et al. (2000) suggest that the ability of community efficacy to 
effect activities and outcomes lies in the expectations for action that are socially transmitted by collective efficacy perceptions. They argue that collective efficacy beliefs are important to group functioning because they explain how organised capacity for action is tapped to produce results (Sampson, et al., 2000). For example, reciprocal and trusting relational networks might reflect high levels of social capital, however, the potential for such social resources to secure outcomes is reached only when that sense of community efficacy (collective beliefs in achieving a positive outcome) is sufficiently strong to compel residents to action to achieve collective outcomes (Sampson et al., 2000).

Perceptions of collective efficacy directly affect the thoroughness and determination with which groups choose to pursue their goals. Hence, perceived collective efficacy is a potent way of characterising the strong normative and behavioral influence of an organisation's culture. Knowledge about community efficacy beliefs is, therefore, critical to understanding the influence of individuals' beliefs in the community and how those collective beliefs are operationalized to achieve community goals that are related to the level of emergency preparedness.

In order for perceived community efficacy to existence there needs to be a network of people. The people need to have a network of friends, neighbours or family and identify with this group, neighbourhood or community. This may be labelled as a social network or community network structure (Ohmer, 2010; Masten \& Obradovic, 2007; Wang \& Kapucu, 2007). Within this structure the people need to interact, share information, participate in formal or informal settings. There needs to be a certain level of trust and the opportunity to reciprocate support activities within the community. These types of activities and attributes can be categorised as social capital (Duncan et al., 2003; Kilpatrick \& Abbot-Chapman, 2005; Larson et al., 2006; Ohmer, 2010; Parisi et al., 2002; Paton, 2007;). Lastly, the community needs to have a sense of shared 
responsibility and a collective competence to undertake challenging or confrontationally situations (Carroll, Rosson, \& Zhou, 2005; Chaskin, 1999; Duncan et al., 2003; Goddard et al., 2004; Goodman, Speers, McLeroy, \& Fawcett, 1998; Masten \& Obradovic, 2007; Ohmer, 2010; Parker, Priest, \& Tapsell, 2009;).

Having briefly describe the three elements of community network structure, social capital and community capacity, a more in-depth investigation into each is required to determine if any one or all may be suitable as a theoretical lanes with which to explore the construct of perceived community efficacy. The next sections describe the components that make up each element and the potential use in the investigation of the construct. Social networks consist of actors, groups and their relationships. A central premise of social networks is that: "The structure of relations among actors . . in the network has important behavioural, perceptual, and attitudinal consequences both for the individual units and for the system as a whole" (Knoke \& Kuklinski, 1982, p. 13). As well as individuals and groups, actors can be part of organisations or communities giving networks a multitude of differing characteristics. The social network approach suggests that the characteristics of social networks have implications for the provision of services and other resources relied upon by communities. The availability of these resources has consequences for actors' well being in crisis situations especially resources required for disaster preparedness (Hurlbert, Haines, \& Beggs, 2000). Kirschenbaum (2004, p. 248) concluded, "Disaster communities, defined in terms of their social networks, have an extraordinary influence on how they perceive and act in the case of a disaster". An actor's relationships with many different types of actors, such as volunteer and disaster organisations, are an important indicator of social capital from a network perspective (Lin, Fu, \& Hsung, 2001; Putnam, 2000).

Actors with a greater range of relationships have access to a greater number of different types of resources and are able to operationalize a greater quantity and quality 
of social capital to achieve preparedness goals. Social capital can be defined as resources embedded in a social structure which are accessed and/or mobilized in purposive actions" (Lin 2001, p. 12). Adequate social support networks and social capital embedded in networks are necessary for households to react successfully to impending disasters (Gladwin, Gladwin, \& Peacock, 2001; Riad, Norris, \& Ruback, 1999). Putnam (2000) describes social capital as aspects of social structures, such as social networks, that facilitate effective cooperation. According to this definition, structural characteristics of social networks such as actors, families and informal and formal groups, are the foundation for social capital. Social capital resources, informal social support and formal disaster services provided by organizations are embedded in social networks (Hurlbert et al., 2000; Wellman \& Frank, 2001). Communities can access social capital by using these interorganisational networks to operationalize disaster preparedness resources such as information, referral, paid personnel, volunteers, training, and transportation, helping to achieve their respective preparedness objectives. Social capital theory goes beyond network conceptualisations by focusing not only on network structures but also on access to social resources (Lin, 2001). The central type of variable in social capital theory is resource embedded in a network. Relationships with a variety of other kinds of actors increase opportunities for an organisation to exchange different resources, in effect a form of reciprocity. A community facing a disaster can have access to embedded social resources that can positively affect the capacity of that community to effectively prepare and mitigate disaster affects. Given the importance of networks and resources, actions by communities to build reciprocal relationships and networks can be seen as a means to increase the availability of social resources (Burt, 2001; Wellman \& Frank, 2001). Networks of organisations and communities can increase social capital at both the organisational and individual levels (Lin, 2001). Leading up to and during an emergency or disaster, networks of relationships between 
organisations and actors facilitate access to preparedness resources including evacuation (Gladwin et al., 2001; Klinenberg, 2002). Strong relationship bonds between formal and informal groups and actors are also important to communities as they improve disaster mitigation at organisational and household levels (Kirschenbaum, 2004).

There appears to be a general consensus in the research into community capacity that there is a shared responsibility to utilise the collective knowledge and skills for the general welfare of the community (Carroll et al., 2005; Duncan et al., 2003; Goddard et al.). Community capacity may function through informal or formal social processes and be established by individuals, organisations, and the networks of association between them. It may also involve the broader systems of which the community is a part. (Chaskin, 1999; Goodman et al., 1998; Homan, 2010; Mancini, Bowen, \& Martin, 2005). The notion of community capacity implies a certain where -with -all to achieve specific outcomes relative to the community aspirations. Capacity is derived from a community's ability to store and make use of forms of power or wealth, particularly knowledge and skill (Delgado, 2000). The community may well have a capacity for skills and knowledge, but it is the application within the community of the attributes that will ensure the well being of the community and its constituent parts (individuals, informal groups, organizations, social interactions, the physical environment). Community capacity therefore is concerned with development of its systems and people, in order to ensure a well-functioning organisation. It is both a sense of shared responsibility of residents and others for the welfare of its members and the competence of the community to act on that responsibility (Kirst-Ashman \& Hull, 2009). Although at a fundamental level the abilities that define community capacity are contained within the neighbourhood, they must also incorporate connections to and interact with the larger structures of which it is a part. A community group or institution, whether a family, neighbourhood group, charity, school, or foundation, gets its capacity from 
drawing on the commitment, resources, and skills from those within and around it. A group or institution must first develop capacity in and for itself before it can help develop capacity in others. A community with increased capacity has the potential to achieve more of its objectives, solve more of its problems and produce systematic growth.

It would seem therefore that in order for community efficacy to exist there needs to be present a network of people (Community Network Structure), a foundation of information, trust, reciprocity and participation (Social Capital) and a willingness of the community to use its skills and knowledge to achieve its goals (Community Capacity). More generally, this study will support a better understanding of perceived community efficacy as a powerful normative dimension of social systems. Given the ability of community efficacy beliefs to influence the outcomes of organised activity, the purpose of this research is to learn more about those aspects of social organisation that may influence resident's community efficacy beliefs specifically in relation to the preparedness activity within emergency management.

\subsection{Summary}

Despite being a relatively new research field the literature on disasters and emergencies is vast and diverse. Early research appeared to concentrate on the response aspects of the physical forces of natural disasters and its effect on the human and social elements. Although there is still a division this exists mainly due to specialisms in field such as geology or anthropological studies. The field of disaster and emergency management has for sometime realised that a natural disaster is made up of an extreme natural event that affects the population. The term 'vulnerability' was found to describe the level of risk to a population relative to the hazard. Social vulnerability includes other variables such as age ethnicity and gender and can influence the behaviours of an individual or a 
group of individuals when faced with an on coming severe event. The literature review also found that resistance to the effects of natural disasters was a key area of research and in the late nineties called for 'disaster resistant communities'. The term 'resilience' was found to provide a number of different views where for example, it was applied to the protection of infrastructure rather than a more inclusive approach involving communities. Most of the current research on resilience provides this more inclusive approach where an agreed definition includes risk assessment, mitigation, preparedness, response and recovery. In fact, resilience research appears have moved to along its spectrum to be focused on the recovery stages both short and long-term. This particular strand of research focuses on the infrastructure rebuilding where the term 'build better' is applied to resilient infrastructure.

Emergency management structures have also evolved to reflect aspects of mitigation and preparedness. Research on mitigation and preparedness has called for more involvement from communities in preplanning and preparedness elements. This has had the effect on disaster research where the attention has been focussed on behavioural aspects of community involvement in disaster preparedness. Evacuation prior to the disaster has accounted for a vast amount of research and although saving lives, it does little to contribute to the overall community resilience if on returning the community infrastructure is devastated and makes recovery seem futile. Mitigation and preparation as part of resilience includes community and agency activities to protect the infrastructure, protect lives and in so doing protect the social fabric that is the community. Having briefly summarised the development of emergency management, the different phases of a disaster, directed planning solutions and eventually community engagement in preparedness, the question arises that if emergency planners are now producing strategies that involved community actions, how is it ascertained whether or not a community will participate in preparedness activities. 
Behaviours of community members towards disasters have been the main focus of this research. However there is no overarching theory to explain a natural disaster and its affects on a population. Theories from other fields have been used in the past to explain the interaction of severe natural events and human behaviour. Social theories have been employed to explain different aspects of behaviour for the pre, during and post phases of a natural emergency or disaster. The review found that social cognitive theory and in particular efficacy beliefs may be provide a useful model in which to explore community actions in being prepared for a disaster. Perceived community efficacy was found to have three main elements, social networks, an infrastructure to allow networks to be effective and a capacity that provides skills and knowledge inherent in the population. An initial model for the investigation of the utility of perceived community efficacy in measuring a community's belief is suggested and comprises community network structure, social capital and community capacity. These elements will be used in the qualitative study to guide enquiry at the initial stages. This deductive approach is explained in chapter 3 methods and used in chapter 4 as part of a deductive / inductive method of knowledge elicitation. The next chapter details the epistemological and methodological and methods used in both the qualitative and quantitative studies 


\section{Chapter 3.0 Methodology}

\subsection{Introduction}

This section provides the link to the previous chapter, literature review, and the research objectives that were developed from gaps in the study of perceived community efficacy and its usefulness in exploring in emergency preparedness. The chapter begins with a discussion on how best to investigate the construct of perceived community efficacy, more specifically addressing the research question. Various techniques are cited including observation, questionnaires or measurement. In social sciences, scales are constructed to measure constructs and the statistics produced can be used to investigate relationships between variables such as behaviours, traits or attitudes. The development of a scale can be theory driven or a more inductive process can be employed. This would commonly involve a qualitative or quantitative study or both. The advantages and disadvantages of single method studies quantitative or qualitative are explored and the rationale for using both quantitative and qualitative data collection is discussed. Although mixed methods research has gradually gained momentum as a viable research method, there is still a debate over its philosophical and best-fit paradigms (Creswell, 2005, p. 225.Hanson, Creswell, Plano-Clark, Petska,) Issues of ontological and epistemological nature are discussed with a view to supporting the researchers pragmatic approach to this research. Tashiro (2002) is cited as an example of sequential mixed methods research used for the purpose of instrument and scale development. The research design is outlined with a detailed description of the qualitative and quantitative processes that are used in the design and development of a scale that can be used to determine the likelihood of a community to engage in disaster preparedness activities by measuring the levels of perceived community efficacy. It will therefore include the 
methods used in qualitative data collection and analysis, quantitative evaluation and validity and reliability procedures.

\subsection{Rationale for Selecting the Research Design.}

Having developed the research questions it is necessary to design the research so that it addresses the main issues in the questions (Bryman and Bell, 2007, p. 304; Cresswell and Tashakkori, 2007, p. 207; Onwuegbuzie and Leech, 2006, p. 475). Firstly there is the construct to consider and how best to investigate the constituent parts, such as community and its beliefs. Secondly there is the aspect of measurement and how to assess the differing elements of the construct. Lastly there is the issue of the domain, which is based on the timescale before an emergency event. In order to explore the construct of perceived community efficacy a number of methods can be employed; these being observations, questionnaires or interviews (Corring and Cook, 2007, Opdenakker, 2006).

However in order to assess the relationship between the construct and the domain of emergency preparedness and more specifically the ability of community efficacy beliefs to measure community behaviours in this domain, there needs to be a an element of measurement (DeVellis, 2003). A scale may be used to explore to construct that in turn generates statistics that measure the relationship between the latent variable, perceived community efficacy and other identified variables (DeVellis, 2003, p. 14). It has already been established in the literature review that there is currently no scale that measures perceived community efficacy in the specific domain of disaster preparedness. It may be possible to adapt items from other efficacy scales and produce a scale that may be used to measure community efficacy beliefs and preparedness however according to Bandura (1999) there is a danger that the items may be measuring the wrong thing and invalidate the research. Schrauf and Navarro (2005) support this position of measurement and found that the logic of validity and reliability in scales 
implies that the most accurate measurement is found on samples that match the population that was used to develop the scale.

In order to explore the construct of perceived community efficacy for the purposes of this research it is necessary to develop a scale where the answers to the questions will expose the strength of beliefs of individuals regarding their community and its collective ability to prepare for a potential disaster. Examples of published mixed methods research that employed a sequential qualitative/quantitative approach to survey development include: Nastasi et al. (2007) O’leary \& Mhaolrúnaigh (2012) and, Tashiro, (2002). Having described the rationale for a mixed methods approach to this research, the next section discusses the epistemological and paradigm issues both at a general level and more specifically within the domain of emergency/disaster research.

\subsection{Epistemological and Paradigm Considerations.}

The debate about quantitative and qualitative research at an epistemological level stemmed from a perception that each was distinct and related to competing paradigms (Bryman, 2006, p. 113). This view was promoted in Kuhn's influential publication 'The structure of scientific revolutions' (1970) where qualitative and quantitative approaches to research could not be combined due to incommensurable issues. Two important issues that still persist are the paradigm-method fit and the best paradigm and have inspired considerable debate regarding the philosophical basis of mixed methods research. The paradigm-method fit issue relates to whether or not philosophical paradigms (e.g., post positivism, constructivism) and research methods fit together whereas the best paradigm issue relates to what philosophical paradigm is the best foundation for mixed methods research (Hanson et al., 2005, p. 225).

Guba and Lincoln (1988), for example, identified paradigm differences between 
post positivist philosophical assumptions and naturalistic assumptions in terms of epistemology (how we know what we know), ontology (the nature of reality), axiology (the place of values in research), and methodology (the process of research). This led to a separation between traditional inquiry paradigms and naturalistic paradigms where some researchers have argued, for example, that a post positivist philosophical paradigm, or worldview, could be combined only with quantitative methods and that a naturalistic worldview could be combined only with qualitative methods (Reichardt \& Rallis, 1994). From this perspective, mixed methods research was viewed as untenable or incommensurable because certain paradigms and methods could not fit together legitimately (Smith, 1983). Reichardt and Cook (1979) suggested a different approach where different philosophical paradigms and methods were compatible. Greene and Caracelli (2003) supports this position and argue that multiple methods may be used in a single research study to, take advantage of the representativeness and generalizability of quantitative findings and the in depth, contextual nature of qualitative findings.

Tashakkori and Teddlie (2003) suggest that pragmatism is the best paradigm for mixed methods research. Pragmatism is a set of ideas that draws its inspiration from "what works", and leads to the use of diverse approaches and valuing both objective and subjective knowledge (Cherryholmes, 1992). Rossman and Wilson (1985) strongly associate pragmatism with mixed methods research. They differentiated between methodological purists, situationalists, and pragmatists. The purists believed that quantitative and qualitative methods derived from different, mutually exclusive, epistemological and ontological assumptions about research. The situationalists believed that both methods have value but that certain methods are more appropriate under certain circumstances. The pragmatists, in contrast, believed that, regardless of circumstances, both methods might be used in a single study. For many mixed methods 
researchers, then, pragmatism has become the answer to the question of what is the best paradigm for mixed methods research. Tashakkori and Teddlie (2003, p. 20) have attempted to formally link pragmatism and mixed methods research, arguing that, the research question should be of primary importance and more important than either the method or the theoretical lens, or paradigm that underlies the method. This position is supported by Bryman (2006, p. 118) where the primacy of the research question is instrumental in bringing together qualitative and quantitative research.

There are a number of different perspectives in the natural hazards and risk literature. On one end of the risk research spectrum is a strong technical or realist approach to risk. In this perspective, the environment is considered to be external to society and capable of being measured objectively. Uncertainties that have no predictable probability are excluded from technical risk analysis, as are social constructions or perceptions (Lupton 1999). At the other end of the spectrum are constructionist (or relativist) approaches that emphasize the ways in which people assign meaning to their world (Irwin 2001) Strong constructivist perspectives approach risk as something only subjectively known. What people think and the cultural worldviews of people are what make risks real (Raynor 1992).

The ontological position of a disaster researcher will undoubtedly lead to the way in which knowledge about disasters is constructed and understood and therefore will determine the overall epistemological position. Disaster studies reflect research positions of both positivist and interpretist nature. The positivist taking a natural science approach where knowledge about disasters is generated based on generalisable propositions where as the interpretivist will generate knowledge that is based on the subjective meaning of social action and is not necessarily generalisable (Bryman and Bell, 2007). However it may be necessary to rise above the epistemological differences between objectivist/positivist and constructivist/interpretivist paradigms and rely as 
much upon qualitative as quantitative methods in order to both conceptualise and estimate the risk from natural or man made disasters. Action and decision inherent in defining disaster risk require the creation of interactions between subjective risk perception and the scientific need for objective measurement (Cardona, 2003). Kreps (1989) appeared to have the foresight of the way forward espoused by Cardona where he comments "I am certain that a cooperative dialogue based on mutual respect for competing epistemologies is the path to scientific progress in disaster research" ( $p$. 280).

Having described the epistemological conflicts in the field of disaster management, a discussion on the methods used within the domain will equally reflect the diversity described previously. The methods of disaster research are not distinguishable from those used throughout mainstream social sciences. Yet these methods must be applied under sometimes exceptional circumstances created by a social situation characterised by non-routine, life threatening physical destruction (Stalling, 2005a). Researchers in this discipline need to understand how the disaster context affects the application of the methods of research. Standard methods of research in the field of disaster studies are for example, qualitative field studies or quantitative survey research (Stalling, 2005b).

The review of literature on disasters and emergencies revealed that qualitative, quantitative and mixed methods approaches were all being utilised to generate knowledge about the domain. Elder et al. (2007) uses six focus groups within a qualitative methodology to elicit information on evacuation decisions in the Katrina disaster whilst in quantitative studies that took place in the United States and New Zealand, Kang et al. (2007) and McIvor and Paton (2007) use survey methods to generate information on disaster behaviour. A mixed methods approach was used to examine adaptive behaviour in the Katrina disaster. This study used a 54 item survey for 
the quantitative data collection and field observations and interviews were used in the qualitative element (Adeola, 2009). Having reviewed the generally position of epistemological and paradigmic issues regarding mixed methods, focus then turned to the domain of disaster and emergency management and how epistemological and paradigmic issues affect research in this area. The next section will explore mixed methods as both a methodology and method of approach.

\subsection{Methodology and Methods}

Mixed methods research has emerged in response to the limitations perceived in using either quantitative or qualitative methods and is now considered as a suitable alternative to these two other methodologies (Doyle, Brady, \& Byrne, 2009, p. 178). There is much debate among researchers about what is involved in mixed methods research. Therefore in trying to define or describe mixed methods several sources provide useful guidance. Terms such as methodology, design and methods can cause confusion because they are used sometimes indiscriminately and in different context by different researchers or authors. It is useful at this stage to be clear as to the terminology used in describing mixed methods research. A methodology can be viewed as a philosophical framework in which research is carried out. This is distinct from individual methods and has a direct link to the paradigmic or ontological perspective (Van Mauren, 1991). It therefore influences all procedures involved in the research project (Crotty, 1998). Cresswell (2009) describes research design as a roadmap or plan that provides a direct connection between philosophical position and specific methods. Lee and Ling (2008) argue that research designs are not automatically secured to certain research methods, and that the principles integral to the design can be represented by various methods.

Examples of research designs described by Bryman (2007) include experimental, social survey, cross-sectional, longitudinal, case study and comparative. 
Methods are specific techniques used for data collection. Examples of methods range from content analysis used in qualitative research to a quantitative approach using survey questionnaires (Cresswell, 2003). Having clarified these terms, the stance taken by some proponents of mixed methods can be explored. Tashakkori and Teddlie (1998) view mixed methods as a research methodology, whilst Greene, Caracelli, \& Graham, (1989) use the term mixed methods to describe the techniques or procedures for collecting and analysing data. For the purposes of this study Creswell and Plano Clark (2011) provide a definition that is in accord with the researcher's philosophical position and links seamlessly to the research questions.

Mixed methods research is a research design with philosophical assumptions as well as methods of inquiry. As a methodology, it involves philosophical assumptions that guide the direction of the collection and analysis of data and the mixture of qualitative and quantitative approaches in many phases in the research process. As a method, it focuses on collecting, analysing, and mixing both quantitative and qualitative data in a single study or series of studies. Its central premise is that the use of quantitative and qualitative approaches in combination provides a better understanding of research problems than either approach alone. (p. 5)

The mixed method approach described above integrates many of the alternatives position statements and will be used to describe the component parts of the research design. Used in isolation qualitative and quantitative methods have certain weaknesses that can be countered by a mixed method approach. Whilst this may seem a trivial argument none-the-less, still holds true. Jick (1979, p. 602) contends that quantitative research is weak in understanding the context or immediate environment in which people communicate. It is also seldom that direct verbal communication occurs between researcher and those being researched. When this does occur communication may be 
limited to closed questions with little or no opportunity to open up dialogue to explore responses fully (Jick, 1979, p. 605). Qualitative research may be seen as biased due to personal interpretation made by the researcher. Further there is a difficulty in generalising to a large population because of limited numbers studied in qualitative studies.

It has also been identified that mixed methods has its own limitations, with much of the criticism focused around the issues of incommensurability. The arguments against combining qualitative and quantitative approaches and in doing so, overlooking issues of ontological and epistemological nature, are well made (Guba, 1987). However, Onwuegbuzie (2002, p. 526) argues that the positivist and non-positivist philosophies are on and epistemological continuum, with mixed methods research residing in the middle ground. In this respect mixed methods may be viewed as a pragmatic approach to conducting research. Pragmatists believe that, regardless of circumstances, both methods may be used in a single study (Bryman, 2006, p. 124). For many mixed methods researchers, pragmatism has become the answer to the question of what is the best paradigm for mixed methods research. Tashakkori and Teddlie $(2003$, p. 9) have suggested that pragmatism is a paradigm in which mixed methods researchers can defend issues of incommensurability arguing that, among other things, the research question should be of primary importance and that the research design should reflect the methods needed to address the problem. Morgan (2007) supports this and views a pragmatic approach as a new guiding paradigm that can act "as a basis for supporting work that combines qualitative and quantitative methods and as a way to redirect our attention to methodological rather than metaphysical concerns" (p. 48). There are also criticisms of the practical application of mixed methods. Concurrent studies can be labour intensive and may be difficult for one researcher to undertake this amount of work in a given timescale (Johnson and Onwuegbuzie, 2004, p. 21). Sequential studies 
may also have drawbacks as identified by Ivankova (2006, p. 5), with the main difficulty being the time it takes to carry out the different phases of the study. There is also a concern that mixed methods researchers may not have the necessary knowledge in order to use both qualitative and quantitative methods in the piece of research (Doyle et al., 2009, p. 184). It is therefore essential that researchers are aware of the limitations and criticisms and ensure that the research design is sufficiently sound to address the above issues. Mixed methods therefore provide a more balanced approach than using either quantitative or qualitative research methods. A philosophical stance of pragmatism has been suggested as an alternative to the positivist and non-positivist positions. Researchers using mixed methods have a larger portfolio of techniques available to them in order to generate more comprehensive findings (Creswell, 2006). Using mixed methods for this type of study aligns with Creswell (2006) who cites research by Tashiro (2002) as examples of sequential mixed methods research for the purpose of instrument and scale development. The research design consists of two main studies; instrument preparation phase, which is a qualitative study where data is generated in order to develop items for inclusion in the instrument. The in sequential order the quantitative study will assess the psychometric properties contained within the newly developed instrument. Each phase follows a logical, sequential process that provides a "methodological road map" (Benson and Clark, 1982, p. 798) in order to ensure that the methods used are sound and appropriate. The next sections will detail the methods used in both qualitative and quantitative studies

\subsubsection{Qualitative Study - Methods}

In providing a structure to the research it is necessary to develop the aim or goal of the study. This has been identified as:

Using the construct of perceived community efficacy, measure the likelihood of a community in undertaking disaster preparedness activities. 
The aim can now be used to select a population that fits with the term 'community' within the purpose statement. As flooding is the major cause of disaster scale events within the United Kingdom, communities who may be at risk from major flooding would be the identified population. This is not to say that all communities at risk would have experienced flooding, some may have experienced another form of disaster or emergency event that would have shaped their thoughts on whether the community was prepared for such an event and would the community participate in preparedness activities for a future disaster event. Therefore in order identify communities that are at risk from natural disasters it was necessary to have access to local emergency planning officers in liaison with the Environment Agency. A request was submitted to provide information through their detailed mapping systems to identify communities who may be at risk from severe weather or other natural disasters. The Environment Agency allows open access to flood risk maps for the whole of the UK land mass. Residents can access these maps online and by inserting their postcode can identify the category of flood risk pertaining to their property. A number of communities were identified using the online maps. In terms of flood risk category as specified by the EA these ranged from medium to high risk areas both in terms of river and surface water (Environment Agency, 2014). The selection of the population is based on purposive sampling technique. Teddlie and Yu (2007, p. 77) define this as "selecting units (e.g., individuals, groups of individuals, institutions) based on specific purposes associated with answering a research study's questions”.

Having conducted a literature review, gaps were found in the knowledge and use of social cognitive theory, which now form the basis of this research. To further provide structure to the research, it is useful to confirm the construct and the domain in which the construct is to be investigated (Benson and Clark, 1982, p. 791). According to the literature review, the construct has been identified as perceived community efficacy. 
The choice of domain is important as efficacy scales must be tailored to the particular domain of functioning that is the object of the research (Bandura, 2006, p. 308). In reference to the literature review the domain could be in emergency management or disaster management however the researcher believes that these domains are too broad in scope and should be narrowed down. Whilst this research is within the remit of emergency and disaster management it is not within the post disaster phase and is in the pre disaster or preparatory phase. Therefore, emergency preparedness is the specific domain of interest.

A major part of the qualitative exploratory research is where the researcher is able to gather information during interviews, analyse the responses and be able to draw inferences and conclusions (Bryson \& Bell, 2007, p. 579). In order to do this, openended questions are developed to ensure that respondents are able to describe their belief in their capacity to undertake preparedness activities. Bandura (2006, p. 311) asserts that using open ended questions will elicit the type of activities people perform regularly and that this information can be used to further the enquiry. Bryson and Bell (2007, p. 259) support this view and describe one of the advantages of open-ended questions are that respondents' level of knowledge and understanding of issues can be tapped and used to form a basis on which to further the research. Having developed knowledge of social cognitive theory, perceived community efficacy and emergency preparedness from the literature review, the researcher will develop 20 questions for use in interviews with residents within the sample population. The collected data from the representative population was to be used to develop an item pool that was then deployed in the quantitative stage of this research. The combination of open ended questions and the use of semi-structured interviews allowed some consistency of approach in dealing with the variety of communities as well as sufficient flexibility for respondents to give detailed insights into their efficacy beliefs. Lee and Ling (2008) suggest that semi 
structured interviews provide "a lot of flexibility to follow up individual points, but in general the same questions will be asked of each interviewee" (p. 218). Having gather the qualitative data, it is necessary to analysis the responses from the interviewees. The aim of the analysis is to identify themes, patterns or trends in order to develop a large item pool and in order to do this a themed coding structure was employed.

\subsubsection{Approaches to Thematic Analysis.}

Thematic analysis (Boyatzis, 1998) is a method used to analyse and report patterns within qualitative data. However, thematic analysis can go beyond this and interpret more specific aspects of the research topic (Boyatzis, 1998, p. 4). Braun and Clarke (2006, p. 81) note that thematic analysis is flexible, and can be used across a range of philosophical paradigms. While Braun and Clarke (2006) offer an excellent guide to approaching thematic analysis, Boyatzis (1998) offers a more descriptive, in depth approach and includes a quantitative technique for validating codes. Boyatzis (1998) was therefore selected as the guiding framework to the qualitative analysis stage. In the description of this process themes are often referred to as being developed by the researcher. Boyatzis identifies three stages in thematic analysis (see table 1.). In the first stage decisions are made regarding sampling and study design. In the second stage, themes are developed and a codebook produced. In the third stage the codebook is validated and then applied to the data. Boyatzis (1998) states that criterion-referenced material is vital to developing a code inductively (p. 160). Criterion-referenced material is data that is closely linked to the research question. Sampling and design decisions are critical to obtaining such material. Given that the present research is primarily focused within the domain of emergency preparedness and efficacy beliefs, it would assist the study to recruit participants who may have high or low efficacy beliefs regarding whether their community would engage in preparedness activities. Participants were 
recruited based upon the their geographical location and the level of risk from flooding. Consequently comparisons between groups of respondents focus upon differences and similarities of experience, and how these might affect beliefs. Boyatzis (1998, p. 165) identifies three approaches to developing themes. The first is theory driven, the second is driven by prior research or data, and the third is driven by the data obtained in one's present work. As such the first two methods represent deductive approaches in which a framework is developed prior to analysis and then applied to the data. The third approach is inductive, developing themes from the raw data obtained through research rather than using prior conceptions to guide analysis.

Table 1. Thematic Analysis from Boyatzis, (1984, p. 78)

\begin{tabular}{ll}
\hline Stage & Activities \\
I: Sampling and Design Issues & 1: Deciding on sampling and design issues \\
2: Selecting subsamples
\end{tabular}

Boyatzis argues that the inductive approach improves understanding of the data and removes biasing effects of prior conceptions. However, as Braun and Clarke (2006, p. 84) note, researchers do not analyse data in an "epistemological vacuum", and suggest that prior conceptions will in some way always influence the inductive process. The method of analysis chosen for this study was a hybrid approach of qualitative methods of thematic analysis, and it incorporated both the data-driven inductive approach of 
Boyatzis (1998, p. 161) and the deductive a priori template of codes approach outlined by Crabtree and Miller (1999, p. 235). This approach complemented the research questions by allowing the tenets of social cognitive theory to be integral to the process of deductive thematic analysis while allowing for themes to emerge direct from the data using inductive coding. A similar approach used by Ali and Birley (1999) combines the use of deductive and inductive approaches to legitimate enquiry. They argue that although a theory exists it may not be wholly appropriate to use a deductive approach and that an inductive element needs to be brought into the research design (Ali \& Birley, 1999, p. 103). Where this is the case, theoretical constructs derived from a deductive approach are explored using inductive, qualitative methods. In this way a theory can be used to guide the researcher but qualitative methods are used for the analysis and knowledge elicitation (Ali \& Birley, 1999, p. 109). Fereday and MuirChocraine (2006, p. 4) endorse the use of deductive and inductive qualitative methods and regard this technique as essential to demonstrate rigor using a hybrid approach to thematic analysis.

\subsubsection{Developing Themes and Codes}

Boyatzis (1998) divides the development of themes and code into five steps: reducing the raw information, identifying themes within subsamples, comparison of these themes between subsamples, creating a code, and determining reliability. Braun and Clarke (2006, p. 94) argue that the stages of developing themes is recursive, rather than linear. Therefore the identification of themes within subsamples and the comparison of themes between subsamples will influence revisions of the themes. Braun and Clarke (2006, p. 100) state that themes should be selected because they capture something of importance to the research question. Consequently it can be argued that the development of a code is a statement about what the researcher considers important to the subject being 
studied. An alternative structured way of achieving codes is suggested by Miles and Huberman, (1994) who employ three main activities in the analysis of data, which are "data reduction, data display, and conclusion drawing" (p. 10). The first activity is data reduction and is defined as "the process of selecting, focusing, simplifying, abstracting, and transforming the data that appear in written-up field notes or transcriptions" (p. 10). The interviews are transcribed and in order to reduce the data, a pattern coding framework is developed in order to detect underlying patterns, themes and links in the data. A similar method is outlined by Crabtree and Miller (1999), where a template in the form of codes from a codebook is applied as a means of organising text for subsequent interpretation. When using a template, a researcher defines the template (or codebook) before commencing an in-depth analysis of the data. The codebook is sometimes based on a preliminary scanning of the text, but for this study, the template was developed a priori, based on the research question and the theoretical framework and then supplemented by an iterative approach of scanning the transcriptions, identifying further themes or codes and amending the codebook. On conclusion of the thematic analysis the researcher will judge as to whether there is sufficient information contained within the data to start writing items to go forward to content validation.

\subsubsection{Writing the Items}

The content of an initial item pool during an item generation stage should be over inclusive and item wording should be carefully studied before testing the item pool along with variables that assess closely related constructs (Devellis, 2003, p. 63). The conceptualisation procedure of the a priori model will be followed by generation of an initial pool. It will include verbatim quotations, others that benefitted from a rigorous literature search of scale development, disaster research and efficacy measurement (Carroll et al., 2005, p. 1-10). In addition, various journal articles cited for good 
descriptions of item generation were researched and where appropriate, will be followed closely in terms of technique and process (Butler, 1991, pp. 643-663; MacKenzie, Podsakoff, \& Fetter, pp. 123-150). All of the generated items will consist of statements written in the first person, for example, "I am certain the community can achieve our preparedness goals", reflecting an answer from a respondent describing a belief in community actions.

\subsubsection{Item Reduction}

An initial qualitative reduction of the identified items/statements will be carried out, in which statements considered inappropriate, ambiguous or redundant are excluded. The decision to retain or remove an item will be based on the following four principles (DeVellis, 2003, pp. 63-70):

- Responsiveness: the item is expected to be sensitive to change over time.

- Universality: the item should capture beliefs of individuals across the observed groups and a broad age range,

- Wording/ambiguity: the item should be clearly worded and understood and is unlikely to evoke a variety of interpretations,

- General Acceptability: the item should resonate with participants and should be felt appropriate for the target population.

This completes the main methods employed in the qualitative element of this research.

The next section will outline exploratory factor analysis (EFA), hierarchical regression analysis (HRA), and confirmatory factor analysis (CFA) that are the main methods used in the quantitative element of this research 


\subsection{Quantitative Study - Methods}

This section details the main quantitative methods used in developing the items into a valid and reliable measurement instrument. The methods used have been selected in order to identify a factor structure, test for the contribution to variance of each identified factor and analyse the structure for goodness of fit to the data.

\subsubsection{Exploratory Factor Analysis}

\subsubsection{Sample Size}

Although sample size is important in factor analysis, there are varying opinions, and several guiding rules of thumb are cited in the literature (Hogart et al., 2005, pp. 8-10). The lack of agreement is noted by Hogarty et al. (p. 203) who noted that the disparity in sample size recommendations was not helpful to those carrying out research. General guides include, Tabachnick's rule of thumb (Tabachnick \& Fidell, 2007, p. 86-89) suggests that having at least 300 cases are needed for factor analysis. Hair, Anderson, Tatham, and Black (1999, p. 156) find that sample sizes should be 100 or greater. A number of textbooks (Hogart et al., 2005, pp. 8-10) cite the work of Comrey and Lee (in their guide to sample sizes: 100 as poor, 200 as fair, 300 as good, 500 as very good, and 1000 or more as excellent. According to MacCallum et al. $(1999$, p. 88), such rules of thumb can at times be misleading and often do not take into account many of the complex dynamics of a factor analysis. Henson \& Roberts (2006, p. 405) provide an example of this complexity where communalities having values $>.60$ and each factor is defined by several items, then sample sizes can actually be relatively small. However, Reise, Comrey, and Waller (2000, p. 290) found that when communalities are low (e.g. when analysing items), the number of factors is large and the number of indicators per factor is small, even a sample size of 500 may not be adequate. 


\subsubsection{Sample to Variable Ratio (N:p ratio)}

There are also recommendations to provide researchers with guidance regarding how many participants are required for each variable. The sample to variable ratio, often denoted as $N: p$ ratio where $N$ refers to the number of participants and $p$ refers to the number of variables (Hogarty et al., 2005, p. 224) For example, rules of thumb range anywhere from $3: 1,6: 1,10: 1,15: 1$, or 20:1 (Pett et al., 2003, pp. 8-10). To highlight this ambiguity, investigators such as Hogarty et al. (2005, p. 222) observed that their results showed that there was not a minimum level of $N$ or $N: p$ ratio to achieve good factor recovery across the conditions they examined. As can be seen, the suggested sample size required to complete a factor analysis of a group of items that participants have responded to, varies greatly. MacCallum et al. (2002, p. 634) using factor analytic theory (MacCallum \& Tucker, 1991) were able to show that it is impossible to derive a minimum sample size that is appropriate in all situations and that it may be more appropriate to limit the number of variables when exploring factorability. The researcher with regard to the extant literature on sample size took a pragmatic view in keeping with the epistemological framework of the research design, aimed for at least $\geq$ 500 participants and thus reaching an acceptable level for most sample size criteria.

\subsubsection{Factorability of the Correlation Matrix}

A correlation matrix should be used in the EFA process displaying the relationships between individual variables. Henson and Roberts (2006, p. 406) pointed out that a correlation matrix is most popular among investigators. Tabachnick and Fidell recommended inspecting the correlation matrix (often termed Factorability of $R$ for correlation coefficients $>.30$. Hair et al. (1995) categorised these loadings using another rule of thumb as $\geq .30=$ minimal, $\geq .40=$ Important, and $\geq .50=$ practically significant, (Hair et al., 1995, p. 88). If no correlations have values of $\geq .30$, then the researcher 
should reconsider whether factor analysis is the appropriate statistical method to utilize (Hair et al., 1995, p. 88; Tabachnick \& Fidell, 2005, p. 203). The assessment of factorability of the data also comes from the determinant of the correlation matrix. The determinant of a matrix is a single value calculated using the values within a square matrix, revealing the presence or absence of possible linear combinations within the matrix. With the exception of cases where the determinant is zero, the values can be arranged into linear combinations. In factor analysis, these linear combinations are considered factors where a non-zero determinant indicates that a factor or component is mathematically possible. It does not however, offer any indication of the practical meaning or significance of the factors. The values for the determinant of a correlation matrix range from 0 to 1 and are most often are very small, suggesting that a few linear combinations exist (Pett et al., 2003).

\subsubsection{Kaiser-Meyer-Olkin (KMO) Measure of Sampling Adequacy/Bartlett's Test of Sphericity}

Prior to the extraction of the factors, several tests should be used to assess the suitability of the respondent data for factor analysis. These tests include Kaiser-Meyer-Olkin (KMO) Measure of Sampling Adequacy, (Kaiser, 1970, pp. 401-415; Kaiser, 1974, pp. 111-117) and Bartlett's Test of Sphericity (Bartlett, 1950, pp. 177-185). The KMO index, in particular, is recommended when the cases to variable ratio are less than 1:5. The KMO index ranges from 0 to 1 with .50 considered suitable for factor analysis (Kaiser, 1974, pp. 111-117) The Bartlett's Test of Sphericity should be significant $(p<$ $.05)$ for factor analysis to be suitable (Bartlett, 1950, pp. 177-185).

\subsubsection{Initial Factor Extraction}

Although there are numerous ways to extract factors, principal components analysis (PCA) and principal axis factoring (PAF), are used most commonly in the published 
literature (Costello \& Osborne, 2005, p. 1; Pett et al., 2003, p. 9). Fabrigar et al. (1999, p. 277) argued that if data are relatively normally distributed, PCA is the best choice because it allows for the computation of a wide range of indexes of the goodness of fit of the model (p. 277). The benefit of PAF however is that does not require distributional assumptions to be met and therefore can be used to analyse data that are not normally distributed. However, PCA is also recommended when no priori theory or model exists (Williams et al., 2010, p. 6). Pett et al. (2003, p. 129) suggested using PCA in establishing preliminary solutions in EFA. The aim of the data extraction is reduce a large number of items into factors. In order to produce scale unidimensionality, and simplify the factor solutions several criteria are available to researchers. However, given the choice and sometimes confusing nature of factor analysis, no single criteria should be assumed to determine factor extraction (Costello \& Osbourne, 2005, p. 2). Whilst there are many rules that can be used to determine the number of factors to retain the two most commonly used are the eigenvalue $>1$ rule (Kaiser, 1960) and the scree test (Cattell, 1966). According to Thompson and Daniel (1996, p. 200) the most frequently used method is the EV $>1$ rule, as it is the default option in most statistics packages, however Costello and Osbourne (2005, p. 3) recommend the scree test. Costello and Osborne, 2005 found that the EV $>1$ rule over estimated the number of factors but this was contrary to the findings of Fabrigar et al. (1999, p. 278), Henson and Roberts (2006, p. 398) and, Schonrock-Adema et al. (2009, p. 227) who noted that the EV > 1 rule may underestimate the number of factors. Due to the factor retention decision directly affecting the EFA results obtained, Henson and Roberts (2006, p. 399) and Schonrock-Adema et al. (2009, p. 228) advise researchers to use both multiple criteria and reasoned reflection. Researchers should also explicitly inform readers about the strategies used in making factor retention decisions. In light of the above research and recommendations, both the $\mathrm{EV}>1$ rule and the scree test will be selected for the current 
study and will be used for factor extraction and comparison between the two methods.

\subsubsection{Selection of Rotational Methods}

Rotation maximises high item loadings and minimises low item loadings, therefore producing a more interpretable and simplified solution. There are two common rotation methods: orthogonal rotation and oblique rotation (Beavers et al., 2013 p. 10).

Regardless of which rotation method is used, the main objectives are to provide easier interpretation of results, and produce a solution that is more parsimonious (Hair et al., 1995; Kieffer, 1999, p. 78). There are several specific types to choose from for both rotation options, for example, orthogonal varimax or quartimax or oblique oblimin or promax. Orthogonal rotations produce factors that are uncorrelated; oblique methods allow the factors to correlate (Henson and Roberts, 2006, p. 400). Costello \& Osborne (2005, p. 3) observe that conventional wisdom steers research to use orthogonal rotation because it produces more easily interpretable results, however may be a flawed argument. According to Fabragar, (1999, p. 282), there is a general expectation that research carried out in the discipline of the social sciences will produce correlation among factors. Orthogonal rotation can result in a loss of valuable information if the factors are correlated, and therefore oblique rotation should theoretically render a more accurate, and perhaps more reproducible solution (p. 283). Oblique rotation produces factors that are correlated, which is often seen as producing more accurate results for research involving human behaviours, or when data does not meet priori assumptions (Costello \& Osborne 2005, p. 3) and for this reason, an oblique rotation was selected for this study.

\subsubsection{Interpretation}

Interpretation involves the researcher examining which variables are attributable to a factor, and giving that factor a name or theme. Traditionally, at least two or three 
variables must load on a factor so it can be given a meaningful interpretation (Beavers et al., 2013, p. 11). Appropriate interpretation, then, must invoke both the factor pattern and factor structure matrices (Henson and Roberts, 2006, p. 400). They also note that the meaningfulness of latent factors is ultimately dependent on researcher definition ( $p$. 396). Pett et al. (2003, p. 207) agrees with this point and suggests the labelling of factors can be a subjective, theoretical, and inductive process. A thorough and systematic factor analyses must be undertaken in order to isolate items with high loadings in the resultant pattern matrices. This produces those factors that taken together explain the majority of the responses. When the researcher is content with these factors, these should then be operationalised by explaining what is being represented by each factor and then descriptively labelled. It is important that these labels or constructs reflect the theoretical and conceptual intent (Beavers et al., 2013, p. 11). EFA is a complex multivariate statistical approach involving many linear and sequential steps. In addition, many options and rules of thumb apply themselves to EFA emphasising that clear decision sequencing and protocols are paramount in each investigation. The resultant factor structure may represent a truly exploratory investigation of the data or it may have produced a structure that represents an a priori model.

\subsubsection{Hierarchical Multiple Regression}

In order to test whether the a priori model can predict perceived community efficacy it is necessary to use multiple regression analysis. That is to say that the factors representing the model should predict the criterion factor. In regression analysis two or more variables are used to predict one other variable. For instance, two independent variables may be selected to predict a relationship in a dependent variable. It is called multiple regression because the analysis is simultaneously using multiple predictor variables (Dewberry, 2004, p. 247). Multiple regression can be used in a number of 
research activities including establishing the correlation between multiple predictor variables and the dependent variable or examining the extent to which each predictor variable uniquely predicts the dependent variable or investigating whether one or more predictor variables explained variation in the dependent variable over and above one or more other predictor variables (p. 247). Multiple regression is a complex statistical technique, which makes several assumptions about data, end the underlying populations. The first assumption is that the predictor variables are continuous or dichotomous and that the dependent variable is also continuous. The second assumption requires the predictor variables are normally distributed. The third assumes that the variables have a linear relationship with each other and lastly, the residuals at each level of the predictors should have the same ingredients. This is called homoscedasticity (Field, 2009, p. 220). In hierarchical regression analysis (HRA) the independent variables are entered into the regression model in a specific order. The decision in which order the variables are entered may be based on logical or theoretical grounds. Each variable is assessed according to the contribution it makes to the model at the point at which it is entered (Field, 2009, p. 212) The variables that are considered irrelevant to the question being asked (socio-demographic variables such as age, ethnicity and gender) maybe entered first so that their effect is controlled (Dewberry, 2004, p. 251). The results of a HRA will depend on the statistical options chosen in the specific software used to undertake the analysis. In this study SPSS version 22 offers range of statistical tests, which provide a composite report of the output.

\subsubsection{Specific Tests used in the Hierarchical Multiple Regression Study}

The individual tests chosen for this study will provide a range of results that will indicate the whether or not the variables representing the factors in the a priori model

predict the dependent variable, jointly through the $R^{2}$ score or individually though the $b$ 
value. It will also indicate the whether or not the model is statistically significant where the Sig. of $F$ Change value is $<.05$. The Estimates option provides the estimated coefficients of the regression model, the estimated $b$ values. Test statistics and their significance are produced for each regression coefficient: A T test is used to see whether each $b$ differs significantly from zero. (Dewberry, 2004, p. 273). The covariance matrix will display a matrix of the correlation coefficients and variances between the regression coefficients of each variable in the model. Model fit provides a statistical test of the model's ability to predict the outcome variable the $F$ test and also the value of $R$ or multiple $R$, the corresponding $R^{2}$ and adjusted $R^{2}$. The $R^{2}$ change in value displays the change in $R^{2}$ resulting from the inclusion of a new predictor or block of predictors. This measure is a useful way to assess the contribution of the new predictors of blocks to explaining variance in the outcome. Collinearity diagnostic can obtain collinearity statistics such as the VIF, tolerance, and eugene values of the scaled and centered cross products matrix. The Durbin Watson test statistic tests for the assumption of independent errors. The test statistic ranges from 0 to 4 with a value of 2 indicating that the residuals are uncorrelated (Field, 2009, p. 228).

\subsubsection{Confirmatory Factor Analysis}

In terms of this research, having produced an a priori model from the theory and literature it is necessary to evaluate, statistically, how well the model fits the data. In Confirmatory Factor Analysis (CFA), a specific hypothesized factor structure is proposed (including the correlations among the factors) and then statistically evaluated. If the estimated model fits the data, then a researcher concludes that the factor structure replication is satisfactory (Reiss, 2000, p. 293). The next section will detail the proposed CFA and the specific criterion used to test the factor structure for goodness for fit. CFA procedures are appropriate when tests for specific relational hypotheses are of 
interest. Gorsuch (1983) explained the purpose of CFA as "Confirmatory factor analysis is powerful because it provides explicit hypothesis testing for factor analytic problems" (p. 134). The tenability of the a priori factor structure will be determined with a CFA using AMOS version 20 and Maximum Likelihood (ML) estimation. According to Henson and Roberts (2006, p. 395) CFA is appropriate because it is generally used to test theory when there is a sufficiently strong rationale regarding what factors should be in the data and what variables should define each factor. Determination of model to data fit will be based on multiple fit indices. Although the chi-square $(\chi 2)$ statistic can be used to determine fit, it is typically influenced by a number of factors and cannot be used as a sole indicator for model to data fit (Brown, 2006). Suggestions by a number of researchers (Bollen, 1989; Breckler, 1990; Fan et al., 1999; Hu \& Bentler, 1999) have encouraged the review and reporting of multiple fit indices when determining model to data fit for CFAs. Brown (2006) recommended the use of fit indices from each of the three categories of fit estimates: an index for a model's absolute fit, an index for fit adjusting for model parsimony and, an index for comparative or incremental fit.

\subsubsection{Fit Indices Selected for Study}

The seven indices selected for this study were the $\chi^{2}$ likelihood ratio statistic (CMIN/DF), Normed Fit Index (NFI), Tucker-Lewis Index (TLI), Comparative Fit Index (CFI), Parsimony-adjusted CFI (PCFI), Root Mean Square Error of Approximation (RMSEA) and the $P$ Value Close Fit (PCLOSE). In the proposed CFA, the number of factors and the pattern of indicator-factor loadings will be specified in advance as well as other parameters such as those bearing on the independence or covariance of the factors and indicator unique variances. The a priori model will then be evaluated in terms of how well it reproduces the sample covariance matrix of the measured variables (Leach et al., 2008). Unlike EFA, CFA requires a strong empirical or conceptual foundation to guide the specification and evaluation of the factor model. 
Accordingly, EFA will be used is early in the process of scale development and construct validation, and CFA will be used in the later phases when the underlying structure has been established on prior empirical and theoretical grounds (Brown, 2006). Assessment of goodness of fit for the models involved multiple fit indexes including the $\chi^{2}$ likelihood ratio statistic (shown as CMIN/DF in AMOS). Schumacker and Lomax (2004) noted that $\chi^{2}$ likelihood values of 5 or less indicated adequate fit, while Garson (2008) recommended values of less than 3 but more than 1 as indicators of good model fit. Based on research precedents (Blunch, 2008; Byrne et al., 2007), CFA models were also evaluated for goodness of fit based on the Normative Fit Index (NFI), Comparative Fit Index (CFI), the Tucker-Lewis Index (TLI), the Root Mean Square Error of Approximation (RMSEA; Browne \& Cudeck, 1993). NFI, CFI and TLI values of .95 or more suggest good fit (Byrne, 2013; Byrne et al., 2007). RMSEA has several advantages as a measure of fit because it approximates a non-central chi-square distribution, which does not require a true null hypothesis, or perfect fit in the population (Kline, 2005), and it includes a correction for model complexity and sample size. By convention, models with RMSEA values between .06 to .08 represent adequate fit and models with values less than or equal to .05 represent good fit (Shumacker $\&$ Lomax, 2004). Models with RMSEA values greater than .10 should not be accepted (Blunch, 2008). Confidence intervals (90\% level) for the RMSEA values are included with the measures of fit, with interval values including .05 indicative of adequate fit and interval values less than .05 indicative of good fit (MacCallum et al., 1999). The closeness-of-fit statistic (PCLOSE) tests the null that the population RMSEA is no greater than .05. If PCLOSE is less than .05, one may reject the null and conclude that the computed RMSEA is greater than .05 and indicative of poor fit (Garson, 2008). Jöreskog and Sörbom (1993) recommended that the PCLOSE value exceed .50. The Akaike Information Criterion (Akaike, 1987)) was included to assess model parsimony. 
The AIC is a method of assessing information loss during CPA and awarding a score the lower of which indicates the better model (Lee et al., 2008).

\subsubsection{Validity}

The validation of a newly developed instrument is almost never accomplished to one study or by one researcher and requires numerous research efforts and for this reason must be considered an ongoing process (Benson \& Clark, 1982, p. 796). Validation of an instrument is essential as validity allows confidence that the instrument is actually measuring what it is supposed to measure. The two types of validity that will be assessed in this research are content validity and construct validity. Content validity as defined by Cronbach (1951, p. 297) pertains to whether the set of items adequately cover the content domain of interest as well as a set of behaviours or beliefs implied by a test score. The second type of validity, construct validity, is the most difficult and perhaps the most important form to obtain.

\subsubsection{Content Validity}

Grant and Davis (1997, p. 269) outline the processes involved in content validation and describe the use of a panel of subject matter experts to rate how well an item represents the given construct. In generating survey items the primary concern for the researcher is content validity, which should be viewed as the minimum psychometric measurement and should support construct validation of a new measure (Schriesheim, Powers, Scandura, Gardiner, \& Lankau, 1993, p. 386). Content validity must be incorporated into the measure through the development of items so that the measure will adequately capture the specific domain of interest yet contain no unnecessary or misleading content. As an initial validity measure Lindell and Brandt (1999, p. 641) suggest that content validity is the extent to which an instrument adequately samples the research domain of interest when attempting to measure phenomena. There appears to be general 
agreement in the literature investigating methodological approaches to content validity that there are two distinct phases. A priori efforts by the scale developer to ensure high levels of validity through careful conceptualisation and domain analysis prior to item generation, and posteriori efforts to evaluate the relevance of a scale's content through expert assessment (Beck \& Gable, 2001; Lynn, 1986; Pollit \& Beck, 2004). There are a number of methods used to measure content validity including Average Congruency Percentage (ACP), Multi-rater Kappa coefficient (MKC) and Content Validity Index (CVI). ACP was developed by Popham (1978) as a simple percentage agreement method across a range of rater scores. It is the most basic of measures used to judge the content validity within a scale where an ACP of $\geq 90 \%$ would be deemed acceptable for a pool of items. Multirater Kappa Coefficient uses a statistical formula to yield an index of degree of agreement beyond chance. Although the MKC is more complex and less transparent in its workings, it is extremely effective particularly when dealing with 3 or less raters due to its ability to account for chance agreement (Wynd et al., 2003, p. 509). The Content Validity Index has two different approaches to measuring content validity, the first being to measure at item level, I-CVI and the second providing a score on the overall scale, S-CVI. The researcher chose to use CVI, as it is simple and effective with a high level of transparency in showing its workings. It also provides detailed information at both item and scale level and using seven raters to assess 40 items lessens the odds of chance agreement considerably. Pollit and Beck (2006, p. 496) suggest that the I-CVI is calculated first, where items judged to have excellent content validity should meet the following criteria, 3-5 experts (I-CVI $=1.0) ; 7-10$ experts (I$\mathrm{CVI} \geq .78$ ). Items not meeting the criteria are deemed not representative of the domain and should be modified or deleted from the pool of items. The S-CVI is applied next and is based on the proportion of items in an instrument that achieved a rating of 2 or 3 by all raters producing a score of (S-CVI $\geq$.8) (Lynn, 1986, p. 384; Pollit and Beck, 
2006, p. 492). Where items have not been rated as satisfactory then a process of revision and redrafting will be required. At this point the pool of items may also be reduced as some items may not reach an approved standard despite revision and rewrite (Pollit and Beck, 2006, p. 496).

\subsubsection{Construct Validity}

Several criteria have been proposed for assessing the psychometric soundness of psychometric measures. They should demonstrate validity and internal consistency, and they should be parsimonious. All of these individual elements contribute to providing evidence of construct validity, that is, the relationship of the measure to the underlying attribute it is attempting to assess. Each step of the process should have statistical rigor and integrity and in this way contribute to increasing the confidence in the overall construct validity of the new measure Hinkin (2005, p. 164)

\subsubsection{Reliability}

There are a variety of forms of scale reliability coefficients, internal consistency, split half and alternative forms coefficients (DeVellis, 2003, p. 28). Among the most commonly used is internal consistency estimates as they are readily calculated from a single administration of a scale or test (Hogan et al., 2000, p. 525). As this model has been developed from survey data using Likert-type scales it is imperative to calculate and report Cronbach's alpha coefficient for internal consistency reliability (Gliem \& Gliem, 2003). Cronbach's alpha reliability coefficient normally ranges between 0 and 1. The closer Cronbach's alpha coefficient is to 1.0 the greater the internal consistency of the items in the scale. George and Mallery (2003) provide the following rules of thumb: “_> $.9-$ Excellent, _> $.8-$ Good, _> .7- Acceptable,_> .6-Questionable, $>.5-$ Poor, and _ $>.5-$ Unacceptable" (p. 231). Internal consistency estimation is a 
feature of SPSS version 22 and will be used to calculate the alpha for the individual variables, individual factors and lastly the a priori model.

\subsection{Summary}

The chapter began with a discussion on how best to investigate the construct of perceived community efficacy and specifically addressing the research question. In social sciences scales are constructed to measure behaviour, traits or attitudes and can be theory driven or a more inductive process can be employed. Although various techniques are cited including observation, questionnaires and interviews the literature would appear to support the use of or development of, a scale. This would commonly involve a qualitative or quantitative study or both. The advantages and disadvantages of single method studies quantitative or qualitative were explored and the rationale for using both quantitative and qualitative data collection is provided. A qualitative study using semi-structured interviews would provide rich data from the sample population. The data when analysed would support the generation of survey items that would be used in a quantitative study to measure PCE. Issues of ontological and epistemological nature are discussed with a view to supporting the researchers pragmatic approach to this research. The research design was outlined with a detailed description of the qualitative and quantitative processes that are used in the design and development of a scale. The qualitative study will involve semi-structured interviews that will be transcribed and thematically analysed. The themes will be used as a framework to develop an item pool that would be subject to a content validity process. Successful completion of this study would result in a survey instrument that would be used in the quantitative study. Using a purposive sampling method, a population was selected and the survey instrument deployed. The quantitative study will use the responses to evaluate the effectiveness of the instrument in measuring PCE. Exploratory factor analysis will be used to identify a factor structure. A hierarchical regression analysis 
will determine whether the a priori model accounts for variance in a dependent variable. Confirmatory factor analysis will be used to determine whether the factor model is stable and a best fit for the data. Content validity will be measured through the content validity index. Reliability in the form of internal consistency will be measured using Cronbach's alpha. Having developed the methodology, research design and selected the methods to be used in this chapter, the first study, qualitative, is detailed in the chapter four. 


\section{Chapter 4.0 Qualitative Study - Residents' Perceptions and Scale Development}

\subsection{Introduction}

In order to investigate perceived community efficacy in the domain of disaster preparedness it was necessary to develop a new scale for this purpose. This chapter presents qualitative data analysis from a study that explored efficacy perceptions in a sample of community members within a flood risk zone. The aim of the study was to gain an insight into what residents views were about their community and how well they could relate to being a community. The community members were also asked about their beliefs on the community's ability to respond to a need, typically a weather related issue or other emergency. In so doing, sufficient data would be produced to construct 40 survey items necessary for the quantitative study to follow. Social cognitive theory was used as framework to guide the deductive approach of investigating was initially used to guide the construct of perceived community efficacy (PCE) within the identified domain of emergency preparedness. Three dimensions are identified; community network structure, social capital and community capacity in order to operationalise the main construct PCE. These were used together with the researcher's knowledge of the main construct under investigation to identify six subdimensions that were used as a framework to develop semi-structured questions. Purposive sampling technique using GIS risk maps was used to select an area where there was a high degree of flood risk. A cold call method was used to invite residents to take part in a pilot in order to test the administration of the semi-structured questions and provide raters with an opportunity to practice on real data. The main study involved twenty residents from two main areas identified and replicated the procedures developed in the pilot stage. An inductive, qualitative approach was then adopted to further analyse transcripts produced from respondents. The sub-dimensions were identified in the data and are illustrated by supporting quotes. As the precursor to item 
generation this part of the research produced sufficient data to support the generation of 40 items that were subject to a content analysis. Seven subject matter experts analysed the items for consistency and meaning against each of the dimensions and subdimensions. Although five items were amended, no items were deleted and all forty items were selected as the item pool to be used in the quantitative study.

\subsection{Development of an 'a priori’ Model and Qualitative Questions}

There are normally two distinct approaches to item construction, deductive and inductive (Hinkin, 2005, p. 4-5). Deductive scale development requires a thorough review of the literature and understanding of the phenomenon to be investigated. This acquired knowledge results in the development of a classification scheme that is used to construct items prior to the data collection (Schwab, 1980). The Inductive approach develops scales using a qualitative methodology that relies on data being gathered from individuals through a series of interviews. A content analysis is then carried out in order to identify themes, categories and codes within the transcribed text. Items are then developed around the coding framework (Tashakkori \& Charles, 2008)

An approach used by Ali \& Birley (1999) combines the use of deductive and inductive approaches to legitimate enquiry. They argue that although a theory exists it may not be wholly appropriate to use a deductive approach and that an inductive element needs to be brought into the research design. Where this is the case, theoretical constructs derived from a deductive approach are explored using inductive, qualitative methods. In this way a theory can be used to guide the researcher but qualitative methods are used for the analysis and knowledge elicitation. In the case of this research and the development of items for the quantitative stage the initial analysis was guided by a deductive approach using the construct of perceived community efficacy and the knowledge elicitation was achieved by an inductive approach based on thematic analysis of transcribed interview responses. The combined approach was used to gain 
the benefits of both inductive and deductive techniques and in doing so address the shortcoming of each technique (Hinkin, 1995). The main benefit of a deductive approach can help assure content validity in the final scale. The main disadvantage being the time taken to gain such a high level working knowledge of the phenomenon under investigation. The inductive approach provides rich data on which to develop scale items, however there is normally no theoretical construct and may be difficult to develop items that are conceptually consistent (Hinkin and Schriesheim, 1989). The deductive element consisted of the researcher developing a sound knowledge and understanding of Social Cognitive theory and in particular the constructs of self efficacy, group efficacy and community efficacy (Bandura, 1988; Benight, 2004). From the literature review it was found that for community efficacy to be present it was necessary for a community to evidence aspects of social networks, social capital and community capacity (Carroll et al., 2005; Lin, Fu \& Hsung, 2001; Mancini et al., 2005). Using the definitions and descriptions of these constructs, main themes were identified and developed into a theoretical framework that was used as a guide to generate an initial set of questions (Appendix A). Table 2. below shows each identified theme within the specific construct. Having the theoretical deductive framework as a guide, 14 questions were prepared to fully explore the construct and grouped logically within the 3 dimensions and 6 themes. Weber (1990) further suggests the introduction of a pilot study to examine the sequence of activities and coding structure. The purposive sampling technique as described in chapter 3 was used to recruit 5 volunteers from with a flood risk zone, to participate in the pilot study (Teddlie and Yu, 2007, Environment Agency, 2014). 
Table 2. Construct, Dimensions and Themes

\begin{tabular}{|c|c|c|}
\hline Construct & Dimension & Theme \\
\hline \multirow{3}{*}{$\begin{array}{l}\text { Perceived } \\
\text { Community } \\
\text { Capacity }\end{array}$} & $\begin{array}{l}\text { community network } \\
\text { structure }\end{array}$ & $\begin{array}{l}\text { Informal networks comprise web of relationships } \\
\text { with friends, neighbours, work associates } \\
\text { Formal networks associated with agencies and } \\
\text { organisations } \\
\text { Relationships, Voluntary \& Obligatory }\end{array}$ \\
\hline & social capital & $\begin{array}{l}\text { Information, reciprocity and trust, aggregate of } \\
\text { community resources } \\
\text { Participation in formal and informal settings } \\
\text { Increased odds of achieving results otherwise not } \\
\text { attainable }\end{array}$ \\
\hline & community capacity & $\begin{array}{l}\text { Shared responsibility and welfare for community } \\
\text { Collective competence and actions to confront } \\
\text { situations. }\end{array}$ \\
\hline
\end{tabular}

\subsubsection{Sampling Risk Population}

The researcher accessed the flood risk mapping system on the Environment Agency website. Several areas were identified as at risk from flooding both surface water and river overflow. A postcode filter was applied on each map so that risk was identified for each postcode area. A search on the Post Office website to identify streets and these were matched with the initial risk areas. This produced 40 streets where over 800 residential buildings were matched and categorised as high risk. In order to engage with the residents within the identified risk zones a cold call 'door to door' approach was employed. This was to ascertain whether or not any of the selected residents would be willing to take part in the interview stage of the research. Lundergren (1995) advocates this approach but advises that success rates are very much based on getting the message across in a friendly manner before resistance builds up within the recipient of the appeal. The canvasser had 3 targets to achieve, getting the flood message across and understood, gaining agreement to take part in the research and obtaining contact details. 
The cold call activity was initialised with a target of thirty acceptances; the first five residents were selected for the pilot study and twenty five for the main study. All were advised by telephone of the date, time and venue. All five verbally accepted and attended the venue at the specific and time with twenty five accepting for the main study.

\subsubsection{Pilot Study}

The pilot was undertaken to test 4 main objectives:

1. The overall operationalisation of this part of the research design including the transcription of recordings, sampling and ethical considerations such as confidentiality, security of data and on going anonymity of individual participants;

2. The simplicity of the language used in the questions in terms of the population understanding what was being asked for;

3. The transcribed answers reflected what had been asked and contained sufficient data within the context of each category, and,

4. To identify any other specific themes in order to assist the analysis in the main study.

30 participants, 5 for the pilot study and 25 for the main study, were asked to take part in a semi-structured interview regarding levels of resident participation in joint action that was beneficial to their community. The participants were made up from 20 male and 10 female residents aged between 21 and 76, with a mean age of 47 . The largest ethnic group was White -21 ; Mixed -4 ; Asian -2 ; Black -2 and, Chinese -1 . The interviews were conducted at a venue close to the selected population. The venue was comfortable and the researcher provided refreshments by way of courtesy rather than inducement. Before interviews were conducted, participants were advised that they 
could withdraw from the research at any time, and that in such an event their data would not be used. Participants were also told that the data would be kept confidential, and that they would not be personally identified or linked with their responses. Participants were asked to sign a consent form, and were given an information sheet that outlined the process, ethical issues such as, data storage and use, consent and contact details for the researcher and supervisor (Appendix C). Interviews lasted approximately 25 minutes. The lengths of interviews varied, but were all between 20 minutes and 30 minutes. Interviews were tape recorded with permission from participants and subsequently transcribed. A prepared list of questions was used to provide consistency to the interview process (Appendix B). The investigation focussed on the participants' views, beliefs and expectations of their community's actions in areas of relationships, information participation and trust, shared responsibility and collective action in times of need. The questions included: "Can you describe your community in terms of size, closeness and make up including for instance, families, friends, neighbours?" This question aligned to Community Network Structure and the informal networks that emerge with communities. By describing this aspect of community behaviour, participants would provide an insight into whether their community had network bonds in place that would be essential for Community Efficacy to be effective (Wang and Kapucu, 2007, p. 59). "Can you describe the level of participation by local residents in community events?" The participation element of this question is tapping into the construct of Social Capital and specifically a community's ability to organise and attend events where they share information and experiences. Furthermore they each see one another as supporting the community and endorsing their belief and sense of community (Ohmer, 2010, p. 6). "What makes you believe your community would assist each other in preparing for an emergency?" This example reflects the dimension of Community Capacity where a sense of shared responsibility would cause a community to act in 
response to the welfare of another member. The belief that they could act together to ensure the welfare of community members would be a strong indicator of Community Efficacy. (Goodman et al, 1998, p. 264.) The remaining questions were distributed across the three dimensions to ensure that the participants had adequate stimulus to talk about their beliefs and experiences within their community and their perceptions on how the community would act together when facing an emergency issue or challenge. At the end of the interview each participant was asked to comment about how the felt about the interview. Feedback from participants was positive in that they understood what was being asked; they did not feel pressurised in answering any of the questions and could relate the questions to their own community. From the researchers' perspective, the process of interviewing including ethical issues, recording and transcribing and gaining rich data on which to base the main study were all positive. The transcriptions were accurate and contained good examples and descriptions of community actions contained within the 3 main constructs. The 6 original themes were confirmed by resident's responses. A further 2 themes were identified from both the pilot transcripts and the literature. This is consistent with Boyatiz's (1998) description of an inductive approach to theme development where themes emerge from data obtained from data obtained the researcher's own work. Four extra questions were developed to investigate the newly identified themes. Table 3. below contains the 2 new themes identified from the pilot transcripts. 
Table 3. Construct, Dimension and Themes (amended)

\begin{tabular}{|c|c|c|}
\hline Construct & Dimension & Theme \\
\hline \multirow{4}{*}{$\begin{array}{l}\text { Perceived } \\
\text { Community } \\
\text { Capacity }\end{array}$} & $\begin{array}{l}\text { community network } \\
\text { structure }\end{array}$ & $\begin{array}{l}\text { - Informal networks comprise web of relationships with } \\
\text { friends, neighbours, work associates. } \\
\text { - Formal networks associated with agencies and } \\
\text { organisations. } \\
\text { - Relationships, Voluntary \& Obligatory. }\end{array}$ \\
\hline & social capital & $\begin{array}{l}\text { - Information, reciprocity and trust, aggregate of community } \\
\text { resources. } \\
\text { - Participation in formal and informal settings. } \\
\text { - Increased odds of achieving results otherwise not } \\
\text { attainable. }\end{array}$ \\
\hline & & - Shared responsibility and welfare for community. \\
\hline & community capacity & - Collective competence and actions to confront situations. \\
\hline
\end{tabular}

The researcher was also able to identify example statements from the respondents that would be useful in developing descriptions for the themes that would be used to analyse textual data in relation to the coding handbook and transcribed interview recordings. Examples are given below as an indication of some of the respondents' replies. In describing events or meeting organised by local members of your community a participant provided the following response. "There are regular meetings and events in the community that I suppose give us a network of people that share information about the things that are happening in our community." This would represent a community with a good network and communications infrastructure and would align well with the construct, community network structure and the theme, networks. When asked about the concept of trust within the theme of aggregate of resources in the community, one respondent replied, "I think little things like keeping spare house keys for the neighbours in case tradesmen need access" and "checking the house if they're away for a holiday or something". These statements suggest the 
presence of elements of social capital and is highly representative of the theme, aggregate of resources, within the dimension social capital. In describing the kind of activities the community might under take in preparing for floods or severe storms another participant stated "Likely activities might be moving pets to safer areas or seeing to the evacuation of elderly people to safer areas, perhaps a neighbour's house that was higher up the street, out of the way of the flood water." This statement supports the dimension, community capacity, but indicates strongly the theme, shared responsibility and welfare, and in particular, welfare, in terms of moving livestock and evacuation of elderly. All 8 themes were matched with descriptive text taken from the pilot transcripts. This was further developed into a coding handbook that would assist raters in analysing transcripts in the main study (Appendix C). An additional use for the handbook was to improve rater reliability. The handbook consisted of each theme having a description or definition, guidance on the indicators of the themes and examples of the themes taken from the pilot transcriptions. Boyatiz (1998) suggests that percentage agreement method is suitable when there are relatively few themes to be coded. Percentage agreement normally involves comparing the number of occasions when both coders agreed on the presence of a theme or code with the number of times that theme or coding was possible. The percentage agreement on presence variation is used where a theme is only of theoretical interest only and when a theme or code is present in the transcript. Whilst Boyatiz does not include guidance on what constitutes a relatively few number of themes, Hsiesh and Shannon (2005, p. 1279) identified coding and cluster structures in the range of 15-20 clusters containing large numbers of codes with some examples containing more than 100 codes. Against these numbers, the researcher was confident that the percentage method would prove sufficient for examining the reliability of the 2 raters and the 8 themes. The raters were able to identify themes in the transcripts without resorting to assistance from the researcher. 
They suggested some amendments regarding the wording of descriptions of the themes in the coding guide that were originally taken from the construct descriptions. Some of the descriptions were altered without affecting the context or meaning of the statement. Reliability was also tested using the manual percentage method and achieved a value of $90 \%$

\subsection{Main Study Semi - structured interviews with residents}

The main study consisted of 20 residents selected using a random formula within a flood risk zone using purposive sampling techniques (Teddlie and $\mathrm{Yu}, 2007, \mathrm{p}$. 77). Participants were asked to take part in a semi-structured interview using the 18 questions developed throughout this process (Appendix D). The interviews were conducted at a venue close to the selected population. The room was well illuminated, warm and comfortable. The researcher provided refreshments such as water, tea and coffee. No inducements were offered. Following a step-by-step approach identical to the pilot study, participants were advised that they could withdraw from the research at any time, and that in such an event their data would be destroyed permanently. Participants were also advised that the data would be kept confidential, and that they could not be identified or linked with their responses at an individual level. After signing a consent form, participants were given an information sheet that outlined the process, data storage and use, consent and contact details for the researcher and supervisor. Interviews again lasted approximately 25 minutes. The lengths of interviews varied, but were all between 20 minutes and 30 minutes. Interviews were tape recorded with permission from participants and subsequently transcribed. A prepared list of questions was used to provide consistency to the interview process. To assist raters, a coding guidance document was produced using the constructs, themes, and theme descriptions identified by the researcher. A numeric marking system was incorporated in order to 
classify statements in the transcriptions (Schilling, 2006, p. 33). Inter-rater agreement was calculated at $92 \%$.

\subsubsection{Findings and Analysis}

Thematic analysis of the interview data with residents in high flood risk areas confirmed the 8 identified themes. No further themes were identified.

\section{Theme 1 - Informal networks comprise web of relationships with friends, neighbours, work associates}

When asked to describe the communities where they live, at first, respondents tended to give an outline description of the wider community, giving approximate sizes in terms of populations, then proceeded to give more detail about closer relationships with neighbours at street level.

The population of my estate is around about eight thousand. My local network is made up of immediate neighbours and people I know in our street. I live on a quiet road on the edge the estate, off a main A class road. A small street community of a few hundred. Really just immediate neighbours for community purposes.

\section{Theme 2 - Formal networks associated with agencies and organizations}

All respondents were able to provide examples of formal networks or organisations within their community. Some respondents were able to give a detailed description of the organisation and its activities. The descriptions also provide an insight into the social networks that exist in the participants' communities.

Right well there's the Catchment school Parent Teacher Association, GRASP which stands for Greater Resources for Autistic Spectrum Disorder Parents and Children through youngest child. There's also the Movers and Shakers, that's a Social Group for Older People through mother in law, Rugby Club, Cricket Club 
and Athletics Club, through sons. Oh also the church and the Community Association about 1,200 subscribers.

There's neighbourhood watch that's part of a bigger neighbourhood action group. The action group is linked to some of the police structures in the community, but its only a few get involved because its quite formal.

For many there was an awareness of formal organisations within their community but their knowledge and involvement was at a peripheral level. "There are a few charitable organisations within the community and there's neighbourhood watch that I'm involved with but that's quite informal. I think that's about it really." A few respondents knew that there were formal networks and organisations within the community and although receiving information on certain activities and updates did not participate or contribute. "Yes there's a Neighbourhood Action Group and Parish Council that meet regularly. I don't attend as its all a bit formal like, but I know a few neighbours that do and they keep me up to date on what's happening." One resident was able to qualify a lack of relationship with the community and organization. "We have a neighbourhood watch in the local area I don't know of any other organizations in the community but then I wouldn't because I keep myself to myself."

\section{Theme 3 - Relationships, voluntary and obligatory}

The concept of relationships is fundamental to social networks where residents build rapport and interact within a community environment. The quotes below highlight a number of different scenarios where residents interact on a voluntary basis.

Both really, GRASP and Movers and Shakers because they are self-started informal volunteer groups, the rest have constitutions and corporate identities. There is a group of local neighbours who get together to try and improve the look of the area by gardening and tidying up verges and plants. 
There appeared to be an association between formal meetings and a requirement to attend. "Most of the meetings and events are attended on a voluntary basis, the obligatory ones are I suppose the more formal community council meetings". The emphasis on voluntary basis contained in the quote below appears to express that anything more formal or obligatory has overtones of work related activities and as such would prevent any relationship building in a formal setting.

I think the pressure of being required to making an attendance at every meeting like a formal committee or something would put people off, it would me, I think anything formal has tones of work related stuff and that so people wouldn't go if it was like work. They get enough of that at work.

\section{Theme 4 - Aggregate of resources including, information, reciprocity and trust}

This theme identifies the resources spread out through a community and aggregated into one theme within the overall dimension of social capital. The information sources and the way information were distributed within the community ranged from hardcopy minutes of meetings to electronic media providing access to information about the community and events forthcoming. "Mainly E-newsletters and meeting minutes, mailshots on matters of local concern." Interestingly for this researcher is the resident who mentions the text alerts for flooding issued by the Environment Agency. After further discussion on this point it was ascertained that a small group within the community had collated all the residents' mobile numbers and setup the flood alerts in conjunction with the regional Environment Agency officer.

We have all sorts of information provided to us things like newsletters, e-mails with information on local events, we've even got a Facebook page for our community.

Oh and we get text alerts on our phones for flood warnings, don't know where they come from or it might be the environment people

The two quotes below have been included as these mention information concerning 
local businesses and that here residents appear to view them as in integral part of the community but when asked about local networks respondents were mainly focussed on residential neighbours and not commercial neighbours. "There's candidate information for Local and National elections, a community newsletter and local business information." When asked further on the issue of inclusivity, the resident replied "Well they're all just like us and live local so yes they are our community." This may indicate that the residents are inclusive and engaged with each other forming a close-knit community with high levels of information sharing.

Residents described many opportunities to help each other, reciprocating helpful actions; some were common, daily activities such as helping to tidy up or chores in the garden whilst for others there was an association with less routine activities such as dealing with affects of extreme weather.

Yes, on a regular basis, it can be small things like watching the kids or holding a key yeah they're all pretty good. Yeah I guess they do help out like doing small things. Keep an eye out on properties and put bins out for each other take packages in and help with garden. Some members of the community are willing to help which was evident during that bad storm we had.

For some members of the community, helping each other out was limited to their immediate neighbours. "Yes, my neighbours are extremely helpful and will go out of their way to assist me and vice versa, but as for the others I don't know really. I doubt it. We hardly speak let alone help each other out." There also appears to be some negatives connotations where residents speak of a lack of participation or a tailing off on the level of support for these types of community initiatives. "Apart from the tidy up thing I don't participate in them. I would say there is very little participation.” and "Generally at the start yes although it does taper off sometimes depending what it is or how long it's expected to last." The issue of trust may be an import element within 
social capital where residents allow each other access to homes or give permissions to carryout specific activities such as looking after a neighbour's children. "Looking after a child or a wallet or purse, yeah, valuables yeah keeping valuables safe if their house was trashed in a disaster." and "I think keeping spare house keys for neighbours in case the alarm goes off or checking the house when they're away for a holiday." Most residents stated that there were good levels of trust in the community although this was limited to a specific group or immediate neighbours. "I think there is a reasonable level of trust but I can only speak for the people I meet through the neighbourhood watch scheme, I mean we trust these people to watch out for the community and sometimes enter gardens checking locks and for open windows." Although agreeing that there was a high level of trust between some individuals, one resident felt that this was not extended to the wider community. "Between some small group of individuals there is a high level of trust demonstrated by holdings keys for property but generally within the community, I don't think there is a high level of trust."

\section{Theme 5 - Participation}

There are a wide variety of formal and informal settings where residents get together and join in the activities. One resident spoke of a number of different organisations, meetings and events. The narrative makes it quite clear as to what the respondent saw as informal and formal.

Ok ones I go to, the formal ones are 'GRASP' and that has monthly support meetings, with speakers and visitors. There's the PTA, that's the Parent Teacher Association monthly meetings and regular events with minutes. Erm, informal I guess would be, Movers and Shakers, and that has a weekly timetable of events and the Church has services, groups and coffee mornings.

The above narrative would indicate that the respondent is highly participative in community events both in formal and informal and informal settings. The narrative 
below indicates a mix of both formal and informal settings where formal participation can provide opportunities for informal problem solving get-togethers.

There are regular meetings and events in the community that give us a network of people and organisations that we interact with. These vary between the informal meetings such as mountain rescue, cycle safety, fire safety, and activities in the village hall such as the community cinema events. The formal ones like community policing and the community council are well attended and sometimes set the agenda for the more informal meeting in someone's house where we can discuss issues and hopefully get them resolved.

The respondent above was involved on an informal basis within the immediate community of neighbours but in the wider community, the walking club, participated in a formal setting that was the AGM.

Nothing formal with neighbours, but we do meet to discuss what we are going to do next with the tidy up programme. With the walking friends, we have an AGM that is formal. It's also linked with a greater 'sports club', so there are other formalities at times to attend and be involved in.

Other examples of participation provide a wider range of events.

The parish council organised by members who are also local residents that helps to represent the views of our bit of the parish. We get together once a year to discuss the neighbourhood watch scheme and some of the organisers report on events during the year and give us the latest advice on home security. We also sometimes meet to help out the animal rescue.

However this level of participation is not reflective of all respondents. Some appeared not to see the need for such participation even to the extent that when in need the first thought was to leave it to the council. "No I can't really go along with the idea of asking my neighbour for help or going to one of these community things, never needed to and 
cant think when we would. If something happens like a flood or that, well that's what the councils for isn't it."

\section{Theme 6 - Increases odds of achieving results by working together.}

One of the main findings of research into group and collective efficacy is the higher levels of task performance and success in problem solving in a group environment as opposed to an individual effort. Respondents provided narratives describing their own experiences and the benefits of working together to achieve an outcome.

Yes, members of the local community tend to work together to achieve results at the same time rather than individuals working for their own end. Because we are relatively remote it makes sense to organize for tradesmen to come at the same time. Most recently we organized for the chimney sweep to come and sweep all chimneys in the local area. This made it worth his while and easier to gain access.

Yeah, our community raised $£ 225,000$ in a month for a boy at the catchment infant school to go to USA for life saving treatment. Now you just couldn't raise that type of money by yourself, not in that time scale.

One respondent was able to identify the more intangible benefits such as keeping a momentum especially over longer periods; motivation and the skills mix which is very much related to community competence. "It is difficult to achieve very much alone, but it's also hard to keep motivated. People working together can get so much more done, keeping up momentum and motivate each other. Also different people offer a variety of skills that one person may not have." Another respondent provided an insight that compared the task in hand to the resources required where some activities might be better tackled by an individual and others would benefit from assistance.

It depends on the size of the task. If it were something straightforward it would be easier achieving the task yourself, as you'd just get on with it and wouldn't have to ask anyone else. On the other hand, if assistance was required it due to the task 
being a bit more complex or physical then it would be an added bonus having help at hand.

The narrative below supports the position of the response above. However this response is based on the individual's belief as the community had not yet undertaken any form of collective action.

When its smaller things that need doing to me it seems simpler to do it myself, because of the clarity of purpose and no need to gain buy in or traction but when its bigger things I guess its best that the more people are involved the more likelihood of success depending on what you were trying to do. But that's just an assumption because there's not been a time yet when we got ourselves together community wise to get something done.

\section{Theme 7 - Shared Responsibility and welfare of the community}

The concept of shared responsibility within a community revolves around individuals and groups taking an active interest in the wellbeing of their neighbourhood (Chaskin, 2001). When asked about their role in preparing for an emergency, some respondents saw responsible shared between residents and council services, others were of the opinion that it was solely down to agencies and the council.

Local authorities should take the initial step in ensuring the public are aware of any such emergency. With the exception of the sick, elderly or children, after an initial warning of an emergency the public should be responsible for their own welfare where possible and also help aim to help out where possible.

Some respondents whilst identifying the dual responsibility also articulated the need for information or warning in order to initiate community action.

The county council would ultimately clear roads, for instance everyone seems to muck in when there have been deep snowfalls. National agencies sort out the local river near my house, so I'd expect that again big organisations would sort it out. At 
the start there would probably just be news on the TV or radio for people to prepare themselves.

I have a leaflet from the Council that has contact details in case of emergency, but I think this is more a countywide thing. I guess its up to both to sort out the problem. The narratives below indicate a belief that dealing with an oncoming crisis is more to do with specialist physical resources such as equipment and trained professional staff. "Local authority and emergency services as they train for that type of stuff and have the heavy gear needed to get things moving." However some respondents believed there was a responsibility for residents to assist in other activities that did not require specialist training or equipment but was-none- the less equally effective at a more local level.

The Council should be responsible, but I think we have a shared responsibility for local stuff especially things we can do to help out. I think the more abled in the community could do things like clearing snow, getting prescriptions, essential food, that type of thing. So if a weather crisis was about to happen I reckon we could play our part and sort some of that stuff.

The responses also covered non-emergency activities. Where problematic events occurred for the community, it was clear that some members felt responsible for issues that may have an adverse affect on the wellbeing of their neighbours and as such collectively acted to resolve the situation

Well there's a few of things that comes to mind. One is the tidy up programme organized because the council refused to cut and tidy the verges, something to do with cut backs and there was a planning issue where the whole street got together to lobby against the change. We got out point over and the planning request was withdrawn. We also organised traffic controls during the cycle event that passed through the village and because of council cut backs we now cut and the maintain 
the verges of the approach to the village.

The welfare of individuals and groups within a community is linked to the concept of vulnerability as discussed in the literature review. Those residents at risk or less able to cope with prevailing circumstances are the focus of this theme. Respondents focused on situations where some form of emergency that adversely affected neighbours or other residents that were more vulnerable to the situation than themselves.

We organised emergency boxes for the elderly. Just plastic boxes with a torch, matches, candles, bottled water even a few bars of chocolate and sweets just to keep them going till someone helped out.

Well nothing formal like, but during heavy snowfall the majority of people on our estate rallied round to help clear the road. We did this to make sure people got to their work in the morning and that nurses and doctors were able to come onto the estate to help those that needed it.

The respondent below give an account which describes a range of activities undertaken by residents in order to ensure the welfare of those less able to help themselves. It is interesting to note that these activities were in the preparatory stages of an oncoming emergency and they were proactive in recruiting other volunteers to assist.

We prepared the community for loss of power by providing candles, blankets etc. Moved people from houses that were at risk of flooding, we organised transport to move the sick and elderly to safe accommodation in the council refuge places and ensured sand bags were available in the worst spots. We also had people going round knocking on doors enlisting as many volunteers as possible.

The inclusion of the next respondent statement is to highlight that not all communities are at risk from the obvious things such as heavy snowfall, flooding, high winds etc., however they may at some point be at risk from subsidence, power cuts, water shortages 
or in the extreme pandemic flu or acts of terrorism. "I've not tried achieving anything with the community cos we've not had anything to prepare for yet."

\section{Theme 8 - Collective Competence and action to confront situations.}

Within any residential community there will be a range of knowledge, skills and attributes that may be usefully employed in preparing for an emergency. Respondents were asked about their perceptions on the range of skills inherent within. Many residents focused on the professions that were present and the skills that are associated with help in an emergency. "Well in the local community we have, doctors, nurses, firefighters, engineers and farmers, all have unique skills which they can contribute to a joint effort in an emergency, probably one of them would be best to lead the rest of us." Other respondents believed that specific skills and were necessary to undertake preparatory measures. "Some may have the skills to use equipment like farmers with tractors and JCB drivers, also skills to drive in hazardous conditions." and "I think probably practical skills like, first aid, what to do in a flood, driving in snow or flooded roads." The issue of transport was also identified siting four wheeled drive vehicles as a potential solution to having a degree of mobility within the community. "People who are used to driving a $4 \times 4$ should be nominated to drive about in bad conditions." Communications were seen as an essential attribute within the residents in order to provide the emergency messages and update information. "Communication, the ability to get a coherent message to each other quickly and also to update each other at regular intervals." Most respondents talked about a need for physical attributes such as strength and agility needed for tasks such as filling of moving sandbags, lifting furniture or people to a safer place, clearing snow or pushing vehicles that a stuck.

Physical attributes for lifting and carrying, you know like furniture and that, and it might even include people that can't manage themselves, we would need people 
who had the strength to the hard work stuff like filling sandbags and clearing blocked roads from snow or stuck vehicles.

There was also a belief that a softer skill set would be needed to organise and plan activities and resources. Also linked to some of the welfare issues was the need for moral support and counselling. "I could organize things like planning and scheduling, I mean people volunteering can't go on forever without a break." and "Giving advice and counselling for those afraid or not confident." Interestingly, within this softer skillset, the issue of leadership was captured. The respondent here was quite clear in advocating a leadership roll where motivation and organizing into action appeared to be the main thrust of the comments.

Strong leaders who can get us going, pull us together and get things done, I could lead one of the work streams you know like logistics, planning and organising or communications. I would also champion assistance from local powers like community council or our borough council, anything beyond our immediate community.

Almost as a theme in itself, some respondents were not able to articulate clearly what type of skills and attributes were needed to take part in preparedness activities. "Not known at this point as it would depend on what type of emergency it was." and "No idea as I don't know enough of the local people to give a reasoned response." This element of the theme focuses on the specific activities that the community members might engage in to prepare for an emergency. Although some of the responses seem to be repetitive they are subtly different from the previous theme narratives that highlighted skills, knowledge and attributes. Respondent one believes that collective action has motivational aspects such as self-pride and achievement as well as issues of collective ownership and identity.

I find there is greater pride and sense of achievement in collective actions. There's 
also the wider skills, knowledge and experience base to call on if collective, I also think there is more ownership and buy in if collective. It's more fun, generally and generates a sense of belonging.

Respondent two supports the aspect of identity but has the additional aspects of collective effort to achieve goals. The respondent also articulates experiences where the community worked together to provide support for the community.

It is easier if you work together to achieve something. It's essential where we live and make it worthwhile for people to feel part of the community. During winter time the community works together to ensure paths are cleared also those with $4 x 4 s$ ensure groceries and provisions are delivered to those who cannot get to town. Similarly when we have had problems with no drinking water, the community has ensured that supplies are delivered from a central point to local residents.

Respondent three uses a flooding scenario to illustrate the point of training prior to an event. There is a belief that given the training and basic tools, flooding in the respondent's local area could be minimized or averted all together.

If flooding were to occur in my community this would most likely be due to inadequate drainage. Groups of people in the community could with minimal training and basic equipment, be able to unblock drains, streams, and culverts. It wouldn't need anything formal like.

The following two responses appear to indicate a negative belief. The first respondent states that the community would not prepare but wait for assistance for an outside organization. The second respondent also believes the community would not prepare but qualifies this with the reasoning that it would be dependent on whether the community believed the risk was real or not. 'I don't think they would prepare, I think they would either wait for the emergency services or council to get things sorted." and "None if they don't believe that the risk is real." Belief that an individual, group or 
community can overcome difficulties is a central concept within efficacy research (Gist, 1987). Confronting situations has similar connotations where individuals and groups identify possible difficulties for a community to prepare for emergencies. There were three semi-structured questions that were used to generate narratives from the respondents that were specific to belief and level of difficulty of task. The first identifies the beliefs an individual has on the difficulties associated with undertaking preparedness activities. The second is similar but from a group or community perspective. The third aspect explores the point at which an individual believes that a preparedness activity undertaken by a community would be too difficult to achieve. The first respondents are concerned with a personal sacrifice of time that may affect work arrangements and family commitments. "Any actions over a sustained period that would interfere with my work commitments." and "I guess the time spent preparing for the emergency against being with my family especially if there was say storms predicted."

The next respondents talked about the physical and technical difficulties that involved lifting or moving heavy objects or a lack of skill to carryout the activity."The main things would be anything very physical like lifting heavy objects including people." The technical difficulties for one respondent focused on driving a $4 \times 4$ but although not skilled would try to undertake the activity if it was needed. "Anything that required a specific skill that I didn't have like driving a 4X4, I mean I'd still have a go if I had to, if it ment helping someone." One respondent talked about possible difficulties in communication in order to gain access to provide assistance. Another described a perceived lack of trust within a specific community grouping. Although both aspects have been included in the previous themes and identified as essential for efficacy to be effective, the inference here is that a lack of trust or poor communication may be a perceived barrier to assisting someone prepare for an emergency. "Gaining access to 
some neighbour's homes can be challenging, especially those from immigrant backgrounds who are not immersed within the rest of the community." and "Maybe getting some of the more older, isolated people in the community to trust me to sort things for them or to rely on me to get medicine or something involving money, bank details." Some respondents perceived leadership as an issue and in this situation described poor leadership as a barrier to their participation in preparedness activities. "I couldn't take orders from someone who was a useless leader, I wouldn't get involved if the person leading the preparation was running around like a headless chicken.” The following statements describe perceived difficulties for community action. Although there appears to be some community activity the respondent below suggests that a lack of participation due to apathy within the community. "General apathy rules, apart from the neighbor hood watch scheme but I suppose that easy to do.” A lack of knowledge and information were also seen as problematic for community participation. It would appear to be a vicious circle where local councils and agencies will have plans and specific activities that may well involve community members, but if there is a lack of participation or apathy on the part of residents then there is a perceived barrier to sharing that knowledge and information. A further consideration may be due to Agencies being limited in the amount of personal information they can release due to Freedom of Information legislation.

Sometimes a lack of knowledge about what can and can't reasonably be achieved can put people off getting involved. It's difficult to identify people at risk because this generally requires some knowledge of both the risk and some knowledge of personal circumstances.

Another perceived barrier to community level action was a lack of agreement or buy in to proposed activities especially if the proposals resulted in a perceived lack of equity in the distribution of resources or preparedness activities. 
I think a huge barrier would be getting all our residents to agree on the same course of action especially if it was to do with providing different levels of protection for peoples' homes, but I guess if we had someone to lead the group it would help to sort out the arguments.

The previous two sub themes dealt with perceived difficulties on an individual and community level. The third subtheme explores residents' beliefs as to when preparedness activities would prove too taxing for community members. For some respondents the limit to community performance appeared to be a matter of technical skills.

There is a sufficient number of individuals with differing levels of work experience, so it would not be a matter of resources but rather a matter of technical skills, in the case of a severely disabled person an inexperienced person could cause unnecessary suffering if trying to move the person. In this instance only someone trained in this type of work would be able to complete the move.

Other residents spoke of when things become too much for them to carry on, feeling overwhelmed and not being able to cope.

When things don't sometimes get completed, frustrations can surface and this can lead to people getting anxious and feeling that it's just all too much. An example could well be starting preparing for an emergency but then running out of time or resources.

The framework provided by the 8 themes previously identified serves as a logical approach to generate items for the initial survey. Each theme is supported by residents' responses to help articulate the construct, dimension, theme and respondents' beliefs. 


\subsubsection{Key Findings}

Finding One. Participating residents could describe their community in terms of geographical layout including streets and local amenities. They were also able to estimate the size of their perceived community in terms of population. However they appeared only to identify with immediate neighbours when it came to assisting and issues of trust and participation and reciprocity.

Finding Two. A number of participants appeared not to be engaged with the rest of the community including immediate neighbours. They expressed a clear wish not to be associated with the rest of the community.

Finding Three. Residents within the sample population appeared to dislike engaging in formal structures. That is to say formal agencies or organisations representing for instance the county council or environment agency. In undertaking any community orientated activity most preferred an informal environment or structure in which to engage other residents.

Finding Four. Many of the participants had expressed a desire for someone to take charge. Leadership of the group was called for with participants expressing and need to be organised and pushed to get things going.

Finding Five. An overall observation in summarizing the outcome of qualitative data is that it produced a general perception that the sample populations were able to collectively undertake actions that resolved local issues.

Finding Six. There is evidence to suggest that the sample population believed their respective communities would collectively prepare for a severe weather emergency. 


\subsubsection{Summary of Findings}

One definition of community efficacy is reliant on effective network structures where residents help each other to overcome difficult issues. The majority of participants appeared to be positively engaged with community activities demonstrating high levels of trust and participation. Although there was a pronounced theme against formalised engagement there was however a wide variety of engagement using an informal structures. A wide variety of informal activities appeared to be evident especially where difficult tasks required to be completed. Residents identified resources such as skills and knowledge necessary to deal with local emergencies. Many of the participants had expressed a desire for someone to take charge. Leadership of the group was called for with participants expressing and need to be organised and pushed to get things going. They generally wanted to pitch in and help each other. The general thrust of the participants answers would appear to suggest that the sample population were able to collectively undertake actions that resolved local issues. This would also suggest a highlevel of community efficacy. Taking the example of working together to assist in weather related emergency would indicate a high level of community efficacy in responding to an event that has already happened. There is some evidence to suggest that the sample population believed the rest of the community would collectively prepare for a severe weather emergency.

The next section will proceed to detail the processes used in writing the items in order to correspond to the dimension and theme.

\subsection{Constructing the Item Pool}

The content of an initial item pool during an item generation stage should be over inclusive and item wording should be carefully studied before testing the item pool along with variables that assess closely related constructs (Devellis, 2003, p. 63). The 
conceptualisation procedure of the a priori model was followed by generation of an initial pool of 62 items / statements. Many of these included verbatim quotations as described above, others included were through a rigorous literature search of scale development, disaster research and efficacy measurement (Carroll et al., 2005, p.1-10). In addition, various journal articles cited for good descriptions of item generation were researched and where appropriate followed closely in terms of technique and process (Butler, 1991, pp. 643-663; Mackenzie et al., 1991, pp. 123-150). All of the generated items consisted of statements written in the first person, for example, "I am certain the community can achieve our preparedness goals", reflecting an answer from a respondent describing a belief in community actions.

\subsubsection{Item Reduction}

An initial qualitative reduction of the identified items/statements was carried out, in which statements considered inappropriate, ambiguous or redundant were excluded. Some of the remaining items were slightly rephrased, merged or modified to fit the intended purpose. The decision to retain or remove an item was also based on the following four principles (DeVellis, 2003, pp.63-70):

- Responsiveness: the item is expected to be sensitive to change over time.

- Universality: the item should capture beliefs of individuals across the observed groups and a broad age range,

- Wording/ambiguity: the item should be clearly worded and understood and is unlikely to evoke a variety of interpretations,

- General Acceptability: the item should resonate with participants and should be felt appropriate for the target population.

This led to 40 items covering eight themes associated with the construct of perceived community efficacy (see Appendix G). Although the main outcome of the study was to 
provide sufficient data from the sample population to generate an item pool for the quantitated study, there were a number of key findings. The following section outlines the findings before moving to detail the content validity process.

\subsection{Content Validity of Item Pool}

Pollit and Beck (2006) suggest that the I-CVI is calculated first where items judged to have excellent content validity should meet the following criteria, 3-5 experts (I-CVI = 1.0); 7-10 experts (I-CVI $\geq .78$ ). Items not meeting the criteria are deemed not representative of the domain and should be modified or deleted from the pool of items. The S-CVI is applied next and is based on the proportion of items in an instrument that achieved a rating of 2 or 3 by all raters producing a score of (S-CVI $\geq .8$ ) (Pollit $\&$ Beck, 2006; Lynn, 1986).

\subsubsection{Participants}

The number of experts selected was determined following the recommendations made by Crocker et al. (1988) for obtaining useful estimates to adequately calculate inter expert agreement. The recommendation is to select at least three experts for each item (Lynn, 1986). However, along with this purely empirical criterion, the characteristics of the experts should be considered. Studies have highlighted the importance of involving experts in test construction/adaptation and individuals who are not experts in the measure but are specialized in the construct of interest or knowledgeable of the discipline it forms part of (Davis, 1992). Combining the two previous criteria, a total of 7 experts were selected: 2 academics from the University of London with proven experience in test construction/adaptation and 5 professionals knowledgeable in weather related disasters and emergencies/community response.

\subsubsection{Guidance}


A guidance note was prepared for each judge to ensure continuity of approach and an appreciation of the domain and sub-domains under scrutiny (Appendix E). Each subdomain was described and a dummy item was created and used as an example of an item matching the sub-domain enhance overall understanding of the process. The domain was Perceived Community Efficacy, with the sub domains being Community Network Structures, Social Capital and Community Capacity. Judges were asked to compare items with each of the sub-domains and select a best fit and assign a score using a 3-point Likert scale. There was also an opportunity for each judge to provide a comment clarifying the subdomain chosen and the score given. Comments would be useful for the researcher when deciding if an item should be modified or deleted.

\subsubsection{Procedure}

After being invited to participate voluntarily, experts were given the guidance notes, items to be assessed in the form of a spreadsheet and asked to complete them within one week. After completing the task, participants returned the completed spreadsheet to the researcher of the study. At that time, feedback was collected on their overall opinion about the task and the items, specific observations, and other relevant aspects. 


\subsubsection{Data analysis}

The Content Validity Index (I-CVI; Polit \& Beck, 2006) has traditionally been use to estimate representativeness, comprehension, ambiguity, and clarity. I-CVI was calculated for the subdomains by dividing the total sub-score by the number of items in the subdomain. The mean I-CVI for the global dimension was calculated similarly but summing all scores and dividing by the number of items. As a general criterion, it is considered that I-CVI values should be $\geq .70$ (Tilden, Nelson, \& May, 1990). When there are a high number of items or the initial intention is to obtain clearly differentiated dimensions, a more restrictive criterion is recommended (Davis, 1992) with a minimum value of $\geq .78$. Although the S-CVI index can be calculated in different ways, the researcher of this study followed the recommendations made by Rubio et al., (2003). According to them, the S-CVI for each item should be calculated by dividing the number of judges issuing a judgment of 2 or 3 on the corresponding Likert scale by the total number of judges. The minimum acceptable score is $\geq .80$. Decisions on items whether eliminating, modifying or conserving them should not exclusively be based on empirical data. DeVellis (2003, p. 86) suggests that items should be subject to overall consideration by the researcher depending on the objective intended when they were created, always based on the definition of the construct. It is also very useful to consider qualitative observations on items or alternative wording suggested for them.

\subsubsection{Findings from Content Validity Analysis}

Appendix F shows the individual item scores together with the I-CVI score. The Mean I-CVI and S-SCI are also calculated and feature at the base of the table. All the judges who were invited to assess the items completed the task. Of the 40 items assessed, 5 were considered to have insufficient content validity (I-CVI $<.70)$. In the dimensions of 
the sub-domains, this led to modifying of 1 item for Community Network Structure, 2 items for Social Capital, and 2 items for Community Capacity.

Table 4. Summary Results for I-CVI and S-CVI

\begin{tabular}{lllll}
\hline Index & Group & $\mathrm{N}$ & Score & Outcome \\
\hline Mean I-CVI & Community Network & $\mathrm{N}=13$ & .82 & Acceptable \\
& Structure & & & \\
Mean I-CVI & Social Capital & $\mathrm{N}=13$ & .78 & Acceptable \\
Mean I-CVI & Community Capacity & $\mathrm{N}=14$ & .86 & Acceptable \\
Mean I-CVI & Global Items & $\mathrm{N}=40$ & .86 & Acceptable \\
S-CVI & Experts Proportionality & $\mathrm{N}=7$ & .88 & Acceptable \\
\hline
\end{tabular}

The mean I-CVI value for Community Network Structure was $(\mathrm{N}=13) .82$, for Social Capital, $(\mathrm{N}=13), .78$ and for Community Capacity, $(\mathrm{N}=14), .86$. The overall mean I-CVI for all items was $(\mathrm{N}=40), .86$. The $\mathrm{S}-\mathrm{CVI}$ was calculated at $(\mathrm{N}=7), .88$ for the full item pool. Although 5 items failed to reach an acceptable I-CVI score, all other items were deemed acceptable I-CVI. The sub-dimension scores were all within the acceptable range as well as the S-CVI. The final item pool consisted of 40 items inclusive of the 5 modified items (Appendix G)

\subsection{Summary}

This chapter detailed the systematic way in which 48 items were generated to be included in a survey used to investigate residents' beliefs as to an emergency preparedness within the community. The theory of social organisation was used to guide initial enquiry into perceived community efficacy and its antecedents. Emerging from the enquiry the antecedents were identified as community network structure, social capital and community capacity. Using this structure of antecedents as well as the knowledge gained through the literature review, six themes were identified and used to develop 14 semi-structured questions for use in the main qualitative study. The results of the pilot study and further iterations using the relevant literature identified two 
further themes. Four semi-structured questions were also added to investigate the two new themes. Although purposive sampling was used to identify the suitable populations, participants were chosen using a random methodology. The interviews where recorded and transcribed and a thematic analysis was carried out using the eight themes identified previously. The inter-rater reliability was calculated at $92 \%$. Key finding were that there was some evidence of voluntary exclusion from rest of the community, overall they were able to collectively undertake actions that resolved local and that there was a general perception from the respondents that their respective communities would collectively prepare for a severe weather emergency. There was also a number of specific findings that were unexpected by the researcher. These were issues of community identity, reluctance to be engaged in activities that had formal overtones and group and the need for someone to lead and organise them in their preparedness activities. The data was synthesised to provide the researcher with sufficient material to construct 48 items related to the eight themes. A review of the items resulted in eight items being removed due to redundancy and non-relevance. The item pool was analysed by seven subject matter experts where each item was given a score representing the goodness of fit. The review of items by the subject matter experts is considered to be important in establishing a level of content validity. The content validity index was selected to be used at both item and scale level. The output values from the content analysis suggested that the items were within and acceptable range and that the scale was also within an acceptable range, demonstrating a high level of content validity for both. Five items recorded unsatisfactory values and were modified before being included in the main item pool. All 40 items were selected to be used in the second study, which used quantitative methodology. Chapter 5 details the methods used in testing the a priori model and validating the item pool to produce a scale with psychometric properties. 


\section{Chapter 5.0 Quantitative Study - Testing the Scale - Exploratory and Confirmatory Phases}

\subsection{Introduction}

As discussed in chapter two, there have been a number of studies that have examined the nature and outcomes of perceived community efficacy however these investigations generally focused on social control and problem solving and although providing a valuable insight into community issues, the findings from such studies may not be appropriate when investigating different community activities or domains (Chavis et al., 1987; Itzhaky and York, 2000, Wandersman and Florin, 2000). This investigation aimed to build on previous knowledge about individuals' beliefs on neighbourhood collective activities. It is also hoped to extend the knowledge base on communities preparing for emergencies by developing a perceived community efficacy scale that would be able to determine levels of efficacy and thus measure the likelihood of a community acting together to prepare for a weather related emergency. The outcome of the qualitative study in chapter four was a pool of items constructed to examine the construct of perceived community efficacy. The distribution of items in the survey was based on the a priori model of the three dimensions and the 8 themes identified in the qualitative study. This ensured that each dimension was adequately covered by a ranged of items in the survey. The 7 items investigating prior experience were adapted from the CCSE scale (Benight, 2004, p. 419) as a dependent variable to that would be used in the HRA. The responses were transferred into SPSS version 22 to carry out tests specific to scale development; the first of those being an exploratory factor analysis in order to investigate the factorability of the variables. Contribution to variance was examined using a hierarchical regression analysis where the dependent variable was, community prepared. The a priori factors; community network structure, social capital and, 
community capacity and the alternative model factors; community network structure and, social capacity were analysed for individual contribution to variance whilst controlling for the effects of the other predictor variables. Following the outcome of the exploratory phase, the confirmatory phase examined the two models (three factor and two factor) using a confirmatory factor analysis (CFA) to determine model fit and in particular whether the a priori model reflected the response data. The chapter concludes with a discussion section that provides an in depth interpretation and synthesis of the results and key findings.

\section{Exploratory Phase}

\subsection{Participants}

The researcher accessed the flood risk mapping system on the Environment Agency website. Several areas were identified as at risk from flooding both surface water and river overflow. A postcode filter was applied on each map so that risk was identified for each postcode area. A search on the Post Office website to identify streets and these were matched with the initial risk areas. This produced 20 streets where over 400 residential buildings were matched and categorised as high risk. The data was collected from residents living within the United Kingdom $(\mathrm{N}=501)$. Respondents were grouped into three main post code categories: Area 1 where $50 \%$ of those responding, resided within DE65, $(N=252)$, Area 2, provided 38\% of responses and resided in the S40/S41 areas $(N=188)$ and a combination of post code areas outside the two main focus areas that accounted for $12 \%$ of respondents $(N=61)$. Residents in Area one, resided within a specific area at risk from flooding where there was a community infrastructure in place for a formal level of preparedness; area two was made up of communities within a specific area at risk from flooding where there are no formal community infrastructure to deal with preparedness measures and area three, where residents responded from a 
variety of other postcode areas due to having made contact through social media networks such as Facebook, Twitter, and LinkedIn.

\subsection{Materials}

A leaflet was produced outlining the research, the researcher's profile, contact details and information on how to take part in the survey. This was distributed to every household in the identified risk areas. The online survey consisted of 3 sections, the first containing 40 survey items in the form of an individual's belief regarding the joint action of the community in preparing for a severe weather emergency. An example for this type of item is "Even when difficulties arise the community will be able to prepare for emergencies". In the second section there were 7 criterion items regarding belief of past performance of the community preparing for a severe weather emergency. An example item for this section is "We were well prepared to respond to our most recent weather related emergency." Section 3 required respondents to provide data on age, ethnicity, gender, postcode and whether they believed they lived in an area at risk from flooding and whether they believed there was a high or low intervention from community members. Section 1 and 2 contained statements that required responses using a Likert scale (Likert, 1932), ranging from 1= Strongly Disagree, 2=Disagree, 3=Neither Agree or Disagree, 4=Agree, 5=Strongly Agree. Section 3 required respondents to complete choice fields apart from 'age' that was formatted to numerical data only (Appendix H).

\subsection{Procedure}

A leaflet drop was arranged in the risk areas selected for the research. All residents that received a leaflet that invited them to visit a landing page where information could be accessed regarding the researcher, the research project and contact details. Once on the landing page residents were also invited to take part in the survey by clicking on a link 
to Bristol Surveys Online where residents were directed to the first page describing the survey, information regarding their participation, the use of the results and the procedure for completing section 1, 2 and 3 (Appendix H). At the end of the survey, participants were thanked for their contribution and provided with links to access the Environment Agency online risk mapping, to find out flood risks in their area or for further advice on how to prepare for a potential flood incident.

\subsection{Participant Data Analysis}

Participant information is useful in determining whether a particular socio demographic characteristic was able to influence or bias the survey responses. For instance the age, gender or ethnicity of a respondent may influence the way that person answers a survey question and in doing so may inform the research about a specific belief with regard to that population group. Cutter, (2003) suggests that gather demographic data from a specific population group is essential if research is to be meaningful when investigating aspects of social vulnerability due to environmental hazards such as severe weather. All respondents completed the survey by accessing the researcher's landing page portal (www.fwatt.co.uk) and selecting a link to Bristol Online Surveys, thus ensuring a uniform approach to completing the survey. Although 501 residents completed the survey, there were a number who did not complete fully and this resulted in missing data. In analyzing the non-responses, there does not appear to have been a pattern, in that the non-responses were not concentrated in one or two questions but spread over the five items dealing with socio demographic data. Lynne (1996) provides several reasons for non response including refusal to provide an answer, inability to provide an answer and the failure to answer (e.g. by accident). The full completions range from $98.4 \%$ to $97 \%$ indicating a high full completion rate and a survey design that appeared to be easy to understand and complete (Dillman, 2000). Table 5. presents information 
regarding gender where males provided the largest response at $60.2 \%$ within females contributing $39.1 \%$. Although there was missing data, this only amounted to $1.6 \%$ of respondents who did not report their gender. The minimum age of respondents was 18 whilst the maximum was 81 . The mean age of participants was 43.65 years $(M=43.65$, $S D=13.211)$

Table 5. Gender

\begin{tabular}{lllll}
\hline & Frequency & Percent & $\begin{array}{l}\text { Valid } \\
\text { Percent }\end{array}$ & $\begin{array}{l}\text { Cumulative } \\
\text { Percent }\end{array}$ \\
\hline Valid & 297 & 59.3 & 60.2 & 60.2 \\
Male & & 39.1 & 39.8 & 100 \\
Female & 196 & 98.4 & 100 & \\
Total & 493 & 1.6 & & \\
$\begin{array}{l}\text { Missing } \\
\text { System }\end{array}$ & 8 & 100 & & \\
Total & 501 & & \\
\hline
\end{tabular}

In Table 6 . the majority of participants accounting for $77.4 \%$ of responses were white The second largest ethnic group represented in the sample, $9.0 \%$, were mixed race The next largest was the Asian respondents who accounted for $6.5 \%$, with Black respondents representing $4.3 \%$ of the total. The Chinese and 'Other Ethnicity' were equal in response numbers with $1.4 \%$ each.

Table 6. Ethnicity

\begin{tabular}{lllll}
\hline & Frequency & Percent & $\begin{array}{l}\text { Valid } \\
\text { Percent }\end{array}$ & $\begin{array}{l}\text { Cumulative } \\
\text { Percent }\end{array}$ \\
\hline \multicolumn{1}{c}{ White } & 380 & 75.8 & 77.4 & \\
Mixed & 44 & 8.8 & 9 & 86.4 \\
Asian & 32 & 6.4 & 6.5 & 92.9 \\
Black & 21 & 4.2 & 4.3 & 97.1 \\
Chinese & 7 & 1.4 & 1.4 & 98.6 \\
Other & 7 & 1.4 & 1.4 & 100 \\
Total & 491 & 98 & 100 & \\
Missing & 10 & 2 & & \\
System & 501 & 100 & & \\
Total & & & 12.8 & \\
\hline
\end{tabular}


Table 7. below presents the data about residents and whether they believed they lived in a flood zone. Given the purposive sampling strategy, a high percentage of residents responding 'yes' to the survey was expected by the researcher. This was confirmed with $66.7 \%$ of respondents believed they lived in a flood risk area. Those residents who believed they did not live in a flood risk area accounted for $17.7 \%$. Residents were also asked whether they believed their communities had a level of formal community flood preparedness in place.

Table 7. Residents' perceptions on whether they lived in a flood risk zone

\begin{tabular}{lllll}
\hline & Frequency & Percent & $\begin{array}{l}\text { Valid } \\
\text { Percent }\end{array}$ & $\begin{array}{l}\text { Cumulative } \\
\text { Percent }\end{array}$ \\
\hline \multicolumn{1}{r}{ Yes } & 324 & 64.7 & 66.7 & 66.7 \\
No & 86 & 17.2 & 17.7 & 84.4 \\
Don't & 76 & 15.2 & 15.6 & 100 \\
Know & & & 100 & \\
Total & 486 & 97 & & \\
Missing & 15 & 3 & & \\
$\begin{array}{l}\text { System } \\
\text { Total }\end{array}$ & 501 & 100 & & \\
\hline
\end{tabular}

According to the retrieved data in Table 8., respondents who did not believe there high levels of preparedness measures in place accounted for $41.5 \%$ with $42.5 \%$ of respondents believing there was low levels of preparedness measures in place. The remaining $16 \%$ of respondents believed that the area where they resided was not at risk from flooding. 
Table 8. Residents' Perceptions on Community Flood Intervention

\begin{tabular}{|c|c|c|c|c|}
\hline & Frequency & Percent & $\begin{array}{l}\text { Valid } \\
\text { Percent }\end{array}$ & $\begin{array}{l}\text { Cumulative } \\
\text { Percent }\end{array}$ \\
\hline $\begin{array}{l}\text { Flood } \\
\text { high } \\
\text { inter }\end{array}$ & 203 & 40.5 & 41.5 & 41.5 \\
\hline $\begin{array}{l}\text { Flood } \\
\text { low inter }\end{array}$ & 208 & 41.5 & 42.5 & 84 \\
\hline $\begin{array}{l}\text { No flood } \\
\text { risk }\end{array}$ & 78 & 15.6 & 16 & 100 \\
\hline Total & 489 & 97.6 & 100 & \\
\hline $\begin{array}{l}\text { Missing } \\
\text { System }\end{array}$ & 12 & 2.4 & & \\
\hline Total & 501 & & & \\
\hline
\end{tabular}

\subsection{Data Screening}

A higher proportion of missing data is directly related to a lower quality of statistical inferences (Cohen, 1988, p. 6). The researcher could not identify an established cutoff point from reviewed literature, regarding an acceptable percentage of missing data in a data set for valid statistical inferences. Schafer (1999) asserts that a missing rate of 5\% or less is inconsequential whilst Bennett (2001) maintained that statistical analysis is likely to be biased when more than $10 \%$ of data are missing. Where missing data is found and at a level that may compromise further analysis, multiple imputation may be applied to insert replacement mean values into the data set (Ruben, 1997). An analysis of the data produced by the 40 items $(\mathrm{N}=501)$ using SPSS, revealed that the highest return on a single item was $98.8 \%$ with the lowest rate of return being $97 \%$. The overall range of missing data for the set of items was between $1.2 \%$ and $3 \%$, which is well within the 5\% and 10\% proffered by Schaffer (1999) and Bennet (2001) and therefore would not require any form of statistical manipulation such as imputation (Rubin, 1976). 


\subsection{Data Distribution}

\subsubsection{Skewness}

The distribution is a summary of the frequency of individual values or ranges of values for, in this case, an item. In order to measure the distribution of data pertaining to the 40 items it was necessary to test for skewness and kurtosis. Normal distributions produce a skewness statistic $(S S)$ of about zero but small variations can occur by chance alone. As the skewness statistic departs further from zero, a positive value indicates the possibility of a positively skewed distribution, that is, with scores loading on the low end of the score scale or a negative value indicates the possibility of a negatively skewed distribution that is, with scores loading on the high end of the scale (Brown, 1996, pp. 138-142). Values of twice the standard error of skewness (SES) or more regardless of whether they are positive or negative would be deemed as skewed to a significant degree (George \& Mallery, 2010). SPSS was employed to calculate descriptive statistics for distribution including, mean, standard deviation, skewness, kurtosis and the standard error of both skewness and kurtosis. Observations made on the data revealed all items demonstrated a degree of skewness. Standard error was calculated using a formula derived by Tabachnick \& Fidell (1996):

$$
\sqrt{\frac{6}{N}}
$$

To find out whether an item is skewed and within the acceptable range of $+/-2 S E S$, the skewness statistic from the data output was used in the above calculation. An approximate estimate of the $S E S$ for this set of data is:

$$
S E S=\sqrt{\frac{6}{501}}=0.11
$$


Since two times the standard error of the skewness is .22 and the value of the skewness statistic for item 1 is -1.99 , which is greater than .22 , the assumption can be made that the distribution is significantly skewed. Since the sign of the skewness statistic is negative, the distribution is negatively skewed. Alternatively, item 35 has a skewness statistic of .48 and greater than .22 indicating that the skewness statistic is positive, and that the distribution was positively skewed. Item 40 however has a skewness statistic of -0.15 and falls within the range between -0.22 and +0.22 , in which case, the assumption is that the skewness was within the expected range of chance fluctuations in that statistic, which would further indicate a distribution with no significant skewness problem. Items 34 and 40 were within range $+/-0.22$ and yielded a skewness statistic $=$ -0.15 and -0.20 with the $S E S=0.11$ for both items. Figure 2 . below is provided as an example and indicates slight skewness compared to normal distribution.

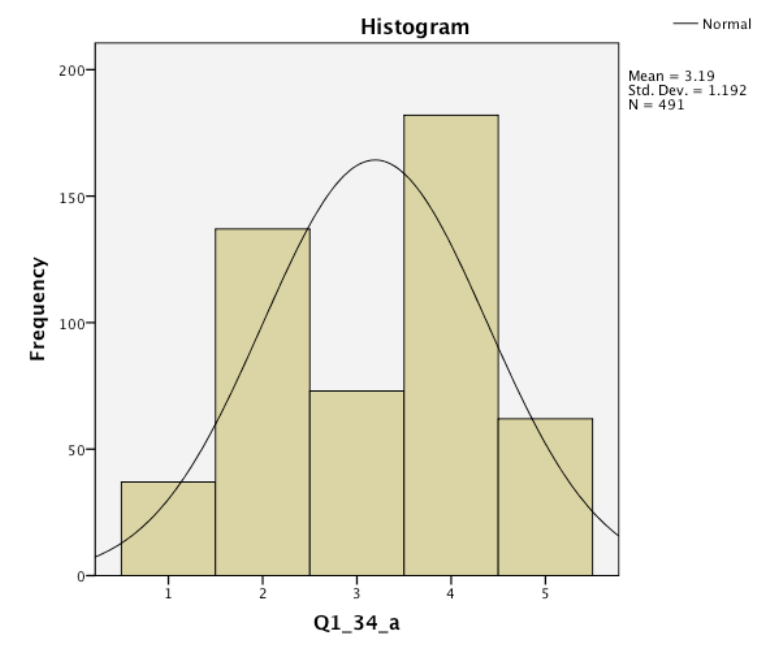

Fig. 2. Example of Acceptable Level of Skewness.

All other items demonstrated scores that were outside the acceptable range for normal distribution range, with variables $33, S S=0.437$ and $35, S S=0.476$ displaying positive skewness. The remaining variables were negatively skewed with variable 28 yielding the highest level of skewness, $S S=-1.354, S E S=0.11$. Figures 3 and 4 provide examples of the relative level of skewness in both positive, item 35 and negative, item 28 . 


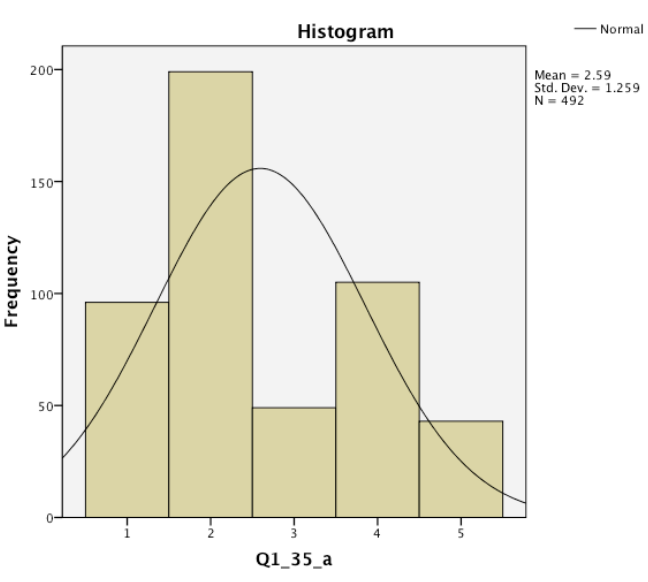

Fig. 3. Example of Positive Skewness

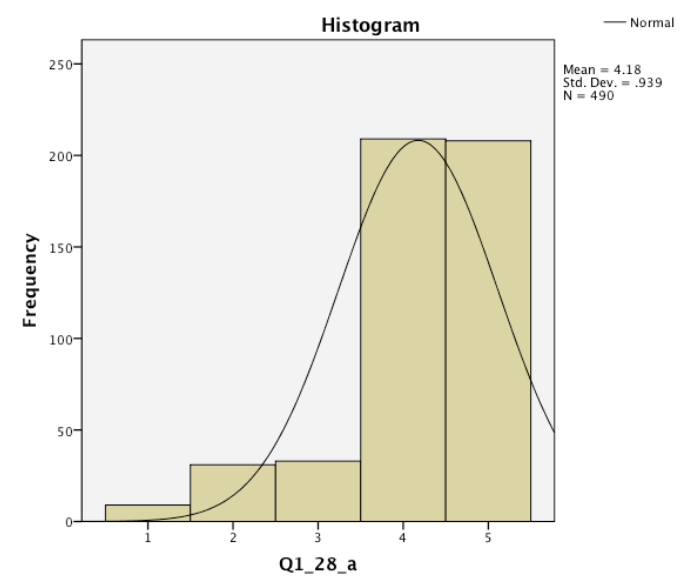

Fig. 4.Example of Negative Skewness

\subsubsection{Kurtosis}

The level of kurtosis characterises the overall shape of the data distribution relative to the shape of the curve. Negative kurtosis will have a sharp profile with lightness of tails while positive kurtosis has a flatter profile with heavier tails (DeCarlo, 1997, pp. 292307). Normal distribution produces a kurtosis of zero with an acceptable range being +/twice the standard error of kurtosis $(S E K)$. Values of twice $S E K$ or more regardless of being positive or negative would be deemed to be out with the acceptable range (Brown, 1996, pp. 138-142). Standard error was calculated using a formula derived by Tabachnick \& Fidell (1996):

$$
S E K=\sqrt{\frac{24}{N}}
$$

To find out whether a variable lies within the acceptable range of $+/-2 S E K$, the kurtosis statistic from the SPSS output was used in the calculations. An approximate estimate of the $S E K$ for this set of data is:

$$
S E K=\sqrt{\frac{24}{N}}=\sqrt{\frac{24}{501}}=0.22
$$


By multiplying the standard error of the kurtosis by 2 , a value of 0.44 is achieved and can be taken as the range that the kurtosis statistic should fall between (range $=/-0.44$ ). Therefore comparing the kurtosis statistic for variable 1 which is 1.072 and greater than 0.44 , the assumption can be made that the distribution has a significant kurtosis issue. Since the sign of the kurtosis statistic is positive, the distribution would be flat with heavy tails. Alternatively, item 2 has a kurtosis statistic of -0.576 and is greater than 0.44 indicating a negative kurtosis issue. Item 3 however has a kurtosis statistic of 0.14 and falls within the range between -0.44 and +0.44 , in which case, the assumption is that the kurtosis was within the expected range of chance fluctuations in that statistic, which would further indicate a distribution with no significant kurtosis problem. Items $3,6,12,16,18,19,22,23,25,26,27$ and 39 produced scores that were within the acceptable range and follows a normal distribution shape similar to figure 5 .

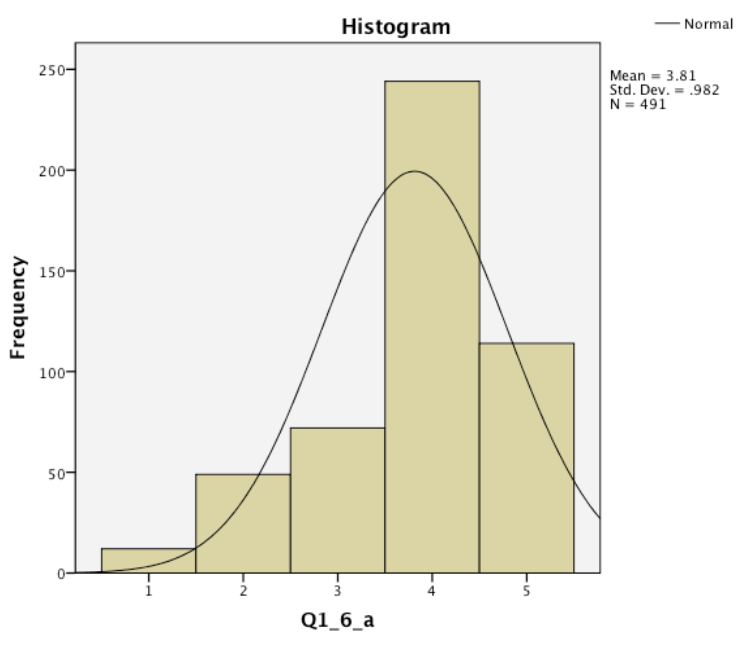

Fig. 5. Example of Acceptable Level of Kurtosis.

Items $2,33,34,35$ and 40 produced scores that are deemed negative and out with the range of $+/-0.44$. The profile is flat with heavy tails when compared to the normal distribution curve and would be similar to figure 6 below. 


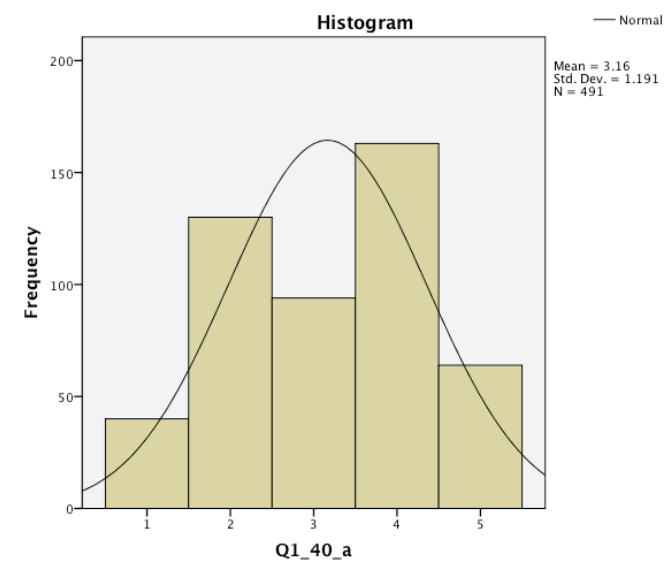

Fig. 6. Example of Negative Kurtosis

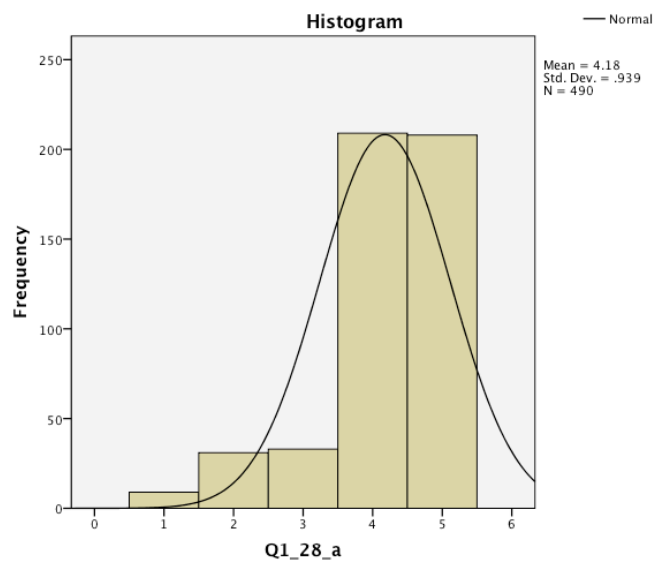

Fig. 7. Example of Positive Kurtosis

The remaining items $1,4,5,7,8,9,10,11,13,14,15,17,20,21,28,29,30,31,32,36$, 37 and 38 are deemed positive and out with the range of $+/-0.44$. Figure 7 . above illustrates the positive profile with a sharp curve and lighter tails as compared to the normal distribution shape.

\subsection{Data Transformation}

Although several items demonstrated normal distribution, the majority of indicated unacceptable levels of skewness. The range of tests and analysis involved in examining a set of variables in order to develop a scale assume the data has a normal distribution (Dewberry, 2004). The previous results show that the items in the data set under investigation have a level of skewness that would violate the assumption of normality and therefore could not proceed further in the scale development without a form of correction or amendment (Zimmerman, 1998, pp. 1-19). Data transformation is a statistical technique that aligns the data into an adjusted alternative form that produces a data distribution that is normal (Osbourne, 2002). The log10 procedure was selected for positively skewed items where as the $\log 10$ plus reflection procedure was selected for the negatively skewed items All items that were not normally distributed were amended using the Transform Compute Variable command in SPSS and the results scrutinized to ensure that all new values were within acceptable levels. Although the new values 
reflect a logarithm calculation all further reports of means will use the original values before transformation thus avoiding confusion when comparing against those items that were not transformed. Howell (2007, pp. 318-324) and Tabachnick and Fidell (2007, pp. 86-89) provide the statistics for positive and negative transformation. The statistic selected for negatively skewed data was:

Logarithmic $(\log 10)$

NEWX $=$ LG10 $(\mathrm{K}-\mathrm{X})$

Where $\mathrm{X}$ is the variable and $\mathrm{K}=\mathrm{a}$ constant from which each score is subtracted so that the smallest score is 1 ; usually equal to the largest score +1 . The statistic for positively skewed data:

Logarithmic $(\log 10)$

$\mathrm{NEWX}=\mathrm{LG} 10(\mathrm{X}+\mathrm{C})$

Where $\mathrm{X}$ is the variable and $\mathrm{C}=\mathrm{a}$ constant added to each score so that the smallest score is 1 .

The new variables 35 and 28 having been transformed now show a SES of -.20 and -.21 respectively, both within acceptable values for skewness and kurtosis.

\subsection{Correlation Matrix}

As part of the data screening process it was necessary to investigate the inter-correlation between variables to check whether the variables correlate at all, with each other or whether they correlate too highly. The test selected to measure correlations was the Pearson product-moment correlation coefficient that is a measure of the strength of a linear association between two variables. Variables that correlate $r<.10$ would not posses the relationship properties necessary to be included in a measurement instrument and would be deleted. Variables stronger than $r \leq .90$ would be deleted as they correlate too highly and indicate multicollinearity or singularity, when variables perfectly correlate. When either occurs, it would be extremely difficult to determine the unique contribution to a factor and the overall measurement of a construct (Field, 2004). 
Having set out the initial parameters for the initial screening of the variables, the next step was to construct a correlation matrix in SPSS. The $r$-matrix output is shown in Appendix I . The correlation co-efficient matrix produced by SPSS revealed that all the variables were correlated higher than $r=.20$ but lower than $r=.90$. A high percentage of variables displayed large correlation co-efficients of $r>.5$ with the largest correlation being variable 31 , “As a community we will work with relevant organisations and agencies to help prepare for emergencies", $r=.89$. Although extremely large the correlation coefficient falls below $r \geq .9$ and therefore will be included in the 40 variables that will be subject to the next stage.

In summarising the data screening stage there were some instances of missing data but due to the sample size $N=501$ the highest percentage of missing data was $3 \%$ and would not affect the ongoing analysis. There was evidence of both negative and positive skewness and kurtosis with a number of variables outside the acceptable ranges for both $+/-.22$ and $+/-.44$ respectively. The strength of the relationship between variables was examined using the Pearson correlation coefficient and found to be within an acceptable range $r=>.2$ and $r<.9$ which indicted that all 40 items should be included in the initial exploratory factor analysis.

\subsection{Exploratory Factor Analysis}

Exploratory factor analysis (EFA) is used to examine a pool of variables and by grouping them together reduce the overall number into other groups of variables called factors (Williams et al., 2010). Before undertaking an EFA, there are a number of important issues to consider regarding which tests to include in the analysis, and more importantly why they are included. The following text provides an outline as to the selection of tests and results from the initial EFA. EFA undertaken using SPSS has a range of options depending on the outcome that is most suited to the research being carried out (Pett et al., 2003). 


\subsubsection{Selection of Exploratory Factor Analysis Tests}

The first consideration may be the specific options that can be selected to provide further analysis and information on the 40 variables such as the development of an $r-$ matrix. Although this type of matrix has already been used in the data screening process, a further analysis provides for more intense scrutiny of the coefficients that have large correlations and may indicate multicollinearity. To assist with identifying this issue, the determinant value of the correlation matrix produced by SPSS, can also indicate multicollinearity. Where the determinant is greater than 0.00001 , the presence of multicollinearity will be small and will not adversely affect further test results (Baguley, 2012, pp.449-454). Prior to the extraction of the factors, several tests should be used to assess the suitability of the respondent data for factor analysis. These tests include Kaiser-Meyer-Olkin (KMO) Measure of Sampling Adequacy (Kaiser, 1970; Kaiser1974), and Bartlett's Test of Sphericity (Barlett, 1950). The KMO index ranges from 0 to 1 , with values greater than .50 considered acceptable and provides a positive indication that the sample size is suitable for factor analysis (Hair et al., 1995; Tabachnick \& Fidell, 2013). The Bartlett's Test of Sphericity should be significant ( $p<$ .05) for factor analysis to be suitable (Hair et al., 1995). The next issue to consider is the extraction of components or factors. Component analysis includes the total variance in the initial extraction and identifies the component or factor structure. The method chosen by the researcher was Principal Component Analysis (PCA) as it is the most widely used extraction method of component analysis and is most appropriate when the purpose is to reduce the number of items to a smaller number of representative components (Costello \& Osborne, 2005; DeCoster, 1998). Once extracted, the component structure requires to be investigated to identify the initial factor solution where the groups of variables have a fewer number of correlations between them and demonstrate the individual factor contribution to variance (Williams et al., 2010, pp. 6- 
7). The most commonly used methods are the Kaiser Criterion (eigenvalue $>1$ rule) (Kaiser, 1960) where factors should be retained if their eigenvalues are greater than or equal to one and the Scree test (Cattell, 1966) where factors retained are above a visible cut-off point on the eigenvalue line (Costello \& Osborne, 2005). The Kaiser Criteria and the Scree test have been selected for this EFA as one provides a table of values indicating cumulative percentage of variance to support the factors extracted and the other provides a scree plot which is a graphical representation of the factors and their corresponding eigenvalues (Beavers, 2013). Using both the Kaiser Criterion and Scree tests to indicate the number of factors extracted provides the opportunity to compare the results of both tests and gives a more informed choice of factor structure. The method of factor rotation chosen for the initial EFA is an oblique rotation and according to Henson and Roberts (2006) incorporates the relationships between the factors, which usually lead to a better fit between data and factors. Having decided on the structure of the EFA the next step is to run the analysis using SPSS.

\subsubsection{Preliminary Analysis}

\subsubsection{A Priori Model (3 Factor 11items)}

The first SPSS output was the Pearson product moment correlation coefficents, the $r$ matrix (Appendix I). This was initially scanned for variables correlated to at least $r=$ .30 with at least one other variable, suggesting reasonable factorability (Neill, 1994)A second scan carried out, revealed that there were no correlation coefficients $r>.90$ indicating no issues of singularity (Field, 2005). The next output provides information from the Kaiser-Meyer-Olkin measure of sampling adequacy and the Bartlett's test of sphericity. The KMO statistic was generated at .98 , which is above the recommended value of .5 (Kaiser, 1974). Bartlett's test of sphericity has an 'acceptable' value of $p<$ .05 . The null hypothesis was disproved generating a value of $p<0.0001,\left(\chi^{2}(501)=\right.$ 
19334.25, $p<.0001)$.

The initial eigenvalues indicated that the first factor explained $67 \%$ of the variance, the second factor approximately $6 \%$ of the variance, and a third factor approximately $3 \%$ of the variance. The eigenvalues after rotation indicated a slight leveling off in importance where factor one decreased from 26.75 to 26.58 , factors two showed an increase from 2.31 to 9.48 and factor 3 increasing from 1.13 to 1.95 . The Scree plot, Figure 8., illustrates a three-factor structure at the cut off point and provides support for the Kaiser Criterion result.

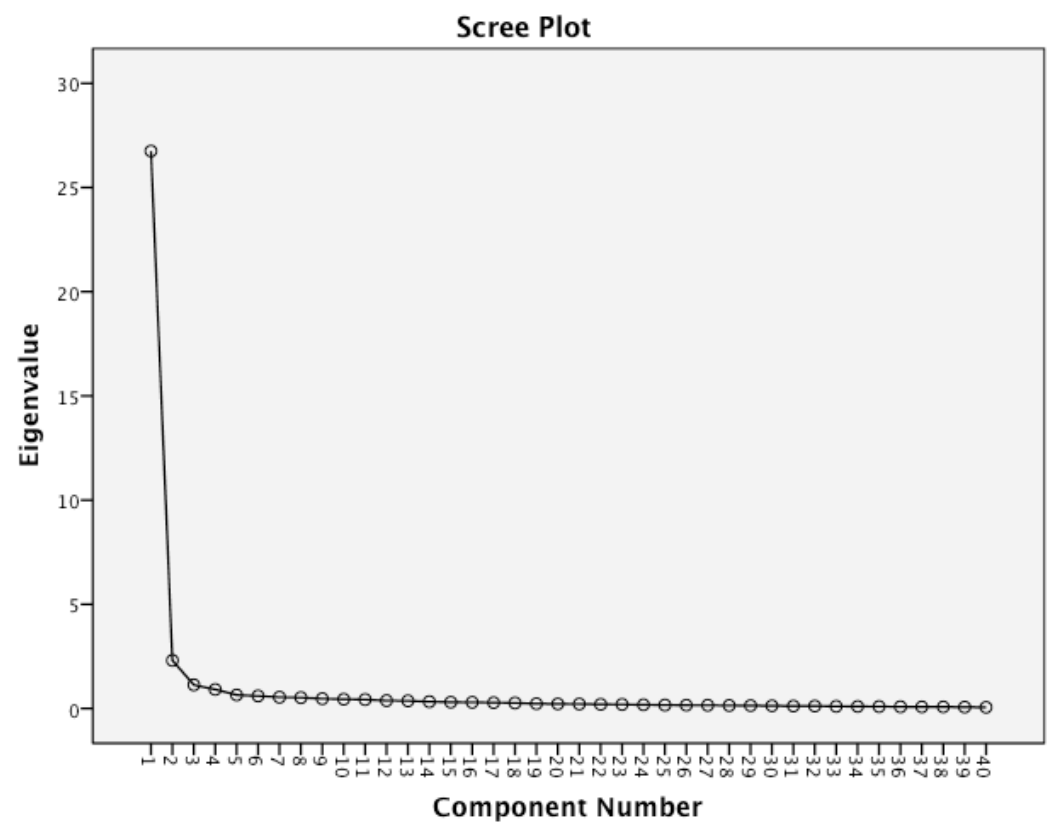

Figure 8. Scree Plot - Three-Factor Model

The three factor solution, which explained $75.476 \%$ of the variance, was preferred because of its previous theoretical support, the 'leveling off' of eigenvalues on the scree plot after three factors, and the insufficient number of primary loadings and difficulty of interpreting the fourth factor and subsequent factors 
The Kaiser's criterion is deemed to be accurate when sample size exceeds 300 and the average communality is greater than .60 (Field, 2005). The communalities confirm that all communalities have score of over .6 and together with a sample greater than 300 in this case $(\mathrm{N}=501)$, the Kaiser criteria was accurate at extracting 3 factors. The final output to consider in this initial EFA is the factor loadings. Although the pattern showed support for the a priori three-factor structure, factor one shows crossloadings with factor three. Furthermore factor one has a loading of 36 variables of which 8 are cross-loaded with factor 3 . This together with the high correlation coefficients shown in the $r$-matrix indicates that a number of variables require to be removed in order to improve the overall factor structure. A review of the correlation matrix produced by the initial EFA revealed 22 variables with correlation coefficients of $r>.8$ and 18 ranging from $r>.25$ to $r<.78$. Field (2005) recommends eliminating variables that correlate very highly, $r>$.8. In the first sift, variables were identified where they demonstrated a very high correlation coefficient, $r>.8$ and possessed multiple correlations with other variables. As the determinant produced a value of $3.738 \mathrm{E}-24$ which is less than the acceptable value of 0.00001 , correlation coefficients of $r>.8$ were then selected and deleted as an iterative process, at the same time recording the value of the determinant figure as it increased and changes in the number of variables remaining, as they decreased. This together with the high correlation coefficients shown in the $r$-matrix indicates that a number of variables require to be removed in order to improve the overall factor structure. The last value, 0.0000393 is very close to the acceptable value of 0.00001 , indicating that an acceptable value may be reached with the deletion of a single variable. The next set of iterations investigated each remaining variables, in singles, pairs and triples, deleting and re-instating until all variables had had been attempted. The determinant value improved to 0.0001 , at which point the determinant value was deemed to be acceptable. The remaining 11 variables 
however, loaded into a new two factor structure that was not representative of the 3 factor a priori factor model. As this phase was exploratory the remaining items that formed a 2-factor structure were subject to a further EFA.

Table 9. Factor loadings and communalities for 3-factor model

\begin{tabular}{lcccc}
\hline \multicolumn{2}{l}{ Factor Matrix } & & & \\
Variable & Soc_Cap & Com_Net_Struc & Com_Cap & Communalities \\
\hline Q1_17_a & .85 & -.02 & .10 & .80 \\
Q1_31_a & .84 & .07 & .05 & .80 \\
Q1_39_a & .78 & .10 & .11 & .79 \\
Q1_33_a & -.15 & .91 & .13 & .79 \\
Q1_34_a & .18 & .86 & -.20 & .82 \\
Q1_40_a & .10 & .80 & .08 & .76 \\
Q1_2_a & .15 & .04 & .89 & .97 \\
Q1_27_a & -.01 & -.03 & .49 & .75 \\
Q1_28_a & -.01 & -.10 & .47 & .70 \\
Q1_37_a & -.02 & .04 & .50 & .71 \\
Q1_38_a & -.04 & .06 & .41 & .76 \\
\hline
\end{tabular}

Extraction Method: Principal Component Analysis.

Rotation Method: Oblimin with Kaiser Normalization.

a Rotation converged in 4 iterations.

\subsubsection{EFA results for 11 item, 2-factor model.}

The variables within the two factor $r$-matrix displayed a range of correlations, the highest being $r=.78$ and the lowest $r=.22$ with all variables correlating at least $r<.3$ with at least one other item. The Kaiser-Meyer-Olkin measure of sampling adequacy was .91, above the recommended value of .6, and Bartlett's test of sphericity was significant $\left(\chi^{2}(501)=3302.735, p<.01\right)$. The communalities were all above .3 apart from variable Q1_2_a, 'We are all committed to being prepared for weather related emergencies', further confirming that each item shared some common variance with other items. The eigenvalues shown in indicate that the first factor explained $58 \%$ of the variance, the second factor approximately $15 \%$ of the variance. The eigenvalues after rotation indicated a slight leveling off in importance where factor one decreased from 
5.836 to 5.569 and factor two showing an increase from 1.471 to 3.511 . The Scree plot illustrates a two-factor structure at the cut off point and provides support for the Kaiser Criterion result. The new model demonstrated a 'leveling off' of eigenvalues on the scree plot after two factors, insufficient number of primary loadings and difficulty of interpreting the third, fourth factor and subsequent factors. The two-factor solution, which explained $73.069 \%$ of the variance, had similar percentage values as the initial a priori model, where the percentage of variance value was $75.476 \%$ for the three factors. The pattern matrix indicated that the variables, 33, 34 and 40 in factor two have remained relatively constant and that the new factor is made up from variables, 17, 31, $39,35,36,24,27,14,11,1$, and 32 loading from factor three and populating factor one resulting in a composite factor. The results of the statistical analysis appear to be suggesting that the new factor structure may provide an alternative to the a priori model and worthwhile taking forward to compare model fit during the confirmatory factor analysis.

Table 10. Factor loadings and communalities for 2-factor model

\begin{tabular}{lccc}
\hline Factor Matrix & & & \\
Variable & Soc_Capac & Com_Net_Struc & Communality \\
\hline Q1_17_a & .91 & -.03 & .80 \\
Q1_31_a & .86 & .06 & .79 \\
Q1_39_a & .84 & .09 & .79 \\
Q1_33_a & -.10 & .92 & .78 \\
Q1_34_a & .05 & .86 & .78 \\
Q1_40_a & .12 & .80 & .76 \\
Q1_2_a & .65 & .06 & .66 \\
Q1_27_a & .50 & -.04 & .74 \\
Q1_28_a & .49 & -.12 & .68 \\
Q1_37_a & .51 & .03 & .69 \\
Q1_38_a & .43 & .04 & .74 \\
\hline
\end{tabular}

Extraction Method: Principal Component Analysis. Rotation Method: Oblimin with Kaiser Normalization. a Rotation converged in 3 iterations.

There is evidence of cross loadings within the new factor structure that produced complex factors where the relationship between variables is both weak and negatively 
correlated (Schonrock- Adema et al., 2009). The strongest cross loadings were .12 in factor one, variable 40, "Our community has formal arrangements with organisations that can assist in preparing for an emergencies" and -0.12 in factor two, variable 28 , "In an emergency, I believe we will take care of those most vulnerable in our community". Schonrock- Adema et al. (2009) suggests that complex variables need careful examination both statistically and conceptually and where the cross loading is greater than .40 the variable should be removed. Further deletions were not required as there were no variables that met these criteria. This position is generally supported by Beaver et al., (2013), where they advise that more emphasis be placed on examining the conceptual significance before factor removal. Having reviewed factor two statistically it was found it to be representative of the factor labeled 'community network structure' due to the inclusion of variables 33,34 and 40 . This supports the factor suggested by the a priori model and therefore no further need to examine the conceptual significance, as this was determined as the model was developed. Factor one however, has changed significantly and having been examined statistically will require being investigated as to its characteristics and whether there is any semblance of the original sub domains descriptions, which will aid in labeling the factor. Pett et al., (2003) suggest that although labeling of factors is an inductive process stemming from theory, it is still subjective. This position is largely supported by Henson and Roberts (2006), where they conclude that the meaning and labeling of factors is ultimately dependent of the interpretation provided by the researcher.

The a priori, three-factor model has clear labels stemming from the literature review, and the deductive and inductive processes of identifying sub domains during the qualitative study. Whilst this appears to reflect the three factor solution produced by the initial EFA, is does not fit the two factor model. Although, community network structure remains relatively unchanged, the variables used to represent factor three, 
social capital, have loaded completely onto factor one, community capacity. In order to understand the measurement properties of factor one, it was necessary to revisit the original definitions and descriptions of both social capital and community capacity and how they relate to the factors in the a priori model.

\subsubsection{Label Development - Social Capacity}

Referencing back to Appendix E, relating to content validity, provides descriptors for both dimension and sub-dimension level. Selecting a variable and identifying where it is located within the table, provided the relevant dimension level descriptor. The dimension, social capital contained two descriptors at sub-dimension level, one pertaining to variable 17 , "Information, reciprocity and trust that can be seen as the aggregate of resources" and one other that pertains to variables 31 and 39, "Results from participation in formal and informal settings". The dimension, community capacity contained a further two descriptors at sub-dimension level, the first relating to variables 2, 28, "Shared responsibility for general welfare of the community and its individual members" and the second that relates to variable 37 and 38, "Collective competence where the community take collective action, and confront situations". The key intent of each sub-dimension was summarized in a set of key words or phrases that were used to determine a new label for variable one. A review technique adapted from Boyatiz (1998) revealed the following themes; socialness, aggregate of resources, social settings, participation, capacity, shared responsibility, community welfare, collective competence and collective actions. A search of references already used in the research provided a range of evidence to support the extracted themes (Carroll et al., 2005; Chaskin, 1999; Goddard et al., 2004; Goodman et al., 1998; Enders, 2001; Homan, 2010; Kilpatrick \& Abbot-Chapman 2005; McIvor \& Paton, 2007; Parisi et al., 2002). When analysed together with the sub domain, element and descriptor, a number of 
themes can be identified such as, resources, socialness, responsibility, collectiveness and competences and capacity. The themes were distilled further using the adapted technique Boyatzis (1998) where two dominant themes emerged 'social' from socialness, responsibility and collectiveness and 'capacity' from capacity, competences and resources. Social capacity, and building social capacity have been covered previously in chapter two, literature review, where the concept of social vulnerability and exposure to natural hazards (Cutter, 2003) was discussed. One of the topics examined was social capacity and its relation to societal risk, socio demographics and communities. Social capacity can be understood to be all the resources available within a social group such as a community, that can be used to anticipate, respond, recover and adapt to hazardous natural events. These include skills, knowledge, social networks as well as organisations, structures and knowledge of how to obtain and use them (Tedmanson, 2003). In a similar vein, Thywissen, (2006), observed that aspects of social capacity involved the capacity within a society or organization that reduced the level of risk or the effects of a disaster. Capacity included physical, institutional, social or collective attributes such as leadership or management. In identifying a label for the composite factor, the thematic approach has produced the term "social capacity", which adequately describes the factor and is supported by the selected literature. The newly created factor, "social capacity" (Soc_Capac) measures a particular area of perceived community efficacy, however as a composite of the original factors, social capital and community capacity may appear to be less discriminating than the factor community network structure and as such may be too broad in its ability to isolate and measure social capacity (Christiansen \& Tett, 2013, p. 324). There are now two models that may be useful in measuring perceived community efficacy; the three-factor model developed by the initial EFA and the two-factor model produced by increasing the determinant 
value to an acceptable level. The 11 variables produced a 3 -factor structure reflecting the a priori model and reduced the issue of multicollinearity to an acceptable level.

\subsection{Reliability of the A Priori and Two Factor Scales}

There are a variety of forms of scale reliability co-efficients, internal consistency, split half and alternative forms coefficients (Henson, 2003; DeVellis, 2003, p.28). Among the most commonly used is internal consistency estimates as they are readily calculated from a single administration of a scale or test (Hogan et al, 2000). As this model has been developed from survey data using Likert-type scales it is imperative to calculate and report Cronbach's alpha coefficient for internal consistency reliability (Gliem \& Gliem, 2003). Cronbach's alpha reliability coefficient normally ranges between 0 and

1. The closer Cronbach's alpha coefficient is to 1.0 the greater the internal consistency of the items in the scale. George and Mallery (2003) provide the guidance on alpha where $>.7$ is acceptable (p. 231). Internal consistency estimation is a feature of SPSS version 22. which was used to firstly calculate the alpha for the individual variables, individual factors for both the three and two factor models. Lastly a scale alpha is produced for each model. The results from the reliability analysis of the eleven individual items accounted for an alpha coefficient of .92, which would suggest acceptable internal consistency. No substantial increases in alpha could have been achieved by eliminating more items. According to the guidelines developed by George and Mallery (2003), all three factors in the a priori model have alpha coefficients that suggest acceptable internal reliability $.90, .84$, and .88 respectively. The overall scale alpha was .81. The alternative two-factor model produced alphas of .90 for social network structure and, .94 for social capacity. The scale alpha was recorded as .83 . Having analysed the a priori model for reliability and producing a set of alpha coefficients that suggest acceptable levels of internal consistency, the next stage in the 
investigation of perceived community efficacy and its potential to measure community preparedness is to explore the relationships of both factor models, socio-demographic variables and a dependent variable. The use of regression analysis and in particular hierarchical regression analysis was selected to examine the relationship of a number of predictor variables to a dependent variable and measure the individual contribution to variance for each. The following section describes a hierarchical regression and its value in determining contribution to variance. Cohen and Cohen (1983) indicate a multiple regression analysis may be used when the dependent variable is quantitative and a study utilizes the dependent variable the relationship among independent variables. In this research the dependent variable is an adapted efficacy scale from Carroll et al. (2005). A frequently used method for the analysis of data involving multiple independent variables is Multiple Regression (Leech et al., 2003). The purpose of a hierarchical regression analysis is to examine whether one or more predictor variables can account for variance in the dependent variable in addition to the variance already accounted for by the other predictor variables (Dewberry, 2004). Before the HRA is carried out an investigation must be carried out on the adapted scale to ensure statistical soundness (DeVellis, 2005).

\subsection{Analysis of the Scale, Prepared Community}

As a Hierarchical Regression Analysis (HRA) will be used in the exploratory stage it was necessary to identify a suitable dependent variable with which to compare the predictor variables. A search of suitable established scales was undertaken where those with properties similar to perceived community efficacy may have provided a useful criterion. No such scale was found, however the CCSE scale (Carroll et al., 2005) had potential to be adapted. Seven items were adapted in order to develop a scale that could be utilised in the HRA. An Exploratory Factor Analysis was carried out on the variables developed as a reference point for the models. Table 11. provides the 
descriptive statistics for the seven items returned values where the mean ranged from $M$ $=3.27$ to $M=3.17$ and the standard deviation from $S D=1.22$ to $S D=1.178$. There were no correlation coefficients $r>.9$ indicating no issues of singularity (Field, 2005). The determinant value for the data was $1.473 \mathrm{E}-4$ suggesting that there were no multicollinearity issues between the variables.

Table 11. Results Exploratory Factor Analysis for Prepared Community.

\begin{tabular}{lllllllllll}
\hline & \multicolumn{3}{c}{ Std } & & & & & & & \\
Item & Mean & Dev & 1 & 2 & 3 & 4 & 5 & 6 & 7 & Alpha \\
\hline 1 & 3.17 & 1.20 & - & .85 & .82 & .82 & .87 & .85 & .84 & .99 \\
2 & 3.24 & 1.18 & & - & .89 & .89 & .85 & .89 & .89 & .98 \\
3 & 3.23 & 1.19 & & & - & .88 & .87 & .88 & .89 & .98 \\
4 & 3.25 & 1.19 & & & & - & .89 & .85 & .88 & .98 \\
5 & 3.22 & 1.22 & & & & & - & .89 & .89 & .98 \\
6 & 3.26 & 1.20 & & & & & & - & .88 & .98 \\
7 & 3.27 & 1.22 & & & & & & & - & .98 \\
\hline
\end{tabular}

Determinant $=1.473 \mathrm{E}-4$

The KMO statistic was generated at .98 , which is above the recommended value of .5 (Kaiser, 1974). Bartlett's test of sphericity has an 'acceptable' value of $p<.05$. The null hypothesis was disproved generating a value of $\mathrm{p}<0.0001,\left(\chi^{2}(501)=6399.586, p<\right.$ $.0001)$. The eigenvalues indicate that a single factor structure explained $91 \%$ of the variance. The Scree plot illustrated a unidimentional structure at the cut off point and provides support for the Kaiser Criterion result. The Kaiser's criterion is deemed to be accurate when sample size exceeds 300 and the average communality is greater than .60 (Field, 2005). All the communality values exceeded .6 and together with a sample greater than 300 in this case $(\mathrm{N}=501)$, the Kaiser criteria was accurate at extracting 1 factor. Internal consistency was measured using Cronbach's alpha, which returned a value of .98. The CFA produced a CMIN/DF value of 4.07 is within the margins of the larger acceptable range $<5$. The NFI, TLI and CFI values were $.98, .97$ and .98 respectively and as all scores exceeded .95 , were deemed to be acceptable. The PCFI 
was adequate recording a score of .62. The RESEA was .075 and the PCLOSE score was .05 indicating both values to be within the acceptable range. The results of this analysis appear to suggest that the adapted seven item scale may be suitable be used as the dependent variable in the hierarchical regression analysis. The dependent variable is named "prepared community" as it reflects the high degree of preparation undertaken by the respondents.

\subsection{Hierarchical Regression Analysis}

A hierarchical multiple regression analysis was carried out to examine whether the factors within the a priori model and the two factor alternative model made a significant contribution to the variance in the dependent variable, prepared community, after controlling for age, gender, ethnicity, high flood intervention and low flood intervention. As the categorical, predictor variable risk zone had more than two levels of response it was necessary to recode the variable. This was achieved by using the nondichotomous variable and creating three dummy variables that were be used to present part of the information captured by the original variable (Dewberry, 2004). The three, new dichotomous variables represented high flood intervention (hi_interornot), low flood intervention (low_interornot and no flood intervention (no_flood) and were numbered 1 to 3 respectively. The two variables that were of interest as predictors of prepared community were high intervention and low intervention as both variables may account for the level of variance in the dependent variable. These were added to the set of variables used in the hierarchical regression analysis. The first set of results represent the a priori model with 3 factors and the second set of results represent the alternative two factor model.

\subsubsection{HRA results for the a priori model}


Results for the a priori model provided no evidence of multicollinearity as the maximum recorded VIF $=4.872$, substantially below the cutoff value of 10 (O'brien, 2007). Descriptive statistics and correlations between the variables entered into the model are presented in Table 12. The results of the regression analysis are summarised in Table 13. The mean scores for the variables in the hierarchical regression analysis $(N$ $=487$ ) were recorded as prepared community, $M=3.24, S D=1.15$; community network structure $M=3.03, S D=1.05$; social capital, $M=3.85, S D=0.89$; and community capacity, $M=3.87, S D=0.76$. The zero order correlations were shown to be strong between the dependent variable, prepared community and the predictor factor, community network structure, $r=.71, p<.05$ and moderate for social capital, $r=.55, p$ $<.05$, and community capacity $r=.51, p<.05$. The variable, high intervention also demonstrating a moderate strength correlation, $r=.60, p<.01$. The correlations for the remaining variables were negligible, gender $(r=.05, p<.05)$, age $(r=-.12, p<.05)$, ethnicity $(r=-.03, p<.05)$ and, low community intervention $(r=-.08, p<.05)$.

Table 12. Correlations between predictor variables and prepared community.

\begin{tabular}{|c|c|c|c|c|c|c|c|c|c|c|c|}
\hline Variables & Mean & $\begin{array}{l}\text { Std. } \\
\text { Dev }\end{array}$ & $\begin{array}{r}\text { prep_ }_{-} \\
\text {com }\end{array}$ & gen & age & ethnic & $\begin{array}{r}\text { inter } \\
\text { high }\end{array}$ & $\begin{array}{r}\text { inter_- } \\
\text { low }\end{array}$ & $\mathrm{sc}$ & cns & $\mathrm{cc}$ \\
\hline prep_coc & 3.24 & 1.15 & - & .05 & -.12 & -.03 & .60 & -.08 & .55 & .71 & .51 \\
\hline Gender & 1.40 & 0.49 & & - & -.06 & .11 & .02 & -.06 & .06 & .05 & .02 \\
\hline Age & 43.62 & 13.17 & & & - & -.09 & .05 & .11 & -.07 & -.05 & -.06 \\
\hline Ethnicity & 1.48 & 1.05 & & & & - & .12 & -.19 & -.13 & .01 & -.18 \\
\hline inter_high & 0.43 & 0.49 & & & & & - & -.37 & -.25 & -.48 & -.21 \\
\hline inter_low & 0.16 & 0.36 & & & & & & - & -.19 & -.01 & -.16 \\
\hline $\mathrm{Sc}$ & 3.85 & 0.89 & & & & & & & - & .50 & .88 \\
\hline $\mathrm{Cns}$ & 3.03 & 1.05 & & & & & & & & - & .47 \\
\hline $\mathrm{Cc}$ & 3.87 & 0.76 & & & & & & & & & - \\
\hline
\end{tabular}

The results for the full regression model show that $47 \%$ of the variation in prepared community can be explained by the five variables in the first model, $F(5,481)=86.43$ that was statistically significant $p<.0 .05)$. The second model, $F(3,478)=98.58$ 
included the additional three factor variables community network structure, social capital and community capacity and showed an increase in $R^{2}$ from .47 to .68 accounting for approximately $20 \%$ increased variance. The second model was also statistically significant $(p<.0 .05)$ with the three factor variables showing values of $(p<$ $.047, p<.042, p<.044)$ respectively. The standardised coefficients or beta values give an indication of the relative importance of the predictor variables in uniquely accounting forward variants in the dependent variable. The greater the beta value, positive or negative, the more important the predictor variable is in accounting for unique variance in the dependent variable (Dewberry, 2004, p.273).

Table 13. Regression of prepared community and predictor variables

\begin{tabular}{|c|c|c|c|}
\hline Variables & & $B$ & Beta \\
\hline prep_com & & 1.401 & .243 \\
\hline Gender & & .032 & .062 \\
\hline Age & & -.004 & .002 \\
\hline Ethnicity & & .010 & .030 \\
\hline inter_high & & 1.018 & .078 \\
\hline inter_low & & -.613 & .096 \\
\hline $\mathrm{Sc}$ & & .171 & .075 \\
\hline cns & & .421 & .037 \\
\hline \multirow[t]{3}{*}{$\mathrm{Cc}$} & & .139 & .085 \\
\hline & $R=.82$ & & \\
\hline & $R^{2}=.68$ & & \\
\hline Adjusted & $R^{2}=.67$ & & \\
\hline
\end{tabular}

The predictor variables, High Intervention has a Beta value of .73 and Low Intervention as a value of -.35. In this model, High Intervention is the most important predictor of the variance in the dependent variable Prepared Community. Both High Intervention and Low Intervention are statistically significant with values .03 and .04 respectively, indicating that the variance is not by chance alone. In the second model where the predictor variables, Social Capital, Community Network Structure and Community Capacity are added, the $p$. value of High Intervention and Low Intervention increased to .44 and .19 respectively and are not statistically significant. Taken as an individual 
predictor variable, High Intervention is still the most important variable accounting for the greatest unique variance in the dependent variable. However the cumulative effect of the three factors representing the a priori model produced a greater cumulative beta value of .56. Therefore the cumulative effect of the a priori model explained the greater $B$ value and hence accounted for the greatest variance in the dependent variable. The predictor variables High Intervention and Low Intervention are not statistically significant; yet all three a priori variables, social capital, community network structure and community capacity remain statistically significant demonstrating that the unique variance is not accounted for by chance alone.

\subsubsection{The results for the two factor model}

Results for the alternative two factor model provided no evidence of multicollinearity as the maximum recorded VIF $=1.483$, substantially below the cutoff value of 10 (O’brien, 2007). Descriptive statistics and correlations between the variables entered into the model are presented in Table 14 . The results of the regression analysis are summarized in Table 15. The mean scores for the variables in the hierarchical regression analysis $(N=487)$ were recorded as prepared community, $M=3.24, S D=$ 1.15; community network structure $M=3.03, S D=1.05$; social capacity, $M=30.81, S D$ $=6.37$. The zero order correlations were shown to be strong between the dependent variable, prepared community and the predictor factor, community network structure, $r$ $=.71, p<.05$ and moderate for social capacity, $r=.55, p<.05$. The variable, high intervention also demonstrated a moderate strength correlation, $r=.60, p<.01$. The correlations for the remaining variables were negligible, gender $(r=.05, p<.05)$, age $(r$ $=-.12, p<.05)$, ethnicity $(r=-.03, p<.05)$ and, low community intervention $(r=-.08$, $p<.05)$. 
Table 14. Correlations between predictor variables and prepared community.

\begin{tabular}{lccccccccccr}
\hline Variables & Mean & $\begin{array}{c}\text { Std. } \\
\text { Dev }\end{array}$ & $\begin{array}{c}\text { prep_- } \\
\text { com }\end{array}$ & gen & age & $\begin{array}{r}\text { Ethni } \\
\text { c }\end{array}$ & $\begin{array}{c}\text { inter_ } \\
\text { high }\end{array}$ & $\begin{array}{c}\text { inter_ } \\
\text { low }\end{array}$ & sc & cns & cc \\
\hline prep_com & 3.24 & 1.15 & - & .05 & -.12 & -.03 & .60 & -.08 & .55 & .71 & .51 \\
Gender & 1.40 & 0.49 & & - & -.06 & .11 & .02 & -.06 & .06 & .05 & .02 \\
Age & 43.62 & 13.17 & & & - & -.09 & .05 & .11 & -.07 & -.05 & -.06 \\
Ethnicity & 1.48 & 1.05 & & & & - & .12 & -.19 & -.13 & .01 & -.18 \\
inter_high & 0.43 & 0.49 & & & & & - & -.37 & -.25 & -.48 & -.21 \\
inter_low & 0.16 & 0.36 & & & & & & - & -.19 & -.01 & -.16 \\
Sc & 3.85 & 0.89 & & & & & & & - & .50 & .88 \\
Cns & 3.03 & 1.05 & & & & & & & & - & .47 \\
Cc & 3.87 & 0.76 & & & & & & & & & - \\
\hline
\end{tabular}

The results for the full regression model show that $47 \%$ of the variation in prepared community can be explained by the five variables in the first model, $F(5,481)=86.43$ that was statistically significant $p<.0 .05)$. The second model, $F(2,479)=146.31$ included the additional two factor variables and social capacity and showed an increase in $R^{2}$ from .47 to .67 accounting for approximately $20 \%$ increased variance. The second model was also statistically significant $(p<.0 .05)$ with the two factor variables showing values of $(p<.042$, and $p<.049)$ respectively.

Table 15. Regression of predictor variables

\begin{tabular}{lccc}
\hline Variables & & $B$ & Beta \\
\hline prep_com & & 1.401 & .243 \\
Gender & & .032 & .062 \\
Age & & -.004 & .002 \\
Ethnicity & & .010 & .030 \\
inter_high & & 1.018 & .078 \\
inter_low & & -.613 & .096 \\
Sc & & .171 & .075 \\
cns & & .421 & .037 \\
Cc & & .139 & .085 \\
& & & \\
& $R=.82$ & & \\
& $R^{2}=.68$ & & \\
Adjusted & $R^{2}=.67$ & & \\
\hline
\end{tabular}

The predictor variables, High Intervention produced a Beta value of .73 and Low Intervention, a value of -.35. In this model, High Intervention was the most important 
predictor of the variance in the dependent variable Prepared Community. Both High Intervention and Low Intervention were statistically significant with values .03 and .04 respectively, indicating that the variance is not by chance alone. In the second model where the predictor variables, community network structure and social capacity were added, the $p$. value of High Intervention and Low Intervention increased to .49 and .2.3 respectively and are not statistically significant. Taken as an individual predictor variable High Intervention was still the most important variable due to accounting for the greatest unique variance in the dependent variable. However the cumulative effect of the two factors representing the alternative model produced a greater cumulative beta value of .60. Therefore the cumulative effect of the two-factor model explained the greater Beta value and hence accounted for the greatest variance in the dependent variable. The predictor variables High Intervention and Low Intervention are not statistically significant; yet both variables, community network structure and social capacity are statistically significant demonstrating that the unique variance is not accounted for by chance alone.

\section{Summary}

A hierarchical multiple regression analysis was carried out to examine whether the factors within the a priori model and the two factor alternative model made a significant contribution to the variance in the dependent variable, prepared community, after controlling for age, gender, ethnicity, high flood intervention and low flood intervention. Both factor models returned encouraging results where the $R^{2}$ value in each increased on their addition to the second regression block $\left(R^{2}=.59, R^{2}=.60\right)$. Although the two-factor model marginally improved the contribution to variance the overall difference between the a priori and the two-factor model is negligible. 


\section{Confirmatory Phase}

\subsection{Confirmatory Factor Analysis}

The two models were subjected to a maximum-likelihood CFA using AMOS 20 (Arbuckle, 2011). Table 16. presents the fit statistics for the two models. Several fit indices were examined to evaluate the overall fit of each model. The chi-square goodness-of-fit statistic was statistically significant for both models, suggesting that neither fit the data. However, the chi-square statistic is sensitive to sample size, so it is rarely used as a sole index of model fit. An adjunct discrepancy-based fit index is the ratio of chi-square to degrees of freedom $(\chi 2 / d f)$. Schumacker and Lomax (2004) suggest that ratios between the hypothesized models and the sample data should be in the range of 3 to 5 indicating an adequate fit and 2 to 3 , a good fit.

Table 16. Fit Indices for Three Factor and Two Factor models

\begin{tabular}{lll}
\hline & \multicolumn{1}{c}{ Factors } \\
Fit Indices & 3fac11var & 2fac11var \\
\hline CMIN/DF & 11.787 & 11.623 \\
NFI & 0.810 & 0.809 \\
TLI & 0.797 & 0.797 \\
CFI & 0.822 & 0.822 \\
PRATIO & 0.863 & 0.876 \\
PCFI & 0.709 & 0.720 \\
RMSEA & 0.148 & 0.147 \\
PCLOSE & 0.000 & 0.000 \\
AIC & 1671.916 & 1671.489 \\
\hline
\end{tabular}

Note. $\mathrm{CMIN} / \mathrm{DF}=\chi^{2}$ likelihood ratio statistic; NFI= Normed Fit Index; TLI $=$ TuckerLewis Index; CFI = Comparative Fit Index; RMSEA = Root Mean Square Error of Approximation; PCLOSE $=p$ value for testing close fit; AIC $=$ Akaike Information Criterion; $p<.001$

Using the CMIN/DF, both the a priori model value (11.787) and alternative model value (11.623) demonstrated unacceptable fit. Three incremental indices of fit were examined next: the normed fit index (NFI), the comparative fit index (CFI), and the Tucker-Lewis index (TLI). Incremental indices reflect the improvement in fit gained by a given factor model relative to the most restrictive (null or independence) model. All three 
incremental indices are scaled from 0 (no fit) to 1 (perfect fit). Hu and Bentler, (1999) advised that values close to .95 are indicative of good fit. By this standard, the a priori model produced values of $\mathrm{NFI}=0.810, \mathrm{TLI}=0.797, \mathrm{CFI}=0.822$ and therefore did not indicate a good fit (Leach et al, 2008, Byrne 2007). Comparing the same fit indices, the alternative model did not demonstrate a good fit producing values of NFI $=0.810$, TLI $=0.797, \mathrm{CFI}=0.822$. The PCFI results show that both models, though less complex than the independence model, have relatively high efficiency values of showing a high degree of complexity. Finally, the root mean square error of approximation (RMSEA) is a population discrepancy function that compensates for the effects of model complexity. The closer the RMSEA coefficient is to 0 , the better the fit of the model. According to Schumacker and Lomax (2004) a RMSEA value of .05 or less indicates a close fit of the model in relation to the degrees of freedom, whereas a value of .08 or less indicates a reasonable error of approximation. The PCLOSE value supports the RMSEA and is the probability test where the value returned should be $\mathrm{p}>.05$. Both models had RMSEA coefficients outside the acceptable range where the a priori model had a coefficient of 0.148 and the alternative model, 0.147 . The PCLOSE values were 0.00 for the a priori and alternative models showing significance at $p>.05$. In terms of a better-fit comparison between the a priori and alternative models, the index, Akaike Information Criterion was used where the lower value indicates a better-fit model (Lee et al., 2008). A value of 1671.916 was recorded for the a priori model and 1671.489 for the alternative indicating that at this stage the two-factor structure may be a better model at this stage. Given that this is not a measure of actual fit but a comparison between models, the values, whilst showing some preference for the alternative model are at this stage not significant due to the poor fit of both models indicated by the previous set of fit indices. The goodness-of-fit statistics did not meet the criterion cutoffs indicative of 2 good fit established for this study in that the $\chi$ likelihood ratio exceeded 3.0 and/or 5.0, 
the relative fit indices were not close to .95 , the parsimony results showed a high level of complexity, the RMSEA values exceeded .05, and PCLOSE values did not reach .05 . Taken together, these eight indices suggested that the a priori model and the alternative model were not a reasonable fit for the data.

\subsubsection{Modification Indices}

A further analysis was carried out and although improvements in the fit indices were identified, the results did not meet the criterion cut-offs indicative of good fit established for this study. The values recorded for the fit indices were, CMIN/DF = $10.374, \mathrm{NFI}=.837, \mathrm{TLI}=.821, \mathrm{CFI}=.850, \mathrm{PCFI}=.711, \mathrm{RMSEA}=.135$ and the PCLOSE $=.000$ indicating that the model still contained points of misfit. The standardized residual covariance output was then used to identify values that may be problematic. Variable 27, Members of the community meet regularly to plan for events including emergency preparedness produced a value of 12.854 , which was significantly greater that other covariance values was deleted and resulted in the indices improving to an acceptable level. Table 17. provides the values recorded at the last iteration.

Table 17. Fit Indices for Two Factor, Ten Item Model

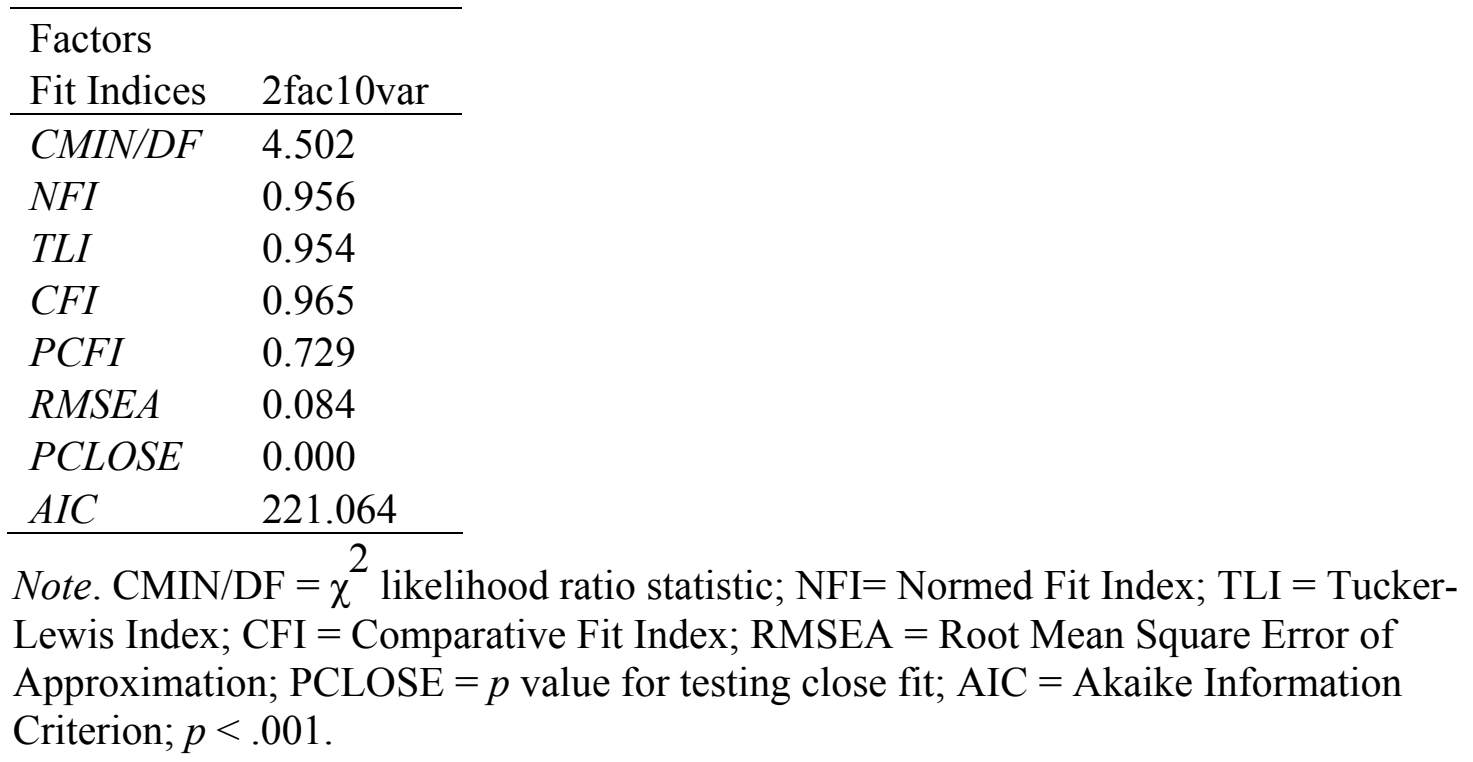


The CMIN/DF value is just within the acceptable range of between 3-5. The NFI, TLI and CFI are greater than .95 indicating a good fit with the PCFI indicating an adequate fit only. Of the remaining indices, the RMSEA $>.08$ produced a mediocre fit and PCLOSE not meeting an acceptable cutoff criterion levels of $>.05$. The a priori, three factor model was examined in the same manner as the alternative model. The values recorded for the fit indices were, $\mathrm{CMIN} / \mathrm{DF}=8.209, \mathrm{NFI}=.901, \mathrm{TLI}=.890, \mathrm{CFI}=$ $.871, \mathrm{PCFI}=.759, \mathrm{RMSEA}=.121$ and the PCLOSE $=.000$ indicating that the model contained points of misfit. The standardized residual covariance output was examined to identify high values that may be problematic in model fit. Variable 27, 'Members of the community meet regularly to plan for events including emergency preparedness' produced a value of 12.857 , which was greater that other covariance values. An iterative process, of identifying, deleting and reinstating variables resulted in an improvement in the model fit indices. Table 18. provides the values recorded at the last iteration.

Table 18. Fit Indices for Three Factor, Ten Item Model

\begin{tabular}{ll}
\hline Factors & \\
Fit Indices & 3fac10var \\
\hline$C M I N / D F$ & 2.953 \\
$N F I$ & 0.971 \\
$T L I$ & 0.973 \\
$C F I$ & 0.981 \\
PCFI & 0.695 \\
RMSEA & 0.063 \\
PCLOSE & 0.057 \\
AIC & 191.175 \\
\hline
\end{tabular}

Note. $\mathrm{CMIN} / \mathrm{DF}=\chi^{2}$ likelihood ratio statistic; NFI= Normed Fit Index; TLI = TuckerLewis Index; CFI = Comparative Fit Index; RMSEA = Root Mean Square Error of Approximation; PCLOSE $=p$ value for testing close fit; AIC $=$ Akaike Information Criterion; $p<.001$

The CMIN/DF value is just within the acceptable range of between 1-3. The NFI, TLI and CFI are greater than .95 indicating a good fit with the PCFI indicating an adequate 
fit only. Of the remaining indices, the RMSEA was less than .08 and the PCLOSE was greater than .05 indicating an acceptable fit for both values. There is also one extra test to consider that is used to compare models. The AIC (Akaike, 1987) is a method of assessing information loss during CPA and awarding a score the lower of which indicates the better model. The interpretation of these findings suggest that there is strong evidence that the a priori, three factor model is the best representation of the structure of responses from the survey data (Leach et al., 2008). Table 19. Shows the structure of item, item label and element for the final model structure.

Table 19. Item, item label and element structure for a priori model.

\begin{tabular}{|c|c|c|}
\hline Item & Item label & Element \\
\hline 33 & $\begin{array}{l}\text { The community has a well-organised structure capable of managing } \\
\text { preparedness activities }\end{array}$ & \multirow{3}{*}{$\begin{array}{l}\text { Community } \\
\text { Network } \\
\text { Structure }\end{array}$} \\
\hline 34 & $\begin{array}{l}\text { The community has an informal structure to assist with emergency } \\
\text { preparedness }\end{array}$ & \\
\hline 40 & $\begin{array}{l}\text { Our community has formal arrangements with organisations that can assist in } \\
\text { preparing for an emergency }\end{array}$ & \\
\hline 17 & $\begin{array}{l}\text { I am certain that we can create a positive community spirit whilst preparing for } \\
\text { an emergency }\end{array}$ & \multirow{3}{*}{$\begin{array}{l}\text { Social } \\
\text { Capital }\end{array}$} \\
\hline 31 & $\begin{array}{l}\text { As a community we will work with relevant organisations and agencies to help } \\
\text { prepare us for emergencies }\end{array}$ & \\
\hline 39 & $\begin{array}{l}\text { The strong network bonds that exist in our community will ensure we } \\
\text { undertake preparedness activities }\end{array}$ & \\
\hline 2 & We are all committed to being prepared for weather related emergencies & \multirow{4}{*}{$\begin{array}{l}\text { Community } \\
\text { Capacity }\end{array}$} \\
\hline 28 & $\begin{array}{l}\text { In an emergency, I believe we will take care of those most vulnerable in our } \\
\text { community }\end{array}$ & \\
\hline 37 & $\begin{array}{l}\text { Some members of the community will be able to undertake the more difficult } \\
\text { tasks in emergency preparedness }\end{array}$ & \\
\hline 38 & $\begin{array}{l}\text { Our community has members with sufficient skills and knowledge to prepare } \\
\text { for emergencies }\end{array}$ & \\
\hline
\end{tabular}

At this stage the variables have demonstrated acceptable levels of content validity, two differing factor models emerging from the EFA and the a priori model indicating 
acceptable levels from the fit indices as an output from the CFA. Although these aspects can contribute towards the overall construct validity of the intended scale, reliability or internal consistency is also required in order to estimate the performance of a set of variables in measuring the same construct or phenonema (DeVellis, 2003).

\subsection{Summary}

The research design called for a systematic analysis of the data to develop a scale that was valid and reliable in order to measure differing levels of perceived community efficacy in the domain of emergency preparedness. The data were prescreened before analysis and it was discovered that statistical assumptions related to normality, linearity and homoscedasticity were violated. Data were then transformed so that specific tests in relation to scale development could be employed. The Exploratory Factor Analysis found the data to be factorable and representative of the a priori model and an alternative two-factor model. The HRA results showed the cumulative effect of the three factors representing the a priori model produced a greater cumulative beta value of .56. Therefore the cumulative effect of the a priori model explained the greater $B$ value and hence accounts for the greatest variance in the dependent variable. All three a priori variables were statistically significant, demonstrating that the unique variance is not accounted for by chance alone. The study examined socio demographic factors age, gender and ethnicity and found no direct relationship between age, ethnicity and gender and the response data. An expected finding was the correlation of high community interventions to the criterion scale. The variable high intervention was found to be have a strong, positive correlation of $r=.60$ with the criterion scale.

Reliability was analysed for internal consistency using Cronbach's alpha. The results provided evidence of the validity and reliability of the measure developed through out this research project. The a priori model and subsequent scale development produced a three factor, eleven-item scale that was found to be internally consistent with a 
coefficient alpha of .92. This compared favourably with the criterion scale, CCSE where Benight (2004, p.407) cites an alpha coefficient of .96 for the original scale. The scale was found to have a multidimensional factor structure accounting for $75.5 \%$ of total variance. The loadings for the 11 items ranged from $r=.45$ to .72 . Construct validity was a cumulative process of analysis including the factorability of the data, Pearson product-moment correlation of inter-item and between factors correlations, content validity, and reliability coefficient (Bandura, 2000, p. 319). The Confirmatory Factor Analysis of the two models resulted in the a priori demonstrating an adequate fit for the indices selected for the research. The quantitative approach has permitted the examination of issues, which are difficult to evaluate using purely qualitative means. It has also provided strong support for the dimensional structure of perceived community efficacy outlined in the qualitative research. As this thesis is built on a mixed methods approach it is necessary to integrate the qualitative and quantitative phases of the research. Chapter six provides a detailed discussion of the combined findings of this research. 


\section{Chapter 6.0 Discussion, Conclusion and, Recommendations}

\subsection{Introduction}

This thesis has adopted mixed methodology combining qualitative and quantitative methods in pragmatic approach to investigate the utility of perceived community efficacy in preparing for emergencies. The theoretical contribution is provided based on the outcome of tis research. The key findings from both studies are presented and used as a framework to guide the discussion. The findings of each approach have been detailed in chapters four and five respectively and will now be combined in order to build an integrated discussion. The conclusions provided cover issues within the research such as household resilience; the predictive nature of perceived community efficacy; participation and involvement of community members; the use of informal methods of engagement and the use of mixed methods in research of this type. The professional relevance is identified and presented with the study limitations. The research limitation provides an insight into the sample population and issues of validity whilst the professional relevance focuses on the practical use of the scale. There are three recommendations covering engagement strategies; flood risk awareness strategies and further research and development in the field.

\subsection{Main Findings and Theoretical Contribution}

The main findings will assert that social cognitive theory and more specifically perceived community efficacy, has a utility in the measurement of community beliefs in the domain of emergency preparedness. Theoretical contribution is also established where this research has added new knowledge to and extended the scope of social cognitive theory. Three individual constructs taken from community based research domains; community network structure, social capital and community capacity were integrated to form a new composite model that was used to investigate how social and community aspects influence beliefs and behaviours of residents. The contribution of 
this model to community based theory and in particular perceived community efficacy has been generate new knowledge on how all three constructs influence a community's collective beliefs and actions. A new scale has been developed that was able to illicit new knowledge regarding perceived community efficacy as a predictor of the likelihood of a community in undertaking preparedness measures in an emergency. Being able to predict likely future performance or behaviours is key to understanding whether or not a community might protect themselves against an imminent disaster. The research has established the application of social cognitive theory in disaster and emergency research and extends the current body of knowledge on community preparedness research.

Finding one - Participating residents could describe their community in terms of geographical layout including streets and local amenities. They were also able to estimate the size of their perceived community in terms of population. However they appeared only to identify with immediate neighbours when it came to assisting each other.

Finding Two - A number of participants appeared not to be engaged with the rest of the community including immediate neighbours. They expressed a clear wish not to be associated with the rest of the community.

Finding Three - Residents within the sample population appeared to prefer informal structures and disliked engaging in formal structures. That is to say formal agencies or organisations representing for instance the county council or environment agency. In undertaking any community orientated activity most preferred an informal environment or structure in which to engage other residents.

Finding Four - There is evidence to suggest that the sample population believed the rest of the community would collectively prepare for a severe weather emergency. Finding Five - Many of the participants had expressed a desire for someone to take charge. Leadership of the group was called for with participants expressing a need to be 
organised and in the initial stages to be cajoled to initiate preparedness activities.

Finding Six - An overall observation in summarising the outcome of qualitative data is that it produced a general perception that the sample populations were able to collectively undertake actions that resolved local issues.

Finding Seven - The study examined socio demographic factors, age gender and ethnicity and found no direct relationship between these and the response data. This is at odds with the findings of Duncan et al. (2003, pp. 251) where they found that age was a significant predictor of perceived community efficacy.

Finding Eight - The Exploratory Factor Analysis found the data to be factorable and representative of the 3 factor a priori model. An alternative 2-factor model emerged from the data and was added to the overall investigation.

Finding Nine - Validity and reliability as psychometric properties have been combined as findings. Content validity was measured using the CVI index where both items and scale recorded acceptable values. Reliability was analysed for internal consistency using Cronbach's alpha. Factors Community Network Structure, Social Capital, and Community Capacity have alpha coefficients that suggest adequate internal reliability. Construct validity was a cumulative process of analysis including the factorability of the data, Pearson product-moment correlation of inter-item and between factors correlations, content validity and reliability coefficient. An overall assessment of the inputs into construct validity would suggest that the construct of perceived community efficacy has a value in measuring community preparedness.

Finding Ten - Hierarchical regression analysis was used to compare adapted items from the CCSE scale and response data. The cumulative effect of the three factors representing the a priori model produce a greater cumulative beta value and accounted for the greatest variance in the dependent variable. All three a priori variables are statistically significant demonstrating that the unique variance is not accounted for by 
chance alone. The variable High Intervention was found to have a strong, positive correlation with the criterion scale and as such, a strong predictor variable.

Finding Eleven - The indices selected from the CFA resulted in an adequate fit for the a priori model.

\subsection{Discussion}

Research on perceived community efficacy in relation to the domain of natural hazards preparedness has been limited by the existing instruments for measuring the construct. The research findings suggest that the construct of community efficacy has value in measuring the perceptions of community residents in undertaking collective actions to prepare for natural hazards. The concept of community efficacy is reliant on effective network structures where residents help each other to overcome difficult issues. In describing their community, respondents were able to detail the wider geographic and population properties but appeared only to identify with a small group of neighbours. Masten and Obradovic $(2007$, p.8) discuss the link between community efficacy and individual and family resilience and the challenge of distinguishing neighbourhood and community effects from individual, family or close group functioning. It would seem that in the context of a community, the way in which an individual or group (neighbours) contribute to preparing the community for an emergency may be similar to the normal interactions using the same network structure. That is, families and neighbours getting together at a very local level making decisions and acting upon them. This notion is supported by the quantitative study where, within the dimension of community network structure, respondents believed that a 'network of friends, family and neighbours' are essential for the community to act collectively in times of need. Wang and Kapucu (2007, p.59) find that individual preparedness decisions are made in social context in which decisions are influenced by decisions of others such as family 
members friends or neighbours. This suggests that at a neighbourhood level, community efficacy is the shared capacity for achieving an intended effect that is enacted through the decisions of small but close networks of residents.

Almost as a complete contrast to findings of an inclusive nature, some residents were at odds with collective action and did not want to be involved with the community. A number of participants appeared not to be engaged with the rest of the community including immediate neighbours. They expressed a clear wish not to be associated with any of the other residents within the community. This finding is important as there appears to be no sense of community need or engagement both of which are needed if community efficacy is to be effective in improving community resilience (Paton and Johnson, 2001, p.274). Further more individuals who perceive themselves as having no investment in the community may develop a level of detachment which, following a natural hazard event, increases feelings of vulnerability (Paton and Johnson, 2001, p.273). The resources required for strong networks of individuals are information exchange, reciprocal actions and trust (Kilpatrick and Abbot-Chapman, 2005). Within the dimension of social capital these aspects were measured in the survey and respondents were found to have strong beliefs that these resources contributed to the social wellbeing of community members. Paton (2007, p.377) regards trust and information exchange between residents as essential in determining actions for confronting natural hazards. Paton (2007) also encourages discussion of hazards within local community forums and faith groups to create collective understanding of local risks and relevant preparedness measures.

Community theory describes residents' identification with a neighbourhood and the ways in which their connections to their community influence their involvement in local organisations and buffer feelings of isolation (Wandersman \& Florin, 2000). McMillan and Chavis (1986) observe that neighbourhood members' needs will be met 
through their commitment to be together (p. 9). Browning and Cagney (2002) observe that theory and research on urban social disorganization may explain the cause for social anonymity and social disconnection.

The term hard to reach, hard to influence has been used to describe people who due to social factors have become withdrawn, recluse like and do not engage in community activities. Haradine, (2004) provides a number of reasons why this particular group of residents develop these types of behaviours including social isolation, language barriers, past negative experience and service providers not developing effective strategies to engage with this particular group.

Having considered these reasons, it would seem that if effective strategies were developed then aspects of isolation, language and past experience would be taken into consideration and adaptations made to existing or new engagement methods. However it may not be due to the above factors and may be down to self-choice or self-exclusion where potential participants choose to exclude themselves for a number of reasons (Skidmore, 2006). Individuals may decide that being an active citizen is not for them, or that being denied the chance to participate becomes a rallying point for alternative forms of collective action or lastly, they think their interests may be better served by shifting the focus into other, less formal arenas where the rules work more in their favour (Skidmore, 2006).

Whilst in itself an interesting finding, disengagement, does not account for the fact that a group of individuals who were not engaged, took part in the interviews nor do any of the above factors shed light on whether the individuals' households were resilient to natural hazards. The last reason, 'less formal arenas' provided by Skidmore (2006), however, resonates closely to another finding both in the qualitative and quantitative studies. Residents within the sample population appeared to dislike engaging in formal structures; that is to say formal agencies or organisations representing county councils 
or non-government agencies, for example. In undertaking any community orientated activity most preferred an informal environment or structure in which to engage other residents. Although there were strong levels of beliefs for informal networks this did not extend to having a well-organised structure to coordinate with organisations. Therefore as an indicator of Perceived Community Efficacy, the level of beliefs associated with this item would suggest low PCE.

These findings are in contrast to Mancini (2005, p. 573) where he describes formal engagement between communities and service providers as significant for promoting social wellbeing of community members. However, if community members will not engage in activities that have formal undertones then informal structures will need to be identified to provide pathways for undertaking preparedness activities. This belief also relates to working with agencies to help prepare for emergencies. Within the survey, responses indicated that participation, a sub-dimension of social capital, was a belief that was strongly supported. This belief relates to participation in informal settings and supports the notion that the respondents believed they would participate with organisations but on an informal footing.

Grassroots community organisations are cited by Ohmer, (2007) as being positively related to civic responsibility and community efficacy (p.111). Paton and Johnson (2001) suggest that the levels of perceived credibility of formal agencies may affect community interaction with them and that factors of enhanced resilience were correlated with the level of involvement in community activities such as membership of clubs and socially active groups (p.274). The informal theme is extended into the next finding where there is evidence to suggest that the sample population believed the rest of the community would collectively prepare for a severe weather emergency. Both the quantitative and qualitative findings provided evidence to supported the dimension of 'community capacity' and the sub-dimension 'shared responsibility for the general 
welfare of the community and its individual members'. The three items that emerged from the EFA and CFA contained key phrases in the items such as 'responsible for welfare of others', 'we are all committed to ensure people are safe' and 'take care of the most vulnerable'. In the example given, the respondent cites an informal approach to prevent flooding in and around the community that encompasses the shared responsibility for the welfare of others.

Although there were good examples from the residents' transcripts of grassroots participation providing collective solutions, Sampson (2002) advises that the potential for social ties to influence outcomes is only reached when a group's sense of collective efficacy is sufficiently strong enough to compel members into action in pursuit of desired organised outcomes. This compulsion may be explained by the obligatory nature of relationships. The community network structure contains the sub-dimension of voluntary and obligatory relationships formed at community level that represent a well organised network of friends and neighbours who can assist in preparedness activities. The survey respondents believed strongly that voluntary and obligatory relations were present in their community and contributed to the preparedness activities.

Wilson and Musik's work on developing an integrated theory of volunteering (1997, p. 700) describes informal volunteering as having an obligatory element especially when the actors involved are helping friends and neighbours outside the household. Wilson and Musik further contend that obligations have a more powerful influence on informal helping than formal volunteering (p. 701). It is important to note that in identifying the informal nature of helping and that it may be limited to friends and neighbours, relates directly to the previous findings on community identity (immediate neighbours) and the effectiveness of informal collective actions (socially active groups).

This far, collective action in engaging in preparedness activities would appear 
involve residents who live close to each other, the organisation of activities is informal (and may include those who generally don't get involved) and there is a collective belief in achieving a positive outcome. To summarise at this point, Parisi et al (2002, p. 21) provides at useful framework of actors, goals and publics where community efficacy embodies actors that are local residents; the goals represent local interests; and the publics are the beneficiaries of the goal oriented actions and are not necessarily the actors. In extending this model to preparedness activities, a likely scenario is where a group of residents set and achieve preparedness goals that reduce risk from natural hazards and provide a benefit to all community members. The scenario is reflective of the volunteer helper theme where individuals or groups provide skills and knowledge that underpin community activities.

A sub-dimension within community capacity is collective competence to confront situations, which in the case of hazard reduction entails the skills and knowledge to carry out preparedness activities. The requirement for collective competence was again evident in both studies where the survey found strong support for the belief that community members had sufficient skills to prepare for emergencies. However within the qualitative study, a very specific and unexpected skill set was identified. The finding related to the issue of leadership at a very localised community level. Many of the participants had expressed a desire for someone to take charge. Leadership of the group was called for with participants expressing a need to be organised and in the initial stages to be cajoled to initiate preparedness activities.

Previously in this discussion, the pursuit of desired organised outcomes was identified, however there was no dialogue regarding the specific of organisation of people and resources to achieve expected outcomes. Perceived Community Efficacy plays a key role in human functioning because it positively affects behaviours related to goals, aspirations and outcome expectations (Bandura, 2000). A group's outcomes are 
in part, the product of shared knowledge and skills within the group (p. 75). Ohmer (2007, p. 116) found that the more volunteers were involved in everyday activities and participation at neighbourhood level the greater their leadership competence and ability to influence. It is leadership skills that may exert influence in order to attain group goals and realise outcome expectations. Pescolido (2001) suggest that informal leaders exert influence over other group members to increase performance as well as influencing their sense of collective efficacy (p. 79). Pescolido (2001) further suggests that the role of informal leaders is most important at the initial stages of activities in order to bring order to where there be ambiguity and chaos. In relation to the finding, this maybe exactly what is required to "get things going".

The next finding under discussion is essentially an observation in summarising the outcome of qualitative and quantitative data and that it produced a general perception that the sample populations were able to collectively undertake actions that resolved local issues even through there was a degree of difficulty. Bandura (2006, p. 308) describes this as a belief in the ability to undertake sustained engagement in taxing activities. An example from the qualitative transcription adequately articulates sustained engagement and at the same time the activities would appear to be demanding.

The theorising and research on human agency has had its focal point almost entirely on personal influence exercised individually (Bandura, 2006, p. 316). To a degree this is also reflected in the research on self-efficacy, however this personal agentic capacity extends to the collective beliefs of groups and communities (Bandura, 1982, p. 143). In the case of community efficacy, people's shared beliefs in their collective power to produce desired results will secure what they could not accomplish on their own (Bandura, 2006, p. 316). Identified in the literature review there are also numerous examples provided in the qualitative study that indicates that the sample of residents have experiences of collective actions that have achieved community or group 
expectations. Supportive data is also found in the quantitative findings where the respondents' beliefs are supportive of the strong bonds at local level that ensure preparedness activities are undertaken. This belief is representative of the subdimension within 'social capital' that is grounded in Bandura's assertion above regarding collective actions being more effective than individual efforts (Bandura, 2006, p. 316).

In the example above, the community exhibits aspects of community efficacy where their collective beliefs were instrumental in getting together to overturn the proposal. That experience where outcome expectancy is achieved will re-enforce positive efficacy beliefs and in turn support further community problem solving. This notion is explained in the efficacy literature by the sources of information that shape efficacy beliefs. A mastery experience is the most powerful source of efficacy information where the perception that a performance has been successful tends to raise efficacy beliefs, contributing to the expectation that performance will be successful in the future (Bandura, 1982, p. 126; Goddard, 2004, p. 5). The perception that a performance has been unsuccessful tends to lower efficacy beliefs and will lower expectations of success in future endeavours (Zulkosky, 2009, p. 97). It is therefore important in community preparedness that initial activities secure successes on which to build on, thereby continually increasing levels of efficacy beliefs. Bandura (1982, p.145) calls for 'proximal goals' to provide incentives and evidence of successful progress.

Having largely discussed the findings in relation to community efficacy and its relation to community activities, the next part of the discussion will focus on socio demographic factors that are important in understanding the their affects on community beliefs and behaviours. The study examined socio demographic factors, age, gender and ethnicity and found no direct relationship between ethnicity and gender and the 
response data. Smith (2000) also found that gender was not related to levels of selfefficacy in a study using the perceived self-efficacy scale. Fernández-Ballesteros, Juan Díez-Nicolás, Caprara, Barbaranelli, and Bandura (2002) however, found age to be highly correlated with efficacy beliefs. The HRA results in this study found that age was not predictive of the dependent variable and as such not correlated to efficacy beliefs at a community level. Benight (2004) included socio demographic factors in measuring the affects of community efficacy post disaster where very little correlation was found between age, ethnicity, gender, and community efficacy. The focus of this study has its domain within disaster research, which is similar to that of Benight (2000). The domain in which the research carried out by Fernández-Ballesteros et al. (2002) has its focus in social change and influence. The dissimilarity in the findings regarding age and efficacy beliefs may therefore be due to the difference in domains however this might be the subject of future research.

Cutter (2003) observes that age, gender, and ethnicity are clearly defined factors contributing to social vulnerability and extends this to include minorities being at a higher risk from natural disasters due to location. The higher percentage of ethnic minority responses together with the flood risk locations would appear to support Cutter's observation with regard to social vulnerability and environmental hazards. That is to say that a higher percentage of ethnic minorities are vulnerable due to their location and exposure to natural hazards such as flooding. There is also a link between ethnic minorities, higher risk from flooding and social deprivation where Shaw et al. (2006, p.106) posits that 'minority' ethnic groups are often in poor socio-economic positions. Research undertaken by Walker (2006, p. 5) found that for all types of flooding, deprived populations are more likely to be living within flood risk zones. Whilst this is the case for some of the respondents it is not the case for all the ethnic minority population that took part in the survey. 
The hierarchical regression analysis found that age, gender, and ethnicity provided extremely small correlations that would indicate that there was no relationship, positive or negative, between these variables and the variables representing high levels of perceived community efficacy. This is in contrast to community efficacy research carried out by Duncan et al. (2003), where ethnicity was a significant predictor of perceived community efficacy. As a means of explaining the difference in findings, socio-economic indicators for both Chesterfield and South Derbyshire (Derbyshire County Council, 2010) suggest that areas at risk from flooding are not limited to those described are socially deprived. An important point here is that vulnerability associated with natural hazards may, but does not necessarily equate with social deprivation. Deprived communities can be expected to contain concentrations of vulnerable households however, not all vulnerable individuals including the elderly and ethnic minorities are located within deprived communities (Walker, 2006).

Having examined the socio demographic factors the discussion turns to the findings of the instrumentation of the item pool. The extant literature has included a number of models for self, collective and community efficacy (Bandura, 2006; Benight, 2004; Carroll, et al., 2005; Smith, 2000). Most of the studies have selected specific items from associated scales that may share similar properties to perceived community efficacy. Although the scales have been developed in different domains, the method used to develop them and the inherent psychometric properties provide a useful comparison for this research. Exploratory factor analysis is used in both this research and the scales used as comparisons. The main purpose of exploratory factor analysis is to establish the factorability of a pool of items in a data set. The general value of exploratory factor analysis is exploratory where the researcher expects to generate a factor model to help explain the theory. This research used exploratory factor analysis to initially test a three dimension, a priori model. The initial findings supported both a 
three and two factor model. Whilst the three factor model was expected, the two factor model provided initial statistical outputs that were encouraging as they were similar to the a priority model. Carroll et al. (2005) provides information on a factor analysis where four factors were extracted using principled component analysis explaining $63 \%$ of the total variance suggesting that the CCE scale is a multidimensional construct. However several items loaded on more than one factor and the variance was disproportionately explained by the first factor. The initial findings of Carroll et al. (2005) are similar to the findings of this research and may be due to both research studies measuring properties of the same construct. Smith (2000) provides an account of the development of and psychometric evaluation of a self-efficacy scale. Although the focus is on self-efficacy, similar properties are relevant for collective and community efficacy skills (Bandura, 2006). Smith, (2000) in developing a self-efficacy scale found that after examining a scree test, a single unidimensional factor structure best represented the data. The eigenvalue was reported as $40.7 \%$ of variance for a single factor solution. Confirmatory factor analysis is used to determine how close the factors represent the data set and is termed, goodness of fit. The findings suggest that although 30 items were deleted, the model produced statistics indicating adequate goodness of fit for the data. Duncan and Englert (2011) and Carter and Bates (2013) use EFA and CFA to provide evidence of factorability, goodness of fit for their data, and use similar fit indices as this research. Carter and Bates (2013) provide descriptions of similar methods of model modification and justify this by the redundancy of items and goodness of fit statistics (p.14). In partial support of the main research question and the measurement of the construct, the findings of this research and the examples provided above demonstrates the factorability of the construct of perceived community efficacy where the data produced both multi and unidimensional scales. Further support for the research question is provided by the adequacy of the goodness of fit statistics produced from a 
confirmatory factor analysis.

Validity and reliability as psychometric properties were combined in the findings in order to structure the discussion and provide focus on the topic. The discussion will initially look at reliability and compare these research findings with other scales. Validity is discussed with the importance of providing a sound psychometric instrument. Benight (2004) developed a collective efficacy scale and although they do not provide detailed information on scale development, they do however provide some useful comparative data on validity and reliability. Reliability may be calculated in a number of ways, but the most commonly accepted measure in field studies for assessing a scale's internal consistency and the method used in this research is Cronbach's alpha. This measure allows a judgement to be made as to how well which tells how well the developed items measure the same construct and is essential if the instrument is to claim to be psychometrically sound (Hinkin, 1995). A large coefficient alpha normally equal to or greater than .70 provides an indication of strong item covariance or homogeneity and suggests that the sampling domain has adequately been captured (Hinkin, 1995). The a priori model and subsequent scale development produced a three factor, ten-item scale that was found to be internally consistent with a coefficient alpha of .92 . This compared favourably with the, CCSE scale where Benight (2004, p.407) cites an alpha coefficient of .96 for the original scale. Satisfactory reliability estimates for internal consistency of $.81, .90,78$ and .94 are reported in separate studies by Ashill and Jobber (2010); Carroll et al. (2005); Neff (2003), and Smith (2000). Only Smith (2000) reports unsatisfactory results where a social self-efficacy subscale produced an alpha of .63 and was not considered appropriate for research purposes. The reliability coefficient produced by this research is adequate to claim that the developed items all measure the same construct and that the strong item covariance suggests that the sampling domain has adequately been captured. 
Having discussed and compared reliability, attention is turned to validity. The first type of validity to be measured in this research was content validity using the CVI index where both items and scale recorded acceptable values. $(\mathrm{N}=40), .86$ and $(\mathrm{N}=7)$, .88 for the full item pool. Few of the selected research papers report on content validity however this is due to the methods in which they used to construct scales which was largely by adapting existing scale items. Ashill and Jobber (2010) report on content validity and the use of subject matter experts in assessing the fit of an item to a particular construct. Whilst a similar method was adopted in this research the results of the SME assessment was then subject to statistical analysis, providing rigour, which help to address the issue of subjectiveness usually leveled at the content validity process (Ashill \& Jobber, 2010, p.1290). This was assessed using hierarchical multiple regression to compare adapted items from the CCSE and response data. The cumulative effect of the a priori model explains the greater $B$ value and accounts for the greatest variance in the dependent variable. All three a priori variables are statistically significant, demonstrating that the unique variance is not accounted for by chance alone. The dependent variable was the scale adapted from the CCSE scale (Benight, 2004). The scale measured collective beliefs in preparedness activities that were associated with high levels of perceived community efficacy. The a priori model was able to account for a sufficient level of variance in the dependent variable thereby having predictive properties. This finding is important as it supports the main research question demonstrating it has measurement properties. Furthermore it addresses research question four by identifying the variables, community network structure, social capital and, community capacity as predictor variables of perceived community efficacy.

The last element of validity is construct validity and according to Benson and Clark (1982) is the most difficult form of validity to obtain. Hinkin (1995) suggests that a stable factor structure provides evidence of construct validity whereas Bandura (2006) 
observes that it is a cumulative process of analysis including the factorability of the data, correlation of inter-item and between factors correlations, content validity, concurrent validity outcomes and reliability coefficient (p.319). Several criteria have been already been proposed for assessing the psychometric soundness of psychometric measures. This research has demonstrated content validity, internal consistency, and parsimony. All contribute to providing evidence of construct validity. Hinkin (2005, p.164) advises that the process of accumulation must involve statistical rigor and integrity and in this way contribute to increasing the confidence in the overall construct validity of the new scale. An overall assessment of the outcomes developed throughout this research would suggest a minimum acceptable level has been reached in attaining construct validity.

The last finding in this discussion relates to a dummy variable that was developed to control for whether or not respondents believed there was a high level of community preparedness for flooding. The variable High Intervention (Hi_inter) was found to be have a strong, positive correlation of $r=.60$ with the dependent variable. High Intervention was also a strong predictor variable where it recorded a value of $B=$ .44. This strong association with the criterion scale in not unexpected as previously discussed the scale represents high levels of preparedness. Therefore as a predictor variable that indicates high levels of preparedness there would be a strong relationship between High Intervention and the dependent variable. It is an important finding as it supports the a priori model. This notion is based on the high levels of perceived community efficacy being associated with high levels of community preparedness.

\subsection{Conclusions and Recommendations}

This research has presented evidence from the literature review that natural disasters are a combination of a natural hazard event and a vulnerable population. Social 
vulnerability is related to both the natural hazard end the level of vulnerability created by social end economic factors. The researcher believes increasing resilience in national infrastructure against terrorism will also mitigate against natural hazards and therefore increase resilience for local communities that may rely on critical infrastructure for power, water or even employment. Resilience can be achieved through mitigation but more importantly and perhaps far less costly, community level preparedness can be extremely effective in providing higher levels of local and household resilience. Research into community preparedness has focused on information and how community members receive this. However measuring a community disposition to carry out collective preparedness measures other than evacuation has received little attention. Social cognitive theory and more specifically efficacy beliefs provide a valuable insight into why a community prepares or does not prepare. Perceived community efficacy is therefore a construct that lends itself to the measurement of the phenomena associated with efficacy beliefs and preparedness. In my research, this relates to a community's beliefs in collective actions that reduce the effects of natural hazards. Perceived community efficacy can measure and predict performance, therefore high levels of perceived community efficacy will predict the likelihood that a community will undertake preparedness actions.

Performance accomplishments and vicarious experiences are likely to increase efficacy beliefs end therefore should be operationalised to articulate what this mean for community engagement in preparedness measures. Successful participation and involvement with other communities who have prepared may increase local efficacy beliefs leading to higher levels of residents' engagement in collective actions to reduce risk from natural disasters.

Measuring perceived community efficacy in a community would provide an indication of the level of belief that the community will engage in preparedness 
activities. Although there were a number of findings, both qualitative and quantitative, the overall assessment of the research is that the sample population believed that they and other residents in the community would engage in preparedness actions. This study found that informal methods are preferred over more formal engagement and that, apart from a few community members, most respondents were likely to engage in preparedness measures. Informal engagement strategies that are able to involve all residents within a community and have a focus of household preparedness would significantly add to the level of resilience at a community level.

Mixed methods as the methodology provides the researcher with a pragmatic approach to problem investigation. Applying different methods provides a strength of approach not available in single method studies. A sequential approach in this research used, qualitative methods to provide rich data to develop an item pool and quantitative methods to provide the statistical methods to provide and ensure sound psychometric properties. Mixed methods, therefore, is an appropriate methodology for this research and more generally in developing measurement scales for specific domains.

\subsection{Research Limitations}

The sample populations resided within the same large county and it is unclear whether the research will generalise to other communities in other counties or for that matter in other countries. The construct validity was based on the cumulation of validity and reliability sources and did not include a specific method to provide a statistical evaluation. This may be an area for future research and development of the current scale. Although the construct has acknowledged predictive properties, sound psychometric evaluation would provide statistical evidence for this claim. 


\subsection{Professional Relevance}

The data collected by the practical application of the scale would provide supplementary information for community risk assessments and the level of resilience afforded by local preparedness measures. The scale provides an approach for emergency managers to assess the likelihood of local communities to undertake preparedness activities in order to reduce the effects of natural hazards. Where high levels of efficacy beliefs are indicated there is evidence to suggest that the community will engage in the preparedness activities. When deploying first line protective resources for community use, the scale data may be useful to determine what, when and more importantly who should receive these resources. Where this indication is low then deploying such resources for a community to use maybe ineffective.

\subsection{Recommendations}

This study found that informal methods are preferred over more formal engagement and that, apart from a few community members, most respondents were likely to engage in preparedness measures. Informal engagement strategies that are able to involve all residents within a community and have a focus of household preparedness would significantly add to the level of resilience at a community level. Increasing the level of community resilience should involve strategies that concentrate on engaging with residents through local, informal channels such as faith groups and social activities groups.

The samples of respondents were residents that lived in flood-risk zones. This research identified that a significant percentage of respondents did not realise the risk from flooding to their properties. Strategies should therefore be developed that provide resources to local residents that both develop risk awareness and increase the likelihood of undertaking preparedness activities. 
In the event of a major natural disaster, communites may well have to fend for themselves for considerable periods of time, it is therefore essential that emergency management organisations identify the likihood of community members in participating in preparitory activites to reduce the level of community risk. Valid and reliable measurement tools represent a crucial step in the assessment and evaluation of community resilience. This scale may contribute to future measurement and preparedness efforts within sphere of natural hazards and emergencies and therefore should undergo further assessed and development in the field.

The aim of the study was to develop a psychometric instrument as a means of better understanding the role of community efficacy in relation to emergency preparedness in local residential communities.

\subsection{Summary}

This chapter initially presented the theoretical contribution, qualitative, and quantitative findings. The discussion integrated the findings and identified support for both hypotheses and research questions. Important findings were identified referenced and supported by other studies where similar or differences were recognised. The way in which an individual or group (neighbours) contribute to preparing the community for an emergency may be similar to the normal interactions using the same network structure. However some residents did not engage with the community. The term hard to reach was used to describe people who due to social factors do not engage in community activities. It is suggested that the reasons why this particular group of residents develop these types of behaviours include social isolation, language barriers, past negative experience and service providers not developing effective strategies to engage with this particular group. However it may not be due to the above factors and may be down to self-choice or self-exclusion where potential participants choose to exclude themselves 
for a number of reasons. Residents within the sample population appeared to dislike engaging in formal structures and in order to address this it is suggested that informal structures will need to be identified to provide pathways for undertaking preparedness activities. In identifying the informal nature of helping and that it may be limited to friends and neighbours. This related directly to previous findings on community identity (immediate neighbours) and the greater effectiveness of informal collective actions (socially active groups). It was also proposed that informal leaders exert influence over other group members to increase performance as well as influencing their sense of collective efficacy and that collective actions are more effective than individual efforts in undertaking preparedness measures. However in order for collective actions to be effective it is important in community preparedness that initial activities secure successes on which to build on, thereby continually increasing levels of efficacy beliefs. Proximal goals are called for to provide incentives and evidence of successful progress. Socio demographic factors gender, age and, ethnicity were found to have no direct relationship with the response data. This was found to be in contrast in other studies involving community efficacy. An important point discussed was that vulnerability associated with natural hazards may, but does not necessarily equate with social deprivation. The data was found to be factorable and produced a three-factor structure to support the a priori model. The factor structure also produced adequate goodness of fit statistics. Reliability and validity were established and all psychometric properties compared favourably to the results of other published test reports. This research has demonstrated content validity; internal consistency and parsimony that contribute to providing evidence of construct validity. An overall assessment of the outcomes developed throughout this research would suggest there is collective evidence in support of construct validity. The discussion also identified the strengths of a mixed methods approach where findings were supported by evidence from both a qualitative and 
quantitative perspective. The professional relevance is identified and presented with the study limitations. The conclusions provided cover issues within the research such as household resilience; the predictive nature of perceived community efficacy; participation and involvement of community members; the use of informal methods of engagement and the use of mixed methods in research of this type. The research limitation provides an insight into the sample population and issues of validity whilst the professional relevance focuses on the practical use of the scale. There are three recommendations covering engagement strategies; flood risk awareness strategies and further research and development in the field. 
References

Abraham, C., \& Sheeran, P. (2005). The health belief model. In M. Conner \& P. Norman (Eds.), Predicting health behaviour: Research and practice with social cognition models $\left(2^{\text {nd }}\right.$ ed.). Buckingham, UK: Open University Press

Adeola, F. O. (2009). Katrina Cataclysm: Does Duration of Residency and Prior Experience Affect Impacts, Evacuation, and Adaptation Behavior Among Survivors? Environment and Behavior, 41(4), 459-489.

Agrawal, A., \& Gibson, G. (1999). Enchantment and disenchantment: the role of community in natural resource conservation. In: M.Pelling, (Ed.), Natural Disasters and development in a globalizing world (pp.95-109). Oxon. Routledge.

Aguirre, B. E., Wenger, D., \& Rico, G. (1998). A Test of the Emergent Norm Theory of Collective Behavior. Sociological Forum, 13, 301-320.

Ajzen, I, (1991). The theory of planned behaviour. Organizational Behaviour and Human Decision Processes, 50, 179-211.

Akaike, H. (1987). “Factor Analysis and AIC,” Psychometrika, 52, 317-332.

Alexander, D. E. (1993). Natural Disasters. London: UCL Press.

Alexander, D.E. (2000). Confronting Catastrophe: New Perspectives on Natural Disasters. Harpenden, UK: Terra and Oxford University Press.

Alexander, D.E. (2002). Principles of emergency planning and management. Harpended, Terra Publishing.

Alexander, D.E. (2005). Towards the development of a standard for emergency planning. Disaster Prevention and Management. 14(2), 158-175.

Ali, H., \& Birley, S. (1999). Integrating deductive and inductive approaches in a study of new ventures and customer perceived risk. Qualitative Market Research: An International Journal. 2(2), 103-110.

Anderson, M.B. (2000). Vulnerability to Disaster and Sustainable Development: A General Framework for Assessing Vulnerability. In R. Pielke, Jr. and R. Pielke Sr., (Eds.), Storms (pp.11-25), London: Routledge.

Anderson, W.A. (2008). Mobilization of the Black Community Following Hurricane Katrina: From Disaster Assistance to Advocacy of Social Change and Equity. International Journal of Mass Emergencies and Disasters. 26(3), 197-217.

Andrews, D.A., Bonta, J., \& Wormith, J.A. (2006). The recent past and near future of risk and/or need assessment. Crime Delinquency, 52(7) doi:10.1177/0011128705281756

Arbuckle, J. L. (2007). Amos 18 user's guide. Chicago: SPSS Inc. 
Ashill, N.J., \& Jobber D. (2010). Measuring state, effect, and response uncertainty: theoretical construct development and empirical validation. Journal of Management, 36(5), 1278-1308. DOI: 10.1177/0149206308329968

Bach, R., \& Kaufman, D.J. (2009). A social infrastructure for hometown security: advancing the homeland security paradigm. Homeland and Security Affairs, 5(2), 2-13.

Baguley, T. (2012). Serious stats: A guide to advanced statistics for the behavioral sciences. Basingstoke: Palgrave.

Baird, A., O'Keefe, P., Westgate, K.N., \& Wisner, B. (1975). Towards an explanation and reduction of disaster proneness, Occasional paper no.11, University of Bradford, Disaster Research Unit. Retrieved from http://www.pccwg2.gov/njlite_download.php?id=5553

Bandura, A. (1977). Self-efficacy: The exercise of control. New York: W.H. Freeman.

Bandura, A. (1986). Social foundations of thought and action: A social cognitive theory. Englewood Cliffs, NJ: PrenticeHall.

Bandura, A. (1988). Organizational Application of Social Cognitive Theory. Australian Journal of Management, 13(2), 275-302.

Bandura, A. (1989). Self-Efficacy Mechanism in Human Agency. American Psychologist, 37(2), 122-147.

Barnard, C. (1938). The functions of the executive. Cambridge, MA: Harvard University Press.

Bandura, A. (1993). Perceived self-efficacy in cognitive development and functioning. Educational Psychologist, 28(2), 117-148.

Bandura, A. (1997). Self efficacy: The exercise of control, New York: W. H. Freeman and Company.

Bandura, A. (2000).Exercise of human agency through collective efficacy. Current Directions in Psychological Science, 9(3), 75-78.

Bandura, A. (2002) Social Cognitive Theory in Cultural Context. Applied Psychology: An International Review, 51(2), 269-290.

Bandura, A. (2006). Guide for constructing self-efficacy scales. In F. Pajares \& T. Urdan (Eds.), Self-efficacy beliefs of adolescents, 5, 307-337.

Bankoff, G. (2001). Rendering of the world unsafe, 'vulnerability' as Western discourse, Disasters, 25,19-35.

Beavers, A.S., Lounsbury, J.W., Richards, J.K., Huck, S.W., Skolits, G.J., Shelley L., \& Esquivel, S.L. (2013). Practical considerations for using exploratory factor analysis in educational research. Practical Assessment, Research \& Evaluation, 18(6), 1-13. Received from http://pareonline.net/getvn.asp? $\mathrm{v}=18 \& \mathrm{n}=6$ 
Beck, C.T., \& Gable, R.K. (2001). Ensuring content validity: An illustration of the process. Journal of Nursing Measurement, 9, 201-215.

Benight, C. C. (2004). 'Collective efficacy following a series of natural disasters', Anxiety, Stress \& Coping. 17(4), 401- 420.

Bennett, P., \& Murphy, S. (1997). Psychology and Health Promotion. Buckingham: Open University Press.

Benson, J., \& Clark, F. (1982). A Guide for Instrument Development and Validation. The American Journal of Occupational Therapy, 36(12), 789-800.

Blaikie, P., Cannon, T., Davis, I., \& Wisner, B. (1994). At Risk: Natural Hazards, People's Vulnerability, and Disasters. London: Routledge.

Blunch, N. J. (2008). Introduction to structural equation modeling using SPSS and AMOS. Thousand Oaks, CA: Sage Publications.

Boin, A. (2005). Disaster research and future crises: broadening the research agenda. International Journal of Mass Emergencies \& Disasters, 23(3), 199-214.

Bolin, R. (2006). Race, Class, Ethnicity, and Disaster Vulnerability. pp.113-129 in Handbook of Disaster Research, (Eds.), H. Rodríguez, E.L. Quarantelli, \& R.R. Dynes. New York: Springer.

Bollen, K.A. (1989). Structural Equations with Latent Variables. New York: JohnWiley \& Sons, Inc

Boyatzis, R. (1998). Transforming qualitative information. Thousand Oaks, CA: Sage Publications.

Braun, V., \& Clarke, V. (2006). Using Thematic Analysis in Psychology. Qualitative Research in Psychology, 3(2), 77-101.

Breckler, S.J. (1990). Applications of Covariance Structure Modeling in Psychology: Cause for Concern? Psychological Bulletin. 107(2), 260-273.

Brennan, M.A., \& Flint, C.G. (2007). Uncovering the hidden dimensions of rural disaster mitigation: capacity building through community emergency response teams. Southern Rural Sociology 22(2), 1-5.

Brennan, M.A., Barnett, R.V., \& Flint, C.G. (2007). Community volunteers: The Front Line of Disaster Response, The Journal of Volunteer Administration, 24(4), 71-77.

Brodie, M., Weltzien, E., Altman, D., Blendon, R. J., \& Benson, J. M. (2006). Experiences of Hurricane Katrina Evacuees in Houston Shelters: Implications for Future Planning. American Journal of Public Health, 96(8), 1402-1408.

Brown, J. D. (1996). Testing in language programs. Upper Saddle River, NJ: Prentice Hall. 
Brown, J.D., \& Damery, S.L. (2002). Managing flood risk in the UK: towards a integration of social and technical perspectives, Transactions of the Institute of British Geographers, New Series, 27(4), 412-426.

Brown, T.A. (2006). Confirmatory factor analysis for applied research. New York: Guilford Press.

Browning, C.R. \& Cagney, K.A. (2002) Neighborhood structural disadvantage, collective efficacy, and self-rated physical health in an urban setting Journal of Health and Social Behavior, 383-399

Bruneau, M., Chang, S.E., Eguchi, R.T., Lee, G.C., O'Rourke, T.D., ...Reinhom, A.M., (2003). A Framework to Quantitatively Assess and Enhance the Seismic Resilience of Communities, Earthquake Spectra, 19(4), 733-752.

Bryant, E. (1991). Natural Hazards. Cambridge: Cambridge University Press

Bryman, A. (2006). Paradigm peace and the implications for quality. International Journal of Social Research Methodology, 9(2), 111-126.

Bryman, A. (2008). Social Research Methods, ( $3^{\text {rd }}$ ed.). Oxford: Oxford University Press.

Bryman, A. and Bell, E. (2007). Business Research Methods, (2 ${ }^{\text {nd }}$ ed.). Oxford: Oxford University Press.

Bulmer, M. (1979). Social Research Methods, Macmillan: London.

Burningham, K., Fielding, J., \& Thrush, D. (2008). 'It'll never happen to me:' understanding public awareness of local flood risk. Disasters, 32(2), 216-238.

Burnside, R., Miller, D.S., \& Rivera, J.D. (2007). The impact of information and risk perception on the hurricane evacuation decision-making of greater new orleans residents. Sociological Spectrum, 27, 727-740.

Burt, R. S. (2001). Structural holes versus network closure as social capital. In N. Lin, K. Cook, \& R. S. Burt, (Eds.), Social capital: Theory and research (pp. 31-56). New York: Aldine de Gruyter.

Burton, I., Kates, R.W., \& White, G.F. (1993). The Environment as Hazard (2 ${ }^{\text {nd }}$ ed.), New York: Guildford.

Burton, M, L., \& Hicks, M. J. (2005). Hurricane Katrina: Preliminary Estimates of Commercial and Public Sector Damages, Marshall University: Center for Business and Economic Research.

Butler, J.K. (1991). Toward understanding and measuring conditions of trust: Evolution of a conditions of trust inventory. Journal of Management, 17, 643-663.

Byrne, B.M. (2013). Structural Equation modeling with AMOS: Basic concepts, Application, and Programming, (2 ${ }^{\text {nd }}$ ed.), New York: Routledge.

Byrne, B. M., Stewart, S. M., Kennard, B. D., \& Lee, P. W. H. (2007). The Beck Depression Inventory-II: Testing for measurement equivalence and factor mean 
differences across Hong Kong and American adolescents. International Journal of Testing, 7(3), 293-309.

Cabinet Office. (2005, March 31). Central Government Arrangements for Responding to an Emergency.Retrieved from:

http://www.cabinetoffice.gov.uk/media/132685/conops.pdf

Cabinet Office. (2009). Civil Contingencies Act. Retrieved from:

http://www.cabinetoffice.gov.uk/ukresilience/preparedness/ccact.aspx\#part2

Cabinet Office (2011). Preparing for Emergencies: Guide for communities, London. Civil Contingencies Secretariat. Retrieved from:

http://www.cabinetoffice.gov.uk/ukresilience/

Cabinet Office (2013). Emergency Response and Recovery: Non statutory guidance accompanying the Civil Contingencies Act 2004, London. Civil Contingencies Secretariat. Received from http://www.cabinetoffice.gov.uk/ukresilience/

Campion, M. A., Metzger, G. J., \& Riggs, A. C. (1993). Relations between work group characteristics and effectiveness: Implications for designing effective work groups. Personnel Psychology, 46, 823-850.

Carroll, J.M., Rosson, M.B., \& Zhou, J. (2005). Collective efficacy as a measure of community. Proceedings of the SIGCHI Conference on Human Factors in Computing Systems, Portland, Oregon, April 2-7.

Cardona, O.D. (2003) The Need for Rethinking vulnerability and Risk from a Holistic Perspective: A necessary review and criticism for effective management. In Bankoff, G., Frerks, G., \& Hilhorst, D. (Eds.), Mapping Vulnerability: Disasters, Development and People. London, Earthscan.

Cattell, R.B. (1966). The scree test for the number of factors. Multivariate Behavioral Research. 1(2), 245-76.

Charmaz, K. (2000). Grounded theory: Objectivist and constructivist methods. In: Dentin, N.K. and Lincoln, S. (Eds.), Handbook of Qualitative Research. Thousand Oaks. CA: Sage.

Chaskin, R.J. (1999). Defining Community Capacity: A Framework and Implications from a Comprehensive Community Initiative. Chicago: The Chapin Hall, Center for Children at the University of Chicago

Cherryholmes, C. H. (1992). Notes on pragmatism and scientific realism. Educational Researcher, 4, 13-17.

Christiansen, N.D. \&. Tett, R.P. (Eds.). (2013). Handbook of Personality at Work. New York: Routledge.

Christoplos, I. (2003). Actors in risk. In: M.Pelling, (Ed.), Natural Disasters and development in a globalizing world, pp.95-109, Oxon. Routledge.

Cockburn, A., St. Clair, J., \& Silverstein, K. (1999). The politics of "natural" disaster: who made mitch so bad? International Journal of Health Services, 29(2), 459-46. 
Conner, M., \& Norman, P. (Eds.). (2005). Predicting health behaviour: Research and practice with social cognition models. Buckingham: Open University Press

Cooper, J.M. (2007). Cognitive Dissonance: 50 years of a classic theory. London: Sage Publications Ltd.

Coppolla, D.P. (2007) Introduction to International Disaster Management. London: Butterworth-Heinemann Ltd.

Costello, A.B., \& Osborne, J.W. (2005). Best practices in exploratory factor analysis: four recommendations for getting the most from your analysis. Practical Assessment, Research \& Evaluation. 10(7), 1-9.

Corring, D.J. and Cook, J.V. (2007). Use of qualitative methods to explore the qualityof-life construct from a consumer perspective, Psychiatric Services, 58, 240-244.

Crabtree, B.F., \& Miller, W.L. (1999). Using codes and code manuals: a template organizing style of interpretation, in B.F. Crabtree, \& W.L. Miller, (Eds.), Doing Qualitative Research, $\left(2^{\text {nd }}\right.$ ed.). Thousand Oaks, CA.: Sage Publications

Crain, W. (2000). Theories of development: Concepts and applications (4th ed.), London: Prentice-Hall.

CRED (Centre for Research on the Epidemiology of Disasters) (2015). Report on Human Cost of Natural Disasters. A global perspective. Brussels: Université catholique de Louvain. Retrieved from: http://www.cred.be/publications

Creswell, J.W. (2003). Research design: Qualitative, quantitative and mixed approaches, Thousand Oaks, CA: Sage.

Creswell, J. W., \& Tashakkori, A. (2007). Exploring the nature of research questions in mixed methods research. Journal of Mixed Methods Research, 1(3), 207-211.

Creswell, J. W., \& Zhang, W. (2009). The application of mixed methods designs to trauma research. Journal of Traumatic Stress, Nov., 1-10.

Creswell, J.W., \& Plano Clark, V.L. (2011). Designing and Conducting Mixed Methods Research, (2 ${ }^{\text {nd }}$ ed.), Thousand Oaks, CA: Sage.

Cronbach, L.J. (1951). Coefficient alpha and the internal structure of tests.

Psychometrika,16(3), 297-334.

Crocker, L., Llabre, M., \& Miller, M.D. (1988). The generalizability of content validity ratings. Journal of Educational Measurement, 25, 287-299.

Crotty, M. (1998). The foundations of social research: meaning and perspective in the research process, London: Sage.

Cuny, F. C. (1983) Disasters and Development. New York: Oxford University Press,

Cutter, S.L. (1996). Vulnerability to environmental hazards. Progress in Human Geography, 20, 529-539. 
Cutter, S.L. (Ed.), (2001). American Hazardscapes: The Regionalization of Hazards and Disasters. Washington, D.C.: Joseph Henry Press.

Cutter, S.L., Mitchell, J.T., \& Scott, M.S. (2000). Revealing the vulnerability of people and places: a case study of Georgetown County, South Carolina, Annals of the Association of American Geographers, 90(4), 713-737.

Cutter. S.L., Boruff, B.J., \& Shirley. W.L. (2003). Social vulnerability to environmental hazards, Social Science Quarterly, 84(1), 242-261.

Cutter, S.L., Barnes, L., Berry, M., Burton, C.G., Evans, E., Tate, E.C., \& Webb, J. (2008). A place-based model for understanding community resilience to natural disasters. Global Environmental Change, 18, 598-606.

Cutter, S.L., Burton, C.G., \& Emrich, C. (2010). Disaster resilience indicators for benchmarking baseline conditions. Journal for Homeland Security and Emergency Management, 7(1), 1-22.

Davis, L.L. (1992). Instrument review: Getting the most from a panel of experts. Applied Nursing Research, 5, 194-197.

DeCarlo, L. T. (1997). On the meaning and use of kurtosis. Psychological Methods, 2, 292-307.

Delgado, M. (2000). New arenas for community social work practice with urban youth: Use of the arts, humanities, and sports. Columbia University Press.

DeMarchi, B., Scolobig, A., Delli Zotti, G., \& Del Zotto, M. (2007). Risk construction and social vulnerability in Italian alpine region. FLOODsite report T11-06-08. Institute of International Sociology. Gorizia

DeVellis, R.F. (2003). Scale Development: Theory and Applications, Newbury Park, CA: Sage Publications.

Dewberry, C. (2004). Statistical Methods for Organizational Research: Theory and Practice. London: Routledge.

Doyle, L., Brady. M, \& Byrne. G, (2009) Overview of Mixed Methods Research, Journal of Research in Nursing, 14, 175-185.

Dow, K. (1992). Exploring Differences in Our Common Future(s): The Meaning of Vulnerability to Global Environmental Change, Geoforum, 23(3), 417-436.

Drabek, T. (2004). Theories relevant to emergency management versus a theory of emergency management, in: Emergency Management Higher Education Conference, National Emergency Training Center, Emmitsburg, Maryland, June, 2004.

Drabek, T. (2005). Sociology, Disasters and Emergency Management: History, Contributions, and Future Agenda Disciplines, Disasters and Emergency Management, in: D. A. McEntire, (Ed.), The Convergence and Divergence of Concepts, Issues and 
Trends from the Research Literature, Federal Emergency Management Agency, Emergency Management Institute.

Drabek, T. (2007). Social Problems Perspectives, Disaster Research and Emergency Management: Intellectual Contexts, Theoretical Extensions, and Policy Implications, Revision and expansion of the E.L. Quarantelli Theory Award Lecture presented at the annual meeting of the American Sociological Association, New York.

Drury, J., Novelli, D., \& Stott, C. (2015). Managing to avert disaster: explaining collective resilience at an outdoor music event. European Journal of Social Psychology, 45(4), 533-547.

Duncan, T.E., Duncan, S.C., Okut. H., Strycker, L.A., \& Hix-Small, H. (2003). A Multilevel Contextual Model of Neighborhood Collective Efficacy, American Journal of Community Psychology, 32(3/4), 245-2.

Dynes, R. (1970). Organized Behavior in Disaster. Lexington, Massechusetts: Heath Lexington Books.

Dynes, R.R. (2006). Social Capital: Dealing with Community Emergencies, Homeland Security Affairs, 2(2), 2- 4.

Dynes, R., DeMarchi, B., \& Pelanda, C. (Eds.). (1987). Sociology of Disaster. Milan; Franco Agneli Libri.

Eisenman, D. P., Cordasco, K.M., Asch, S., Golden, J. F., \& Glik, D. (2007). Disaster Planning and Risk Communication With Vulnerable Communities: Lessons From Hurricane Katrina, American Journal of Public Health, 97,109-115.

Elder, K., Xirasagar, S., Miller, N., Bowen, S.A., Glover, S., \& Piper, C., (2007). African Americans' Decisions Not to Evacuate New Orleans Before Hurricane Katrina: A Qualitative Study, American Journal of Public Health. 97, 124-129.

Elliott, J. R., \& Pais, J. (2006). Race, class, and Hurricane Katrina: Social differences in human responses to disaster, Social Science Research, 35, 295-321.

Enarson, E. (2007). Identifying and Addressing Social Vulnerabilities. In W. Waugh Jr. and K. Tierney (Eds.), Emergency Management: Principles and Practice for Local Government, $\left(2^{\text {nd }}\right.$ ed. $)$. pp.257-278, Washington, DC: ICMA.

Enders, J. (2001) Measuring Community Awareness and Preparedness for Emergencies, Australian Journal of Emergency Management, 16(3), 52-58.

Environment Agency (2014). Environment Agency - Risk of Flooding from Rivers and Sea. Received from http://watermaps.environmentagency.gov.uk/wiyby/wiyby.aspx?topic $=$ floodmap $\# x=357683 \& y=355134 \&$ scale $=2$

Fabrigar, L.R., MacCallum, R.C., Wegener, D.T., \& Strachan, E.J. (1999). Evaluating the Use of Exploratory Factor Analysis in Psychological Research. Psychological Methods. 4(3), 272-299 
Fan, X., Thompson, B., \& Wang, L. (1999). "Effects of Sample Size, Estimation Methods, and Model Specification on Structural Equation Modeling Fit Indexes," Structural Equation Modeling, 6(1), 56-83.

Feltz, D.L., \& Lirgg, C.D. (2001). Self-efficacy Beliefs of Athletes, Teams, and Coaches. In R. N. Singer, H. A. Hausenblas, \& C. Janelle (Eds.), Handbook of SportPsychology, (2 ${ }^{\text {nd }}$ ed.). (pp.340-361). New York: John Wiley \& Sons.

Fereday, J., \& Muir-Cochrane, E. (2006). Demonstrating rigor using thematic analysis: A hybrid approach of inductive and deductive coding and theme development. International Journal of Qualitative Methods, 5(1), 105-126.

Field, A. P. (2013). Discovering statistics using IBM SPSS Statistics: and sex and drugs and rock ' $n$ ' roll ( $4^{\text {th }}$ ed.). London: Sage publications.

Fordham, M. (1998). Making women visible in disasters: problematising the private domain, Disasters, 22, 126-143.

Fothergill, A., Maestas, E., \& Darlington, J. (1999). Race, ethnicity and disasters in the United States: a review of the literature, Disasters, 23, 156-173.

Gabe, T., Falk, G., \& McCarty, M. (2005). Hurricane Katrina: Social-Demographic Characteristics of Impacted Areas. Washington, DC: Congressional Research Service.

Garson, D. G. (2008). Factor Analysis: Statnotes. Retrieved from http://www2.chass.ncsu.edu/garson/pa765/factor.htm.

George, D., \& Mallery, M. (2010). Using SPSS for Windows step by step: a simple guide and reference. Boston, MA: Allyn \& Bacon.

Gibson, C. B. (1999). Do they do what they believe they can? Group efficacy and group effectiveness across tasks and cultures, Academy of Management Journal, 42(2), 138152.

Giles, M., McClenahan, C., Cairns, E., \& Mallet, J. (2004). An application of the Theory of Planned Behaviour to blood donation: The importance of self-efficacy, Health Education Research: Theory and Practice, 19(4) 380-391.

Gillespie, D. F., Colignon, R. A., Banerjee, M. M., Murty, S. A., \& Rogge, M. (1993). Partnerships for community preparedness (Program on Environment and Behavior, No. 54). Boulder: Institute of Behavioral Science, University of Colorado.

Gist, M.E. (1987) Self-Efficacy: Implications for Organisational Behaviour and Human Resource Management, Academy of Management Reviewl, 12(3), 472-485.

Gladwin, C. H., Gladwin, H., \& Peacock, W. G. (2001). Modeling hurricane evacuation decisions with ethnographic methods, International Journal of Mass Emergencies and Disasters. 19(2), 117-143.

Gliem, J., \& Gliem, R. (2003). Calculating, interpreting, and reporting Cronbach's Alpha Reliability Coefficient for Likert-type scales. Midwest Research-to-Practice Conference in Adult Continuing and Community Education. Retrieved from 
http://hdl.handle. net/1805/ 344

Goddard, R. D. (2001). Collective efficacy: A neglected construct in the study of schools and student achievement. Journal of Educational Psychology, 93(3), 467-476. http://dx.doi.org/10.1037/0022-0663.93.3.467

Goddard, R.D., Hoy, W.K., \& Hoy, A.W. (2004). Collective Efficacy Beliefs: Theoretical Developments, Empirical Evidence and Future Directions, Educational Researcher, 33(3), 3-13.

Goodman, R.M., Speers, M.A., McLeroy, K., \& Fawcett, S. (1998). Identifying and Defining the Dimensions of Community Capacity to Provide a Basis for Measurement, Health Education \& Behaviour, 25(3), 258-278.

Gorsuch, R. L. (1983). Factor Analysis, (2 ${ }^{\text {nd }}$ ed.). Hillsdale: Lawrence Erlbaum Associates.

Grant, J.S., Davis, L.L. (1997). Selection and use of content experts for instrument development, Research in Nursing \& Health, 20(3), 269-274.

Greene, J. C. (2008). Is Mixed Methods Social Inquiry a Distinctive Methodology?, Journal of Mixed Methods Research, 2(1), 7-22.

Greene, J., \& Caracelli, V. (2003) "Making Paradigmatic Sense of Mixed Methos Inquiry". In Handbook of Mixed Methods in Social \& Behavioral Research, Tashakkori, A \& Teddlie, C. (Eds.), Sage, California.

Greene, J. C., Caracelli, V. J., \& Graham, W. F. (1989). Toward a conceptual framework for mixed-method evaluation designs, Educational Evaluation and Policy Analysis, 11, 255-274.

Greenberg, M. R., Lahr, M., \& Mantell, N. (2007). Understanding the Economic Costs and Benefits of Catastrophes and Their Aftermath: A Review and Suggestions for the U.S. Federal Government, Risk Analysis: An International Journal, 27, 83-96.

Guba, E.G., \& Lincoln, Y.S. (1994). Competing Paradigms in Qualitative Research, in N.K. Denzin and Y.S. Lincoln (Eds.), Handbook of Qualitative Research, Thousand Oaks, California: Sage.

Haddow, G., \& Bullock, J. (2004). Introduction to Emergency Management. London: Butterworth-Heinemann Ltd.

Hair, J., Anderson, R.E., Tatham, R.L., \& Black, W.C. (1995) Multivariate data analysis. (4th ed.). New Jersey: Prentice-Hall Inc;

Hanson, W.E., Creswell, J.W., Plano Clark, V.L., Petska, K.S., \& Creswell, J.D. (2005). Mixed Methods Research Designs in Counseling Psychology, Journal of Counseling Psychology, 52(2), 224-235.

Harradine, S. (Ed.). (2004). Delivering services to hard to reach families in On Track areas: definition, consultation and needs assessment. RDS Development and Practice Report no.15. London: Home Office. 
Henson, R.K., \& Roberts, J.K. (2006). Use of Exploratory Factor Analysis in Published Research: Common Errors and Some Comment on Improved Practice. Educational and Psychological Measurement, 66(3), 393-416.

Hewitt, K. (1997). Regions of Risk: A Geographical Introduction to Disasters. Essex, U.K.: Longman.

Hinkin, T. R. (1995). A review of scale development in the study of behavior in organizations, Journal of Management, 21(5), 967-988.

Hinkin, T. R. (2005). Scale development principles and practices, in R.A. Swanson, \& E.F. Holton, (Eds.), Research in Organizations: Foundational Principles, Processes, and Methods of Inquiry, New York: Berrett-Koehler Press, 161-180.

Hinkin, T. R., \& Schriesheim, C. A. (1989). Development and Application of New Scales to Measure the French and Raven (1959) Bases of Social Power, Journal of Applied Psychology, 74, 561-567.

Hogan, T. P., Benjamin, A., \& Brezinski, K.L. (2000). Reliability methods: A note on the frequency of use of various types. Educational and psychological measurement, 60, 523-531.

Hogarty, K., Hines, C., Kromrey, J., Ferron, J., \& Mumford, K. (2005) The Quality of Factor Solutions in Exploratory Factor Analysis: The Influence of Sample Size, Communality, and Overdetermination. Educational and Psychological Measurement, 65(2), 202-26.

Holloway, A. (2003) ' Disaster risk reduction in Southern Africa: Hot rhetoric, cold reality', African Security Review 12(1), 1-12. Received from http://dx.doi.org/10.1080/10246029.2003.9627568

Homan, M.S. (2011). Promoting community change: Making it happen in the real world, $\left(5^{\text {th }}\right.$ ed.). Belmont, CA: Thomson, Brooks/Cole.

Hsiu-Fang, H.F., \& Shannon, S.E. (2005). Three Approaches to Qualitative Content Analysis, Qualitative Health Research, 15(9), 1277-1288.

Hsu, L.M., \& Field, R. (2003). Interrater Agreement Measures: Comments on Kappa, Cohen's Kappa, Scott's $\pi$, and Aickin's Alpha, Understanding Statistics, 2, 205-219.

Hu, L.T., \& Bentler, P.M. (1999). "Cutoff Criteria for Fit Indexes in Covariance Structure Analysis: Conventional Criteria Versus New Alternatives," Structural Equation Modeling, 6(1), 1-55.

Hurlbert, J. S., Haines, V. A., \& Beggs, J. J. (2000). Core networks and tie activation: What kinds of routine networks allocate resources in non-routine situations? American Sociological Review, 65(4), 598-618.

Irwin, A. (2001). Sociology and the environment: a critical introduction to society, nature, and knowledge. Oxford. Blackwell Publishers. 
Itzhaky, H., \& York, A. S. (2000). Sociopolitical control and empowerment: An extended replication. Journal of Community Psychology. 28, 407-415. doi: 10.1002/1520-6629(200007)28:4<407::AID-JCOP3>3.0.CO;2-R

Ivankova, N.V., Creswell, J.W., \& Stick, S.L. (2006). Using mixed-methods sequential explanatory design: from theory to practice, Field Methods, 18, 3-20.

Jackson, J.R., and Englert, P. (2011). Task-Based Assessment Centre Scores and their Relationships with Work Outcomes, New Zealand Journal of Psychology, 40(2), 37-46.

Jensen, S. (2010). Taking the Analysis One Step Further, Qualitative Research in Psychology, 7(4), 281-298.

Jensen, M., \& Meckling, W. (1976). Theory of the firm: Managerial behavior, agency costs, and ownership structure. Journal of Financial Economics, 3, 305-360.

Jick, T.D. (1979). Mixing qualitative and quantitative methods: Triangulation in action, Administrative Science Quarterly, 24, 602-611.

Johnston, D., Becker, J., \& Paton, D. (2008). Building disaster-resilient communities: the need for community-based programmes, New Zealand Local Government, 44(6), pp. 17-20.

Johnson, R.B., \& Onwuegbuzie, A.J. (2004). Mixed Methods Research: A Research Paradigm Whose Time Has Come. Educational Researcher. 33(7), 14-26. doi: 10.3102/0013189X033007014

Jöreskog, K. G., \& Sörbom, D. (1993). LISREL 8: User's guide. Chicago: Scientific Software.

Khan, H., Vasilescu, L.G., \& Khan, A. (2008). Disaster Management CYCLE - a theoretical approach, Management and Marketing Journal, 6(1), 43-50.

Retrieved from http://EconPapers.repec.org/RePEc:aio:manmar:v:6:y:2008:i:1:p:43-50.

Kahan, D. M. (2002). The Logic of Reciprocity: Trust, Collective Action, and Law, John M. Olin Center for Studies in Law, Economics and Public Policy Working Papers. Paper 281.

Retrieved from http://digitalcommons.law.yale.edu/lepp_papers/281

Kahan, J.H., Allen, A.C., \& George, J.K. (2009). An Operational Framework for Resilience, Journal of Homeland Security and Emergency Management 6(1) 83.

Kaiser, H.F. (1960) The application of electronic computers to factor analysis. Educational and Psychological Measurement, 20, 141-51.

Kaiser, H.F. (1970). A Second-Generation Little Jiffy. Psychometrika. 35(4), 401-415.

Kaiser, H.F. (1974). Little Jiffy, Mark IV. Educational and Psychological Measurement. 34, 111-117.

Kang, J.E., Lindell, M.K., \& Prater, C.S. (2007). Hurricane Evacuation Expectations and Actual Behavior in Hurricane Lili, Journal of Applied Social Psychology, 37(4), 
887-903.

Kasperson, J. X., Kasperson, R.E., \& Turner, B.L. (Eds.), (1995). Regions at Risk: Comparisons of Threatened Environments, Tokyo: United Nations University Press.

Kates, R. W. (1971). "Natural Hazard in Human Ecological Perspective: Hypotheses and Models." Economic Geography, 47(3), 438-451.

Karanci, N.A., Aksit, B., \& Dirik, G. (2005). Impact of a Community Disaster Awareness Training Program in Turkey: Does it Influence Hazard-related Cognitions and Preparedness Behaviors, Social Behavior And Personality, 33(3), 243-258.

Kelman, I., \& Karnes, E. (2007). Re-localising disaster risk reduction in Boulder, Colorado, Australian Journal of Emergency Management, 22(1).

Kendon, E. (2015). Batten down the hatches, Barometer, p.1 Received from http://www.metoffice.gov.uk/barometer/science/2015-03/batten-down-the-hatches

Ketteridge, E.M., \& Fordham, M. (1995). Flood warning and the local community context, Flood Research Centre: Enfield.

Kieffer, K.M. (1999) An introductory primer on the appropriate use of exploratory and confirmatory factor analysis, Research in the Schools, 6(2), 75-92.

Kilpatrick, S. and Abbott-Chapman, J. (2005). Community Efficacy and Social Capital, Paper presented at the $2^{\text {nd }}$ Future of Australia's Country Towns Conference, Bendigo, 11-13 July. Received from: http://core.ac.uk/download/pdf/12176225.pdf

King, D. (2000). You're on your own: community vulnerability and the need for awareness and education for predictable natural disasters, Journal of Contingencies and Crisis Management, 8(4), 223-8.

Kirschenbaum, A. (2004). Chaos organization and disaster management, Public Administration and Public Policy, 105. New York: Dekker.

Kirst-Ashman, K.K., \& Hull, G.H. (2009). Generalist Practice with Organizations and Communities, $\left(4^{\text {th }}\right.$ ed. $)$, Belmont, CA. Brooks/Cole.

Kline, R. B. (2005). Principles and practice of structural equation modeling. ( $2^{\text {nd }}$ ed.). New York: The Guilford Press.

Klinenberg, E. (2002). Heat wave: A social autopsy of disaster in Chicago. Chicago: University of Chicago Press.

Knoke, D., \& Kuklinski, J. H. (1982). Network analysis (Sage University Paper, Quantitative Applications in the Social Sciences, No. 28). Thousand Oaks, CA: Sage.

Kozub, S. A., \& McDonnell, J. F. (2000). Exploring the relationship between cohesion and collective efficacy in rugby teams. Journal of Sport Behavior, 23(2), 120-129.

Kreps, G. A. (1989). "Future Directions in Disaster Research: The Role of Taxonomy". International Journal of Mass Emergencies and Disasters. 7, 215-241. 
Kreps, G. A., \& Bosworth, S.L. (2006). Organizational Adaptation to Disaster. pp.297315 in Handbook of Disaster Research, (Eds.), H. Rodríguez, E. Quarantelli, and R. R. Dynes. New York: Springer.

Kreps, G. A., \& Drabek, T.E. (1996). "Disasters Are Non-Routine Social Problems." International Journal of Mass Emergencies and Disasters. 14, 129-153.

Kuhn T. S. (1970) The Structure of Scientific Revolutions. Chicago: Chicago University Press.

Lagemann , E.C. (2000). An Elusive Science: The Troubling History of Education Research, University of Chicago Press: Chicago.

Larson, R.C., Metzger, M.D., \& Cahn, M.F. (2006). Responding to Emergencies: Lessons Learned and the Need for Analysis, Interfaces, 36(6), 486-501.

Leach C. W., van Zomeren M., Zebel S., Vliek M. L. W., Pennekamp S. F., Doosje B., ..., \& Spears R. (2008). Group-level self-definition and self-investment: A hierarchical (multicomponent) model of in-group identification. Journal of Personality and Social Psychology, 95, 144-165. http://dx.doi.org/10.1037/0022-3514.95.1.144

Lee, N., \& Hooley, G. (2005). The evolution of "classical mythology" within marketing measure development, European Journal of Marketing, 39(3/4), 365-385

Lee, N., \& Ling, I. (2008). Doing Business Research, A Guide To Theory and Practice, London, Sage Publications Ltd.

Lewis, J., O'Keefe, P., \& Westgate, K.N. (1976) A philosophy of planning, Occasional paper no 5, Bradford, Disaster Research Unit, University of Bradford. Retrieved from http://nla.gov.au/anbd.bib-an1252883

Lichterman, J.D. (2000). A Community as a Resource Strategy for Disaster Response, Public Health Report, 115(2-3), 262-265.

Lin, N. (2001). Building a network theory of social capital. In N. Lin, K. Cook, \& R. S. Burt (Eds.), Social capital: Theory and research (pp. 3-29). New York: Aldine de Gruyter.

Lin, N., Fu, Y., \& Hsung, R. (2001). The position generator: Measurement techniques for investigations of social capital. In N. Lin, K. Cook, \& R. S. Burt (Eds.), Social capital: Theory and research (pp. 57-81). New York: Aldine de Gruyter.

Lindell, M.K. (1994). Are Local Emergency Planning Committees Effective in Developing Community Disaster Preparedness, International Journal of Mass Emergencies \& Disasters 12(2), 159-182.

Lindell, M.K., \& Perry, R.W. (1992). Behavioral foundations of community emergency planning, Hemisphere: Washington, D.C.

Lindell, M.K., \& Brandt, C.J. (1999). Assessing inter rater agreement on the job relevance of a test: A comparison of the CVI, T, rWG(J), and ${ }^{*} \mathrm{WG}(\mathrm{J})$ indexes, Journal of Applied Psychology, 84, 640-647. 
Little, B.L., \& Madigan, R.M. (1997). The relationship between collective-efficacy and performance in manufacturing work teams. Small Group Research, 28, 517-534.

Lundgren, S.R. (1995)."Cold Call Sales Effectiveness: an Investigation of Source Perceptions and Gender Differences", in NA - Advances in Consumer Research Volume 22, (Eds.), Frank R. Kardes, \& Mita Sujan, Provo, UT : Association for Consumer Research, pp. 606-610.

Lupton, D. (1999). Risk. New York: Routledge.

Lynn M.R. (1986). Determination and quantification of content validity, Nursing Research, 35, 382-385.

MacCallum, R. C., Widaman, K. F., Zhang, S., \& Hong, S. (1999). Sample size in factor analysis, Psychological Methods, 4, 84-99.

MacCallum, R. C., Widaman, K. F., Preacher, K. J., \& Hong, S. (2002). Sample size in factor analysis: The role of model error. Multivariate Behavioral Research, 36, 611637.

MacKenzie, S.B., Podsakoff, P.M., \& Fetter, R. (1991). Organizational citizenship behavior and objective productivity as determinants of managerial evaluations of sales persons' performance, Organizational Behavior and Human Decision Processes, 50, 123-150.

MacQueen, K.M., \& Milton, B. (1999). A Systems Approach to Qualitative Data Management and Analysis, Field Methods, 11(1), 27-39.

Mancini, J.A., Bowen, G.L., \& Martin, J.A. (2005). Community Social Organization: A Conceptual Linchpin in Examining Families in the Context of Communities, Family Relations, December, 54, 570-582.

March, J. (1962). The business firm as a political coalition. Journal of Politics, 24, 662678.

Masten, A.S., \&Obradovic, J. (2007). Disaster preparation and recovery: lessons from research on resilience in human development, Ecology and Society, 13(1), 225-251.

McIntire, D.A. (2004a). The Status of Emergency Management Theory: Issues, Barriers, and Recommendations for Improved Scholarship, Paper Presented at the FEMA Higher Education Conference, Emmitsburg, Maryland.

McEntire, D. A. (2004b). Development, disasters, and vulnerability: A discussion of divergent theories and the need for their integration. Disaster Prevention and Management, 13(3), 193-198.

McIvor, D., \& Paton, D. (2007). Preparing for natural hazards: normative and attitudinal influences, Disaster Prevention and Management, 16(1), 79-88.

McMillan, D., \& Chavis, D. (1986). Sense of community: A definition and theory. American Journal of Community Psychology, 14, 6-23. 
Miles, M.B., \& Huberman, A.M. (1994). Qualitative Data Analysis: A Source Book of New Methods, (2 ${ }^{\text {nd }}$ Ed.). London: Sage.

Mileti, D. S. (1999). Disaster by Design: A reassessment of natural hazards in the United States. Washington, DC: Joseph Henry Press.

Morenoff, E.D., Sampson, R.J., \& Raudenbush, S.W. (2001). Neighborhood Inequality, Collective Efficacy, and the Spatial Dynamics of Urban Violence, Criminology, 39(3), 517-56.

Morgan, D. L. (2007). Paradigms lost and pragmatism regained: methodological implications of combining qualitative and quantitative methods, Journal of Mixed Methods Research, 1, 48-76.

Morrow, B.H. (1999). Identifying and Mapping Community Vulnerability, Disasters. 23(1), 11-18.

Nastasi B.K., Hitchcock J., Sreeroopa S., Burkholder G., Varjas K., \& Jayasena A. (2007) Mixed methods in intervention research: theory to adaptation. Journal of Mixed Methods Research, 1(2), 164-182.

Neal, D.M. (1997). Reconsidering the phases of disaster. International Journal of Mass Emergencies and Disasters. 15(2), 239-264.

Nigg, J.M., Barnshaw, J., \& Torres, M.R. (2006). Hurricane Katrina and the flooding of New Orleans: Emergent issues in sheltering and temporary housing, Annual American Academy Political Social Science. 604, 115-128.

Norman, P., Boer, H., \& Seydel, E. R. (2005). Protection motivation theory. In M. Conner \& P. Norman (Eds.), Predicting Health Behaviour: Research and Practice with Social Cognition Models, (2 ${ }^{\text {nd }}$ ed.). (pp. 81-126). Maidenhead: Open University Press.

Norris, F.H., Stevens, S.P., Pfefferobaum, B., Wyche, K.F., \& Pfefferbaum, R.L. (2008). Community Resilience as a Metaphor, Theory, Set of Capacities, and Strategy for Disaster Readiness, American Journal of Community Psychology, 41,127-150.

O'Brien, G. (2008). UK Emergency Preparedness: A Holistic Response? Disaster and Prevention Management, 17(2), 32-243.

O'Brien, G., \& Read, P. (2005). Future UK emergency management: new wine, old skin? Disaster Prevention and Management: An International Journal, 14(3), 353-361

Ohmer, M. L. (2007). Citizen Participation in Neighborhood Organizations and Its Relationship to Volunteers' Self and Collective Efficacy and Sense of Community. Social Work Research. 31(2), 109-120.

Ohmer, M. L. (2010). How Theory and Research Inform Citizen Participation in Poor Communities: The Ecological Perspective and Theories on Self- and Collective Efficacy and Sense of Community. Journal of Human Behavior in the Social Environment, 20(1), $1-19$. 
O'leary, D. F., \& Mhaolrúnaigh, S. N. (2012), Information-seeking behaviour of nurses: where is information sought and what processes are followed? Journal of Advanced Nursing, 68: 379-390. doi: 10.1111/j.1365-2648.2011.05750.x

Oliver-Smith, A. (1996). Anthropological Research on Hazards and Disasters. Annual Review of Anthropology, 25, 303-328.

Onwuegbuzie, A. J. (2002). Positivists, post-positivists, post-structuralists, and postmodernists: Why can't we all get along? Towards a framework for unifying research paradigms, Education, 122(3), 518-530.

Onwuegbuzie, A. J., \& Leech, N.L. (2006). Linking Research Questions to Mixed Methods Data Analysis Procedures. The Qualitative Report, 11(3), 474-498.

Opdenakker, R. (2006). Advantages and Disadvantages of Four Interview Techniques in Qualitative Forum. Qualitative Social Research, 7(4), Art. 11.

Retrieved from http://nbn-resolving.de/urn:nbn:de:0114-fqs0604118.

Osborne, J. (2002). Notes on the use of data transformations. Practical Assessment, Research \& Evaluation, 8(6).

Retrieved from http://PAREonline.net/getvn.asp?v $=8 \& n=6$.

Paine, A.E., Locke, M., \& Jochum, V. (2006). Volunteering, Active Citizenship and Community Cohesion: From Theory to Practice, in: Proceedings of the 7th International Society for the Third Sector Research Conference (V). 9-12 July, 2006, Bangkok, Thailand.

Parisi, D., Grice, S.M., Taquino, M., \& Gill, D.A. (2002). Building Capacity for Community Efficacy for Economic Development in Mississippi. Journal of the Community Development Society, 33(2), 19-38.

Parker, D.J., Priest, S.J., \& Tapsell, S.M. (2009). Understanding and enhancing the public's behavioural response to flood warning information. Meteorological Applications, Special Issue: Flood Forecasting and Warning, 16(1), 103-114.

Paton, D. (2000). Community Resilience: Integrating Hazard Management and Community Engagement. Journal of American Society for Professional Emergency Management, 7, 109-118.

Paton, D. (2003). Disaster preparedness: a social perspective. Disaster Prevention and Management, 12(3), 210-216

Paton, D. (2005). Community resilience: integrating hazard management and community engagement, in: Proceedings of the International Conference on Engaging Communities, Brisbane Convention and Exhibition Centre, Queensland, $14^{\text {th }}-17^{\text {th }}$ August, Queensland Government/UNESCO.

Paton, D. (2007). Preparing for natural hazards: the role of community trust. Disaster Prevention and Management, 16(3), 370-378.

M.Pelling, (Ed.). (2003). Natural Disasters and development in a globalizing world, Oxon. Routledge. 
Perry, R.W., \& Mushkatel, A.H. (1986). Minority Citizens in Disasters. Athens: University of Georgia Press

Perry, R.W., \& Lindell, M.K. (1991). The effects of ethnicity on evacuation decisionmaking. International Journal for Mass Emergency Disasters. 9, 47-68.

Pescosolido, A. (2001). Informal Leaders and the Development of Group Efficacy, Small Group Research 32(1), 74-93. DOI: 10.1177/104649640103200104

Pett, M.A., Lackey, N.R., \& Sullivan, J.J. (2003). Making Sense of Factor Analysis: The use of factor analysis for instrument development in health care research. California: Sage Publications Inc;

Pidgeon, N., \& Henwood, K. (1997). Using grounded theory in psychological research, In Hayes, N., (Ed.). Doing qualitative analysis in psychology, Hove: Psychology Press

Pitt, M. (2008). Learning Lessons from the 2007 Floods. The Pitt Review, Cabinet Office: London.

Platt, R. (1999). Disasters and Democracy: The Politics of Extreme Natural Events, Washington, D.C. Island Press.

Pfeffer, J. (1981). Power in Organizations. Ballinger, Cambridge, MA

Polit, D.F., \& Beck, C.T. (2004). Nursing research: Principles and methods (7th ed.). Philadelphia: Lippincott, Williams, \& Wilkins.

Polit, D.F., \& Beck, C. T. (2006). The Content Validity Index: What's Being Reported? Critique and Recommendations, Research in Nursing \& Health, 29, 489-497.

Polit, D.F., Beck, C. T., \& Owen, S. V. (2007). Focus on Research Methods: Is the CVI an Acceptable Indicator of Content Validity? Appraisal and Recommendations, Research in Nursing \& Health, 30, 459-467.

Putnam, R. D. (2000). Bowling alone: The collapse and revival of American community. New York: Simon \& Schuster.

Quarantelli, E.L. (1988). Disaster Crisis Management: A Summary of Research Findings, Journal of Management Studies, 25(4), 373-385

Quarantelli, E.L. (1991). "More and Worse Disasters in the Future: The Social Factors Involved." Newark, Delaware: Disaster Research Center, University of Delaware. (Preliminary Paper \#173).

Quarantelli, E.L (Ed.), (1998). 'What is a disaster?', Perspectives on the question, Rutledge: London.

Raudenbush, S.W., Rowan, B., \& Cheong,Y. F. (1992). Contextual effects on the selfperceived efficacy of high school teachers, Sociology of Education, 65,150-167.

Raynor, S. (1992), 'Cultural theory and risk analysis'. In S. Krimsky, \& D. Golding 
(Eds.), Social theories of risk, (pp. 83-116), Praeger Publications, Westport

Reichardt, C. S., \& Cook, T.D. (1979). Beyond qualitative versus quantitative methods. In T. D. Cook, \& C. S. Reichardt (Eds.), Qualitative and quantitative methods in evaluation research (pp.7-32). Beverly Hills, CA: Sage

Reichardt, C. S., \& Rallis, S. F. (1994). Qualitative and quantitative inquiries are not incompatible: A call for a new partnership. New Directions for Program Evaluation 61: 85-91.

Reise, S.P., Comrey, A.L., \& Waller, N.G. (2000). Factor Analysis and Scale Revision, Psychological Assessment, 12(3), 287-2

Riad, J., Norris, F., \& Ruback, R.B. (1999). Predicting evacuation in two major disasters: risk perception, social influence, and access to resources, Journal of Applied Social Psychology, 29, 918-934.

Richards, T., \& Richards, L. (1994), "Using computers in qualitative research", in N.K. Denzin, \& Y.S. Lincoln, (Eds.), Handbook of Qualitative Research, London: Sage, pp. 445-62.

Ronan, K. R., Crellin, K., Johnston, D.M., Finnis, K., Paton, D., \& Becker, J. (2008). "Promoting Child and Family Resilience to Disasters: Effects, Interventions, and Prevention Effectiveness," Children, Youth and Environments, 18(1), 332-353.

Rossman, GB., \& Wilson, BL. (1985). "Numbers and words: Combining qualitative and quantitative methods in a single large scale evaluation." Evaluation Review, 9(5), 627643.

Rubio, D.M., Berg-Weger, M., Tebb, S.S., Lee, E.S., \& Rauch, S. (2003). Objectifying content validity: Conducting a content validity study in social work research. Social Work Research, 27, 94-104.

Sale, J.E., Lohfeld, L.H., \& Brazil, K. (2002). Revisiting the Quantitative-Qualitative Debate: Implications for Mixed-Methods Research, Quality \& Quantity, 36, 43-53.

Sampson, R.J., Morenoff, J.D., \& Gannon-Rowley, T. (2002). Assessing "Neighborhood Effects": Social Processes and New Directions in Research. Annual Review of Sociology, 28, 443-478. Retrieved from http://www.jstor.org/stable/3069249.

Sampson, R. J. (2004). Neighbourhood and Community. New Economy, 11, 106-113. doi: $10.1111 /$ j.1468-0041.2004.00346.x

Sampson, R. J., Raudenbush, S.W., \& Earls, F. (1997). Neighborhoods and violent crime: A multilevel study of collective efficacy, Science, 277, 918-924.

Schawdt, T.A. (2001). A Dictionary of Qualitative Inquiry, Thousand Oaks, CA: Sage.

Scheuren, J. M., le Polain de Waroux, O., Below, R., Guha-Sapir, D., \& Ponserre, R. (2008). Annual Disaster Statistical Review - The Numbers and Trends 2007, Melin: Belgium. 
Schilling, L. (2006). On the pragmatics of qualitative assessment: Designing the process for content analysis, European Journal for Psychological Assessement, 22(1), 28-37.

Schonrock-Adema, J., Heijne-Penninga, M., Van Hell, E.A., \& Cohen-Schotanus, J. (2009). Necessary steps in factor analysis: enhancing validation studies of educational instruments, Medical Teacher, 31, e226-e232. doi: 10.1080/01421590802516756.

Schrauf, R.W., \& Navarro, E. (2005). Using Existing Test and Scales in the Field, Field Methods, 17(4), 373-393.

Schriesheim, C.A., Powers, K.J., Scandura, T.A., Gardiner, C.C., \& Lankau, M. J. (1993). Improving construct measurement in management research: Comments and a quantitative approach for assessing the theoretical adequacy of paper-and-pencil and survey-type instruments. Journal of Management, 19, 385-417

Schumacker, R.E., \& Lomax, R.G. (2004). A beginner's guide to structural equation modeling $\left(2^{\text {nd }}\right.$ ed.). Mahwah, NJ: Lawrence Erlbaum Associates Publishers.

Schunk, D.A. (1995). Self-efficiacy, motivation and performance. Journal of Applied Sport Psychology, 7(2), 112-137.

Schwab, D. P. (1980). Construct validity in organizational behavior. In L. L. Cummings, \& B.M. Staw, (Eds.), Research in organizational behavior, 2, 3-43. Greenwich, CT. JAI Press.

Schwarzer, R., \& Renner, B. (2000). Social-cognitive predictors of health behavior: Action self-efficacy and coping self-efficacy. Health Psychology, 19(5), 487-495. http://dx.doi.org/10.1037/0278-6133.19.5.487

Schwarzer, R., \& Luszczynska, S. (2008). How to Overcome Health-Compromising Behaviors, The Health Action Process Approach, European Psychologist. 13(2), 141151. DOI 10.1027/1016-9040.13.2.141

Scutchfield, F.D., Marks, J.S., Perez, D.J., \& Mays, G.P. (2007). Public Health Services and Systems Research, American Journal of Preventive Medicine, 33(2), 169-171,

Sementelli. A. (2007). Toward a Taxonomy of Disaster and Crisis, Theories Administrative Theory \& Praxis, 29(4), 497-512.

Silverman, D. (2008). Doing Qualitative Research, Thousand Oaks: Sage.

Skidmore, P., Bound, K., \& Lownsbrough,H. (2006) Community participation: Who benefits? Oxford. Joseph Rowntree Foundation. Retrieved from https://www.jrf.org.uk/report/do-policies-promote-community-participationgovernance-build-social-capital

Slingo, J., Belcher, S., Scaife, A., McCarthy, M.,Saulter, A., McBeath, K., Jenkins, A., Huntingford, ..., \& Parry, S. (2014). The Recent Storms and Floods in the UK, Synopsis report CSc 04, Exeter, Met Office. Retrieved from http://www.metoffice.gov.uk/media/pdf/j/7 
Smith, H.M., \& Betz, N.E. (2000). Development and Validation of a Scale of Perceived Social Self-Efficacy, Journal of Career Assessment, 8(3), 283-301.

Smith, J.K. (1983) Quantitative versus Qualitative Research: An Attempt to Clarify the Issue. Educational Researcher, 12(3), pp. 6-13.

Smith, K. (2001). Environmental Disasters, ( $3^{\text {rd }}$ ed.). London, Routledge.

Stallings, R. A. (1995). Promoting Risk: Constructing the Earthquake Threat, New York: Aldine deGruyter.

Stallings, R.A. (2006). "Causality and 'Natural' Disasters." Contemporary Sociology, $35(3), 223-227$.

Stalling, R.A. (2006). “Methodological Issues.”. In Handbook of Disaster Research. (Eds.), H. Rodriguez, E. L. Quarantelli, \& R. R. Dynes. New York: Springer.

Tabachnick, B.G., \& Fidell, L.S. (2007). Using Multivariate Statistics. Boston: Pearson Education Inc;

Tashakkori, A., \& Charles T. (2008). Introduction to Mixed Method and Mixed Model Studies in the Social and Behavioral Sciences, In V.L.P. Clark and J.W. Creswell, (Eds.), The Mixed Methods Reader, (pp.7-26). California: Sage Publications,

Tashakkori, A., \& Teddlie, C. (1998). Mixed methodology: Combining qualitative and quantitative approaches. Thousand Oaks, CA, Sage.

Tashakkori, A., \& Teddlie, C. (Eds.). (2003). Handbook of mixed methods in social and behavioral research. Thousand Oaks, CA: Sage.

Tashiro, J. (2002). 'Exploring Health Promoting Lifestyle Behaviors of Japanese College Women: Perceptions, Practices, and Issues', Health Care for Women International, 23(1), 59-70.

Teddlie, C., \& Yu, F. (2007). Methods Sampling: A Typology With Examples, Journal of Mixed Methods Research, 1(1), 77-100.

Tedmanson, D. (2003). Whose capacity needs building? Open hearts and empty hands: Reflections on capacity building in remote communities. Paper given at the $4^{\text {th }}$ International Critical Management Studies Conference, University of South Australia.

Thompson, B., \& Daniel, L.G. (1996). Factor analytic evidence for the construct validity of scores: A historical overview and some guidelines. Educational and Psychological Measurement. 56(2), 197-208.

Thywissen, K. (2006). Core terminology of disaster reduction: A comparative glossary. In: Birkmann, J. (Ed.). Measuring vulnerability to natural hazards: Towards disaster resilient societies. (pp.448-496). New York: United Nations University Press. 
Tidball, K.G., \& Krasny, M.E. (2015). Resilience in the Red Zone. In K. G. Tidball, \& M. E. Krasny, (Eds.), Greening in the Red Zone: Disaster, Resilience and Community Greening, (pp.25-44), Dordrecht, Springer.

Tierney, K. J. (2006). Foreshadowing Katrina: Recent sociological contributions to vulnerability science, Contemporary Sociology, 35, 207-212.

Tierney, K. J., Lindell, M.K., \& Perry, R.W. (2001). Facing the Unexpected: Disaster Preparedness and Response in the United States, Washington, D.C.: Joseph Henry Press.

Tilden, V., Nelson, C., \& May, B.(1990). The IPR Inventory: development and psychometric characteristics. Nursing Research, 39(6), 337-343.

Tobin, G., \& Montz, B. (1997). Natural Hazards: Explanation and Integration, New York: Guilford.

Twigg, J. (2004) 'Disaster risk reduction: Mitigation and preparedness in development and emergency programming', Good Practice Review 9, Overseas Development Institute Humanitarian Practice Network, London.

Retrieved from http://www.ifrc.org/

UN/ISDR (2004) Living with risk: A global review of disaster risk reduction initiatives, 2, UN / ISDR, Kobe. Retrieved from http://www.unisdr.org/files/657_lwr1.pdf

Van Maanen, J. (1998). Different strokes: qualitative research in the Administrative Science Quarterly from 1956 to 1996. In Van Maanen, J. (Ed.), Qualitative Studies of Organizations. London: Sage.

Wadel, C. (1991). Field work in your own culture, Seek A/S, Flekkefjord, Norway.

Wandersman, A., \& Florin, P. (2000). Citizen participation and community organizations. In J. Rappaport \& E. Seidman (Eds.), Handbook of community psychology. New York: Kluwer Academic/Plenum Publishers.

Wang, X., \& Kapucu, N. (2007). Public Complacency under Repeated Emergency Threats: Some Empirical Evidence, Journal of Public Administration Research and Theory, 18, 57-78.

Weber, R. (1990). Basic content analysis, Newbury Park, Calif.: Sage Publications.

Wellman, B., \& Frank, K. (2001). Network capital in a multilevel world: Getting support from personal communities. In N. Lin, K. Cook, \& R. S. Burt (Eds.), Social capital: Theory and research, pp.233-273, New York: Aldine de Gruyter.

Werritty, A., Black, A. R., Duck, R. W., Finlinson, W., Shackley, S., \& Crichton, D. (2002). Climate Change, Flood Occurrences Review. Scottish Executive Environment Group Research Program Research Findings No 19, Edinburgh: Scottish Executive.

Werritty, A., \& Chatterton, J. (2004). Future Flooding Scotland, London: Office of Science and Technology. 
Werritty A (2006). Sustainable flood management: oxymoron or new paradigm? Area, $38,16-23$.

Werritty, A. (2007). Assessment of drivers: Scotland, in Future Flood and Coastal Erosion Risks in the UK, C.R. Thorne, E.P. Evans and E.C. Penning-Rowsell (Eds.), London: Thomas Telford.

Werrity, A., Houston, D., Ball, T., Tavendale, A., \& Black, A. (2007). Exploring the Social Impacts of Flood Risk and Flooding in Scotland. Scottish Executive: Scottish Executive Social Research: Edinburgh.

West, D.M., \& Orr, M. (2007). Race, Gender and Communications in Natural Disasters, The Policy Studies Journal, 35(4), 569-586.

White, G. F., Kates, R. W., \& Burton, I. (2001). Knowing better and losing even more: the use of knowledge in hazards management, Global Environmental Change Part B: Environmental Hazards, 3(3-4), 81-92.

White, P., Pelling, M., Sen, K., Seddon, D., Russell, R., \& Few, R. (2004). Disaster Risk reduction, a development concern - A Scoping study on the links between Disaster risk reduction, Poverty and Development, London: Department for International Development.

Williams, B., Onsman, A., \& Brown, T. (2010). Exploratory factor analysis: A five-step guide for novices, Journal of Emergency Primary Health Care, 8(3), 1-13.

Williamson, J. B., Karp, D.A. Dalphin, J.A., \& Gray, P.S. (1982). The research craft: An introduction to social research methods, $\left(2^{\text {nd }}\right.$ ed.). Glenview, IL: Scott Foresman.

Wilson, J.W., \& Musik, M. (1997). Who Cares? Toward an Integrated Theory of Volunteer Work, American Sociological Review, 62, 694-7I3.

Wisner, B., Blaikie, P., Cannon, T., \& Davies, I. (2004). At risk: Natural hazards, people's vulnerability and disasters. Routledge, London.

Wisner, B., Blaikie, P., Cannon, T., \& Davies, I. (2008). At risk: Natural hazards, people's vulnerability and disasters. Routledge, London.

Woolley, C.M. (2009). Meeting the Mixed Methods Challenge of Integration in a Social Study of Structure and Agency, Journal of Mixed Methods Research, 3(1), 7-25.

Wynd, C.A., Schmidt, B., \& Schaefer, M.A. (2003). Two quantitative approaches for estimating content validity, Western Journal of Nursing Research, 25, 508-518.

Zakour, M. J. (2008). Social Capital and Increased Organizational Capacity for Evacuation in Natural Disasters, Social Development Issues, 30(1), 13-28.

Zimmerman, B. J. (1998). Developing self-fulfilling cycles of academic regulation: An analysis of exemplary instructional models. In D. H. Schunk, \& B. J. Zimmerman (Eds.), Self-regulated learning: From teaching to self-reflective practice (pp. 1-19). New York: Guilford Press. 
Zulkosky, K. (2009). Self-Efficacy: A Concept Analysis, Nursing Forum, 44, (2), 93 102. 
Appendix A

Dimension, Sub-dimension, References and Questions 